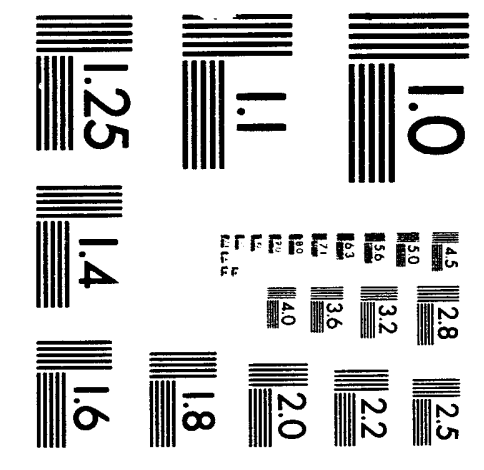



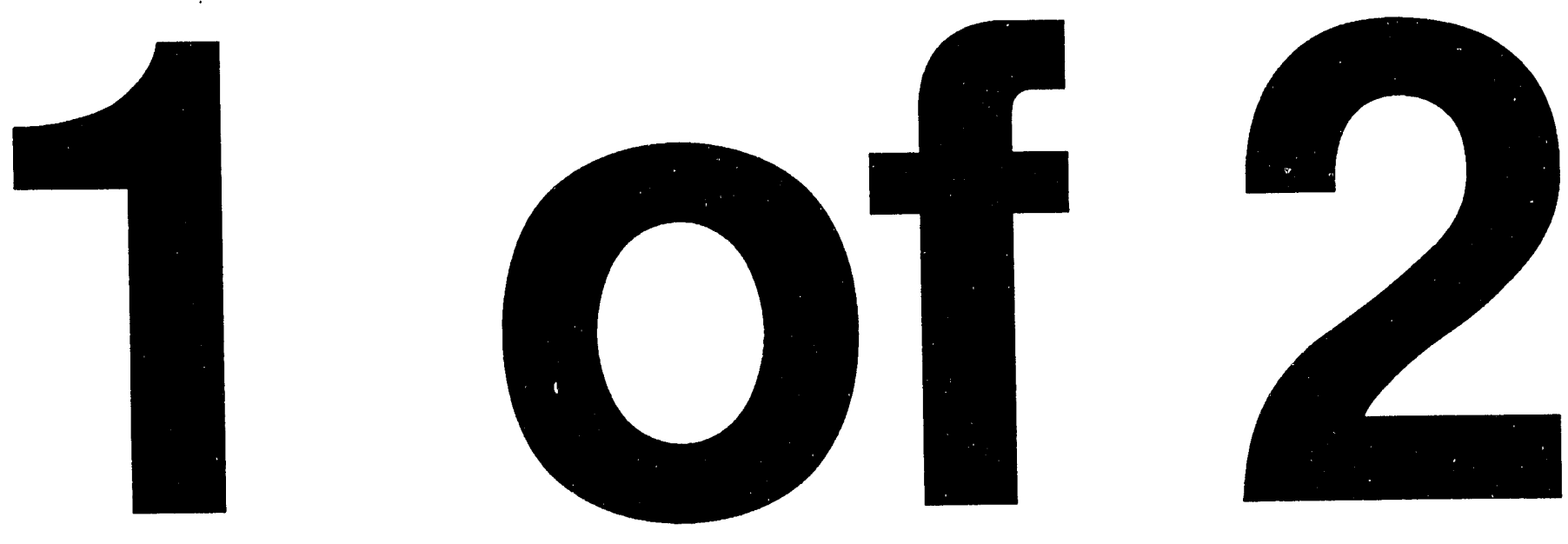
UC-940

Issued: December 1993

Chemical Composition

of Hanford Tank SY-102

Edward Birnbaum

Steve Agnew

Gordon Jarvinen

Steve Yarbro

\section{Maptern

DISTRIBUTION OF THIS DOCUMENT IS UNLIMITED

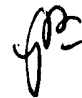

\section{Los Alamos \\ NATIONAL LABORATORY \\ Los Alamos, New Mexico 87545}




\title{
CHEMICAL COMPOSITION OF HANFORD TANK SY-102
}

\author{
by \\ Edward Birnbaum, Steve Agnew, Gordon Jarvinen, and Steve Yarbro
}

\begin{abstract}
The US Department of Energy established the Tank Waste Remediation System (TWRS) to safely manage and dispose of the radioactive waste, both current and future, stored in double-shell and single-shell tanks at the Hanford sites. One major program element in TWRS is pretreatment which was established to process the waste prior to disposal using the Hanford Waste Vitrification Plant. In support of this program, Los Alamos National Laboratory has developed a conceptual process flow sheet which will remediate the entire contents of a selected double-shelled underground waste tank, including supernatant and sludge, into forms that allow storage and final disposal in a safe, cost-effective and environmentally sound manner. The specific tank selected for remediation is 241-SY-102 located in the 200 West Area.

As part of the flow sheet development effort, the composition of the tank was defined and documented. This database was built by examining the history of liquid waste transfers to the tank and by performing careful analysis of all of the analy tical data that have been gathered during the tank's lifetime. In order to more completely understand ihe variances in analytical results, material and charge balarces were done to help define the chemistry of the various components in the tank. This methodology of defining tr: tank composition and the final results are documente $n$ this report.
\end{abstract}

\section{Introduction and Brief Tank History}

As part of our efforts to develop a flow sheet capable of completely remediating the more than 600,000 gallons of supernatant and sludge contained in the SY-102 waste 
storage tank at Hanfrrd, we have attempted to develop as accurate an understanding as possible of the composition of that tank. These efforts have considered the waste stream going into and out of the tank during the tank lifetime (determined by Steve Agnew at Los Alamos National Laboratory), as well as consideration of the analytical results from core and grab samples taken from the tank.

SY-102 was originally placed into service in the second quarter of 1977 as a primary receiver for supernatants from various process sites at Hanford, and served as the feed tank for the 242-S evaporator. The evaporator reduced the volume of the supernatants by a nominal $50 \%$, after which the concentrated solution was returned to SY-102. The concentration of these supernatants produced a high nitrate salt waste and the resulting precipitates were allowed to accumulate in SY-102. The evaporator operation continued from 1977 through 1981, resulting in the formation of a "salt cake" at the bottom of the tank. This salt cake, estimated to be $38 \mathrm{in.} \mathrm{high} \mathrm{in} \mathrm{1981,} \mathrm{is} \mathrm{expected}$ to contain the bulk of the radioactive cesium and strontium present in the tank.

In 1981, when the tank became a primary receiver of dilute wastes from T- and ZPlant, the nature of the solids deposited in the tank changed dramatically with the influx of low levels of TRUs and fission products from reprocessing operations. In addition, a large portion of the salt cake accumulated earlier redissolved in these relatively dilute waste streams and was transferred to other tanks. As a result of the complexity of the waste stream transfers into and out of SY-102 during this period (Figures 1 and 2) and the lack of analytical data on the composition of the transferred liquids, more direct tank analytical data are needed to characterize the current tank composition. 


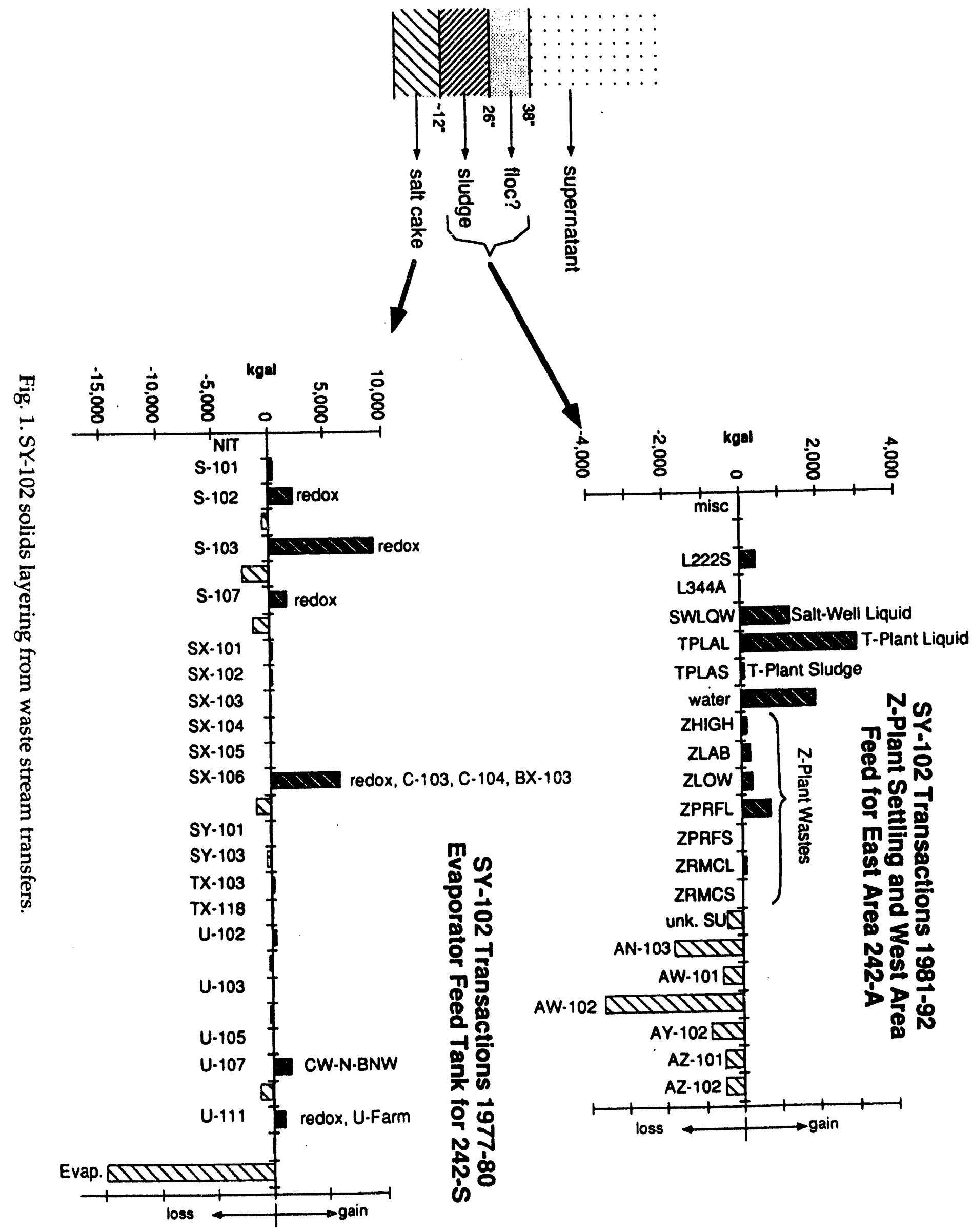




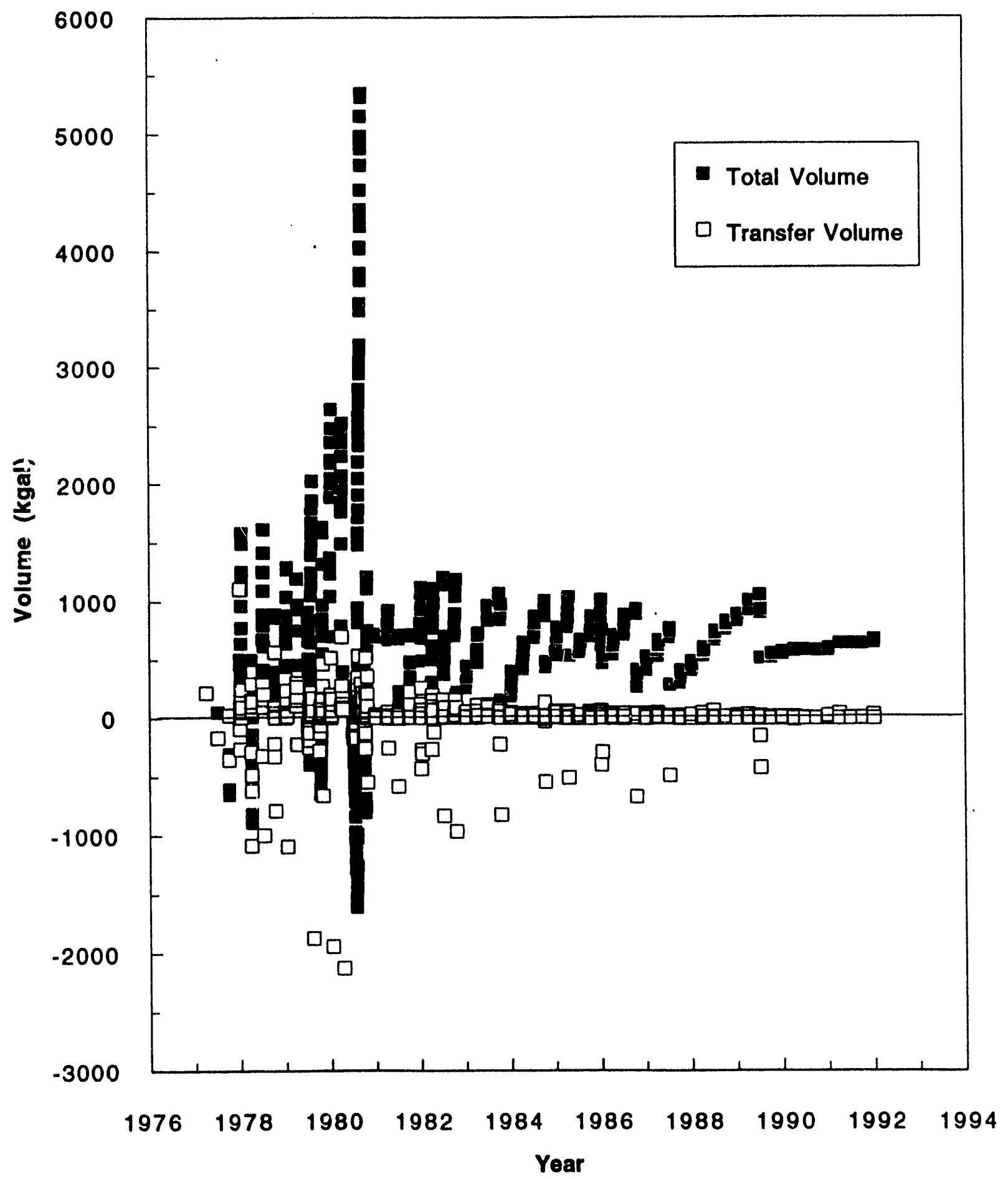

Fig. 2. SY-102 tank history from waste stream transfers. 


\section{Description of Available Analytical Reports}

After the evaporator campaign ended in 1981, several grab samples were taken from various locations in SY-102 and a limited elemental analysis was performed on both the supernatant and solid portions of the sludge sample. In addition, americium, cesium, strontium, plutonium and neptunium levels in the samples were also monitored by radiochemical analysis, although the isotopic distribution is often unknown. We have also received analytical results on grab samples taken in 1984, 1985, 1988 and 1989.

The most detailed analytical results on the SY-102 tank composition comes from a core sample taken at the end of October 1988. At this time, a 1-in. diameter core sampling pipe was pressed into the sludge of the tank reaching close to the bottom of the tank. Four separate core segments were obtained, each of which should have been $19 \mathrm{in.} \mathrm{long.} \mathrm{The} \mathrm{bottom} \mathrm{core} \mathrm{segment} \mathrm{recovered} \mathrm{was} 4$ in. shorter than expected and we have assumed that the missing $4 \mathrm{in}$. is from the bottom of the tank, since the recovered sludge from the lowest portion of the bottom 19-in. segment is quite dense and hard. As a result, the core sampler may have become jammed at the bottom of the tank, preventing recovery of the last $4 \mathrm{in}$. of the sludge.

A color, density, and hardness demarcation exists in the bottom segment, 4 in. from the lowest portion of the segment recovered. We have assumed that this lowest 4 in. represents the salt cake in the tank, and if we include the missing 4-in. portion of the bottom segment, we can estimate a total of 8 in. of salt cake left in the tank compared to the 38 in. present in 1981. The remainder of the sludge recovered, i.e., the upper $11 \mathrm{in}$. of the fourth core segment and the $19 \mathrm{in}$. of the third segment are primarily wastes from plutonium reprocessing in which iron hydroxide was used to precipitate 
the TRU content. Figure 3 shows a breakdown of the core segments as well as some of the physical characterization data available.

Due to the limited amount of material recovered in the core operation, the decision was made to combine and/or homogenize various sections of the core prior to submitting samples for analysis. Six different sample types were sent for analysis either to Batelle's Pacific Northwest Laboratories (PNL) and/or to the Process Chemistry Laboratory (PCL) currently operated by Westinghouse. These sample types include: 4B, the bottom 4 in. of the fourth core segment, presumably representative of the salt cake; $4 \mathrm{C}$, the homogenized, remaining $11 \mathrm{in}$. of the fourth segment; $3 \mathrm{C}$, the homogenized third segment; 3T4S, the solid portion of an homogenized mixture of the third core segment (3C) and the remainder of the fourth core segment (4C) after centrifugation; $3 \mathrm{~T} 4 \mathrm{~L}$, the liquid portion of the same mixture after centrifugation; and 1-2, a composite of the first and second core segments which were both liquids. A flow sheet describing the preparation of these samples types is also shown in Figure 3.

A limited amount of information is also available on the analytical results from the core taken in February 1990, in particular the 34COMP sample from that core, which is a composite of the third and fourth segments from the bottom of the tank. A limited set of analytic data for this 1990 core sample is included in Lumetta and Swanson's sludge washing report. In addition, the analysis on the same sample, reported by Gray at the Process Chemistry Laboratory, includes nearly 20 metals, 3 anions and activity measurement of 6 radioactive metals. Unfortunately, we do not have any information on the core characterization, or how the sample composites were prepared. This lack of information increases the uncertainty associated with any detailed comparison between the 1988 and 1990 cores. 


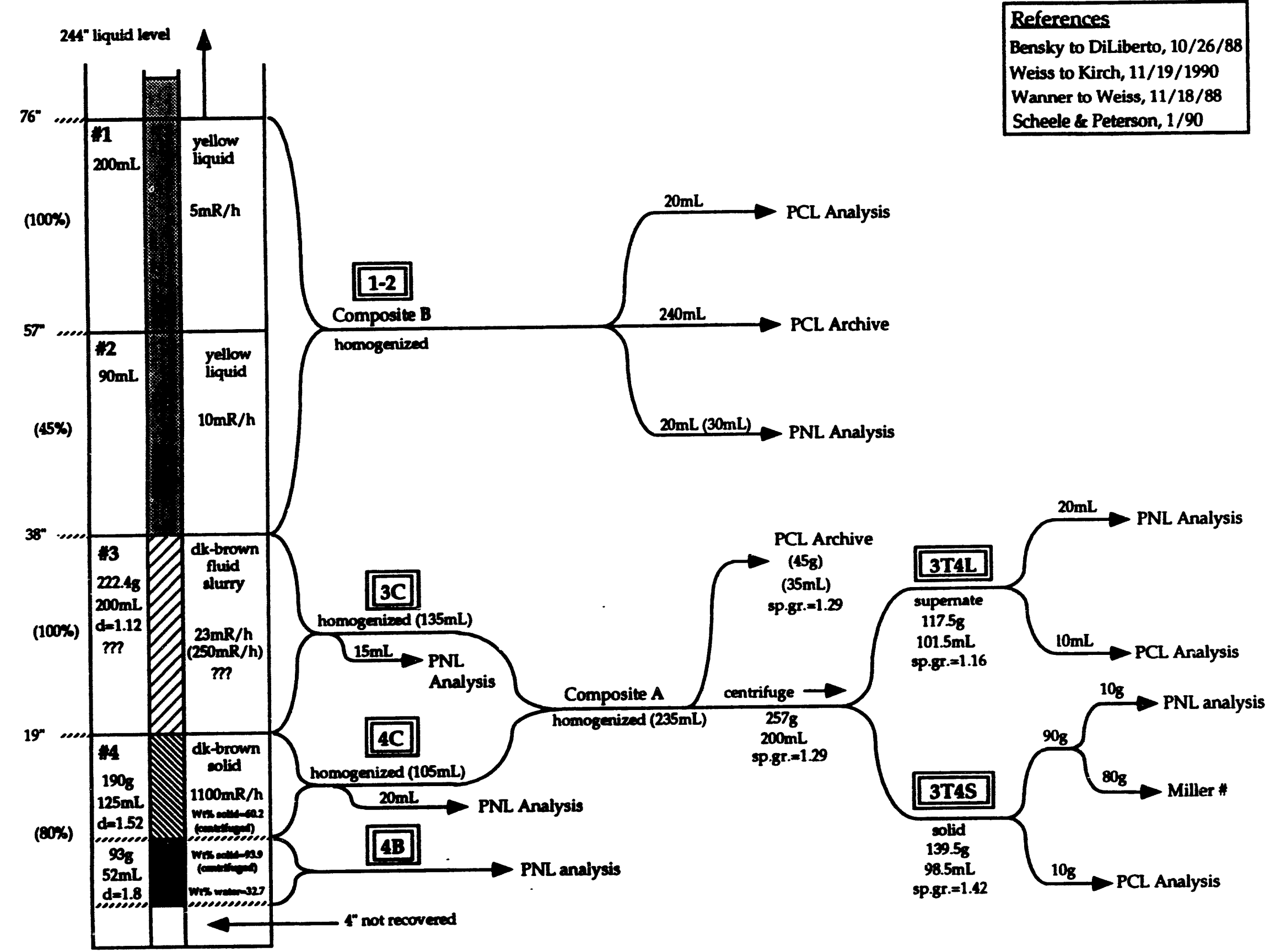

Fig. 3. Breakdown of the core segments, physical characteristics, and sample preparation. 
The analytical data available to us have been inserted into five Macintosh Excel spreadsheets attached in Appendix A. The first of these spreadsheets (filename: Comp.SL.final) lists the analytical and radiochemical data by element for each of the core and grab analyses performed in the original units reported and in wt \% (nonradioactive) or $\mathrm{g} / \mathrm{g}$ (radioactive). It also includes information regarding the physical characterization of the sample, such as density, and notes needed to proper'y interpret the analytical results. Two spreadsheets, one for solids (filename $=$ Solid.Values) and one for supernatants (filename = Liquid.Values), are derived from the first spreadsheet by stripping away the original data and notes in order to permit a direct comparison to be made between all the analyses available in units of $w t \%, g / L$ and $\mathrm{M}$ for nonradioactive elements and $\mathrm{g} / \mathrm{g}, \mu \mathrm{Ci} / \mathrm{g}$ and $\mu \mathrm{Ci} / \mathrm{L}$ for radioactive elements. An additional spreadsheet (filename $=3$ T4S.Data.Solid) summarizes the analytical results from Lumetta and Swanson's sludge washing experiment on the 3T4S sample from the 1988 core and the 34COMP sample from the 1990 core. Finally, we have presented a fifth spreadsheet (filename $=88 / 90$ CoreComp3) which includes the analytical data for the 34COMP sample (1990 core) from Gray's report and compares it to the data available for the $4 \mathrm{~B}$ and $3 \mathrm{~T} 4 \mathrm{~S}$ (1988 core) for the same elements. The data for the 1990 34COMP samples are not included in the Comp.SL.final spreadsheet. The charts presented on the supernatant in the tank are derived from the Liquid.Values spreadsheet, those on the tank sludge from the Solid.Values spreadsheet, those on the 3T4S sample from the 3T4S.Data.Solid spreadsheet and those on the 34COMP sample from the 88/90 CoreComp3 spreadsheet.

\section{Potential Problems in the Interpretation of the Analytical Data}

Before using the analytical results available to define the composition of SY-102, it is important to recognize the implicit limitations on their utility and accuracy. First let us consider the sampling problem, using the tank sludge as an example. A similar, 
although less serious sampling problem, will exist for the tank supernatants due to density variations of the liquid layer. We have available ten sets of analytical results listed in the Comp.SL.final spreadsheet for tank sludge. One of these (Kirkbride) is not a true analytical result since it is an undocumented estimate of tank sludge composition based on the other analytical data. Of the remaining nine sets of data, one is on sample 4B from the 1988 core, two are on sample 3T4S from the 1988 core, one is simply labeled as "solids" and five are grab samples taken from a point reported to be 6 in. from the bottom of the tank. In contrast to the core, which was obtained in October of 1988, the grab samples were obtained in November of 1984.

Considering the size of the tank and the time frame over which the sludges were accumulated, it must be recognized that the nine sets of analytical data presently available represent an extremely limited sampling program which is incapable of determining the magnitude of any horizontal inhomogeneity in tank composition that may be present. Horizontal inhomogeneities are likely to result from pumping slurries into the tank and supernatants out of the tank, since the sluicing action of the pump will tend to preferentially deposit or remove sludge from the region close to the riser used for the transfer. If different risers were used to carry out the transfers over the years, then we can expect horizontal inhomogeneities to be present over a large portion of the tank. Temperature gradients between the tank contents already present and the incoming slurry can also induce significant horizontal inhomogeneities to form. In the absence of horizontal inhomogeneities, the analyses of grab samples taken 6 in. from the bottom of the tank in 1984 might be expected to closely match the analyses of the $4 \mathrm{~B}$ and 3T4S samples taken from the 1988 core. However, it should be noted that differences between the grab and core results can be ascribed either to mixing of the bottom sludge layer between 1984 and 1988, horizontal inhomogeneities in the tank composition, errors in the estimated depth of the grab sample, or analytical errors. 
The utility of the analytical data obtained for the grab samples is severely limited by the selectivity of the analyses that were carried out. Although the sludge is an extremely complex mixture, analyses for up to only ten elements and two to three anions were reported. Analyses for sodium, nitrate and nitrite, the largest components in the sludge were not reported. A much more detailed analysis was carried out on the 1988 core samples, but serious omissions also occur here. For example no anion analyses were carried out by Scheele and Peterson for the 3T4S sample whereas Herting reports a limited anion analysis but almost no radiochemical information on the same sample. These differences in what analytical information is available from the various analytical reports makes comparison of the reports to confirm the reliability of the data inconclusive.

The radiochemical results reported depend to a significant extent on the isotope mixture present in the sample. For example, Scheele and Peterson report individual alpha activities for Pu-238, Pu-239, Pu-240, and Pu-241, whereas Weiss reports only the sum of Pu-239 and Pu-240 activities. Similar problems occur for other radiochemical measurements where more than one isotope of the same element is present in the sludge.

Finally there is the question of the accuracy of the analytical data. In a complex mixture, such as the Hanford tank sludge, matrix interferences can dramatically affect ICP (inductively coupled plasma) or AA (atomic absorption) results. Without having access to the analytical protocols used to carry out these analyses, it is difficult to assess the extent to which matrix interferences have affected the results reported. A memo from R. L. Weiss of the Office of Sample Management (November 19, 1990) indicates that no matrix-specific standards or spikes were run for the 1988 core analyses carried 
out by PCL. No mention of analytical controls are reported for any of the other analyses on the SY-102 samples, suggesting that there may be large errors in the reported analytical results. It should also be noted with regard to the anion analytical results reported, that Scheele and Peterson's data for the October 1988 core were obtained by ion chromatography on a solution obtained by extraction of the sludge with water. This implies that anions found in the sludge in the form of insoluble salts (e.g., aluminum phosphate and chromium(III) fluoride) went undetected by this analytical technique. Other reported anion analyses may be similarly affected.

\section{Tank Supernatant Composition}

Sixteen different analyses are listed in the Comp.SL.final and Liquid.Values spreadsheets on supernatants from tank SY-102. These include analyses on supernatants from twelve grab samples between 1984 and 1989, and four analyses of supernatants from the 1988 core, i.e., the 1-2 and 3T4L samples. Each of the core samples was analyzed by PNL and by PCL, although the PCL analyses were less comprehensive, whereas the grab samples were analyzed only by PCL. In addition to the grab samples being dispersed over time, they were also taken from different depths in the tank and possibly from different risers, making direct comparisons difficult.

The most recent analyses of the homogenized supernatants from the 1988 core generally show relatively low levels (below $1 \%$ ) of all elements and radionuclides, except for sodium which was reported to be in excess of $8 \%$ by weight in the $3 \mathrm{~T} 4 \mathrm{~L}$ core sample and $2 \%$ in the 1-2 sample. One analysis of the 3T4L sample also reports anion concentrations, in which high levels (in excess of $1 \%$ ) of nitrate, nitrite, carbonate and hydroxide were found. Lesser amourits, but still significant levels of chloride, phosphate and sulfate were also found in these supernatant samples. The only other elements present in significant amounts in the supernatants from the core samples were 
aluminum and potassium $(\sim 0.3 \%$ by weight). All other elements analyzed were found at levels of $0.05 \%$ or less. Earlier grab samples taken in 1984 are reported to have a higher level of aluminum ( $0.7 \mathrm{wt} \%)$.

The variation in the reported abundance of an element in the supernatant can be illustrated using a bar chart in which a plot is made of the concentration of that element for each sample taken from the tank. Bar charts showing the variation in the analytical results for three of the major elements found in the supernatant, aluminum, sodium and potassium are shown in Figures $4-6$, respectively. It is reassuring to note the analytical results, presented in adjacent bars, for the 3T4L and 1-2 samples by PNL and PCL are very similar for all three metals.

Although an analytical report for these three elements is not available for every sample taken, it is clear that the analytical pattern is not the same for each element. For example, in the aluminum chart (Figure 4), the aluminum content of the R4656 sample is more than 20 times that of the $\mathrm{R} 5027$ sample. For sodium (Figure 5), the sodium content in the R4656 sample is only 10 times that of the R5027 sample, and for potassium (Figure 6), the potassium content of the R4656 sample is only 1.5 times that of the R5027 sample. Similar fluctuations in the relative elemental content are apparent when comparing other pairs of samples. These fluctuations could be associated with the difference in the sampling date, or the sampling depth, or the riser used to obtain the sample. In some instances, the sample was obtained as a liquid; in others it is the supernatant resulting from centrifugation of a slurry. Extraction of the solid fraction by the supernatant during sample preparation may be responsible for the higher aluminum concentration found in the R3316, R3317 and R3318 slurry samples obtained 6 in. from the bottom of the tank. The somewhat smaller elevation in the aluminum concentration found for the $3 \mathrm{~T} 4 \mathrm{~L}$ sample may be due to the same phenomenon, since 


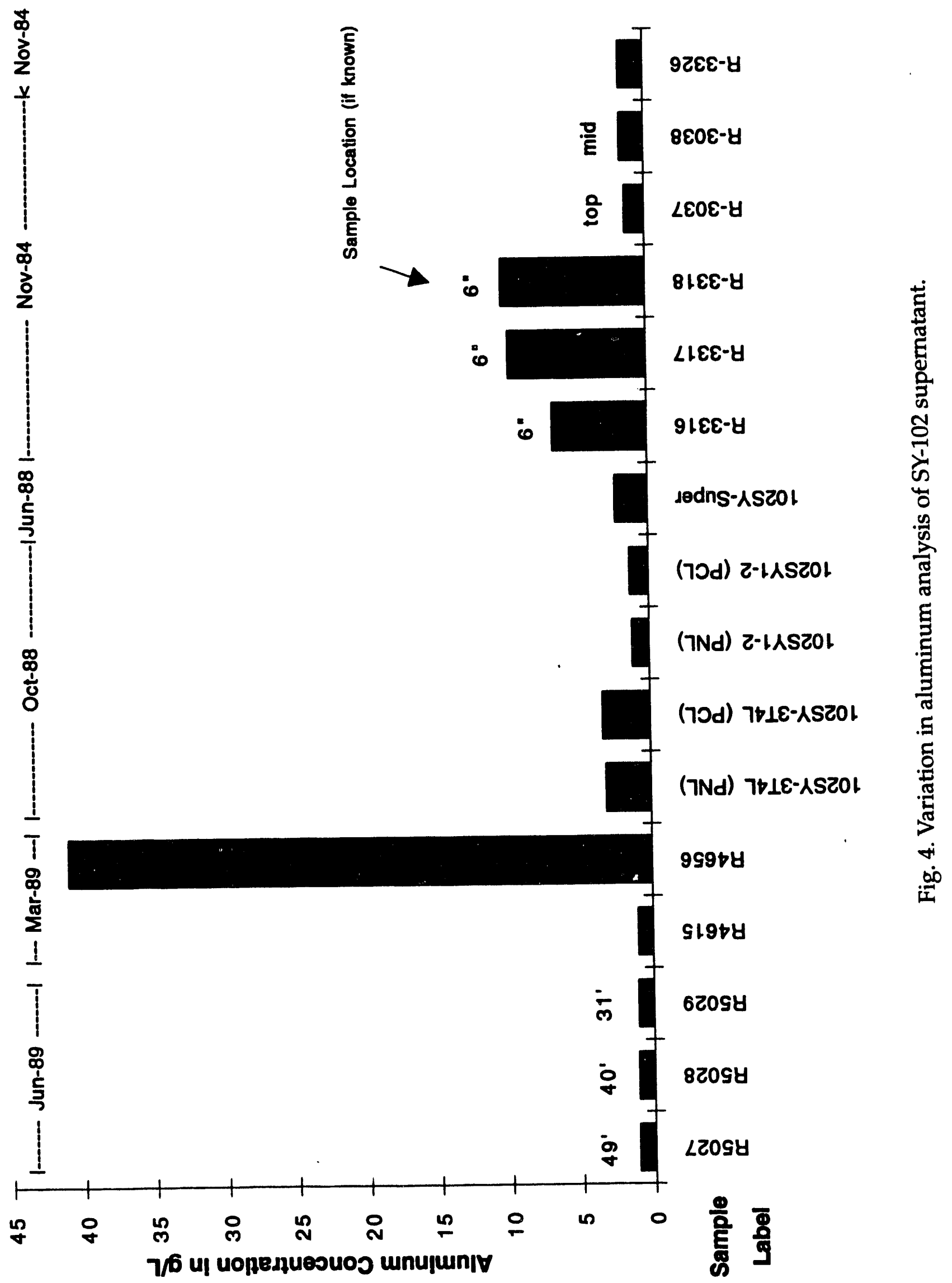




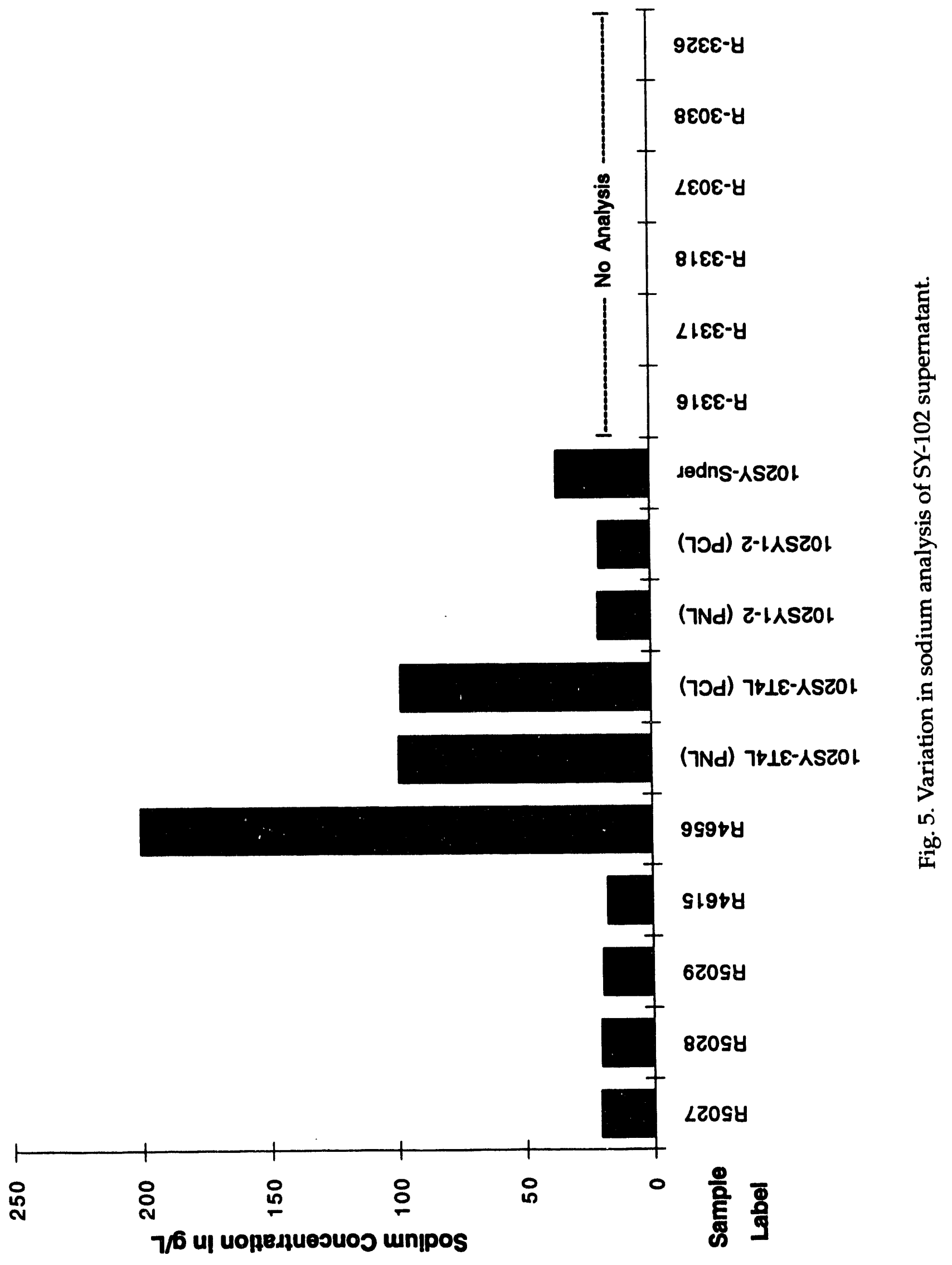




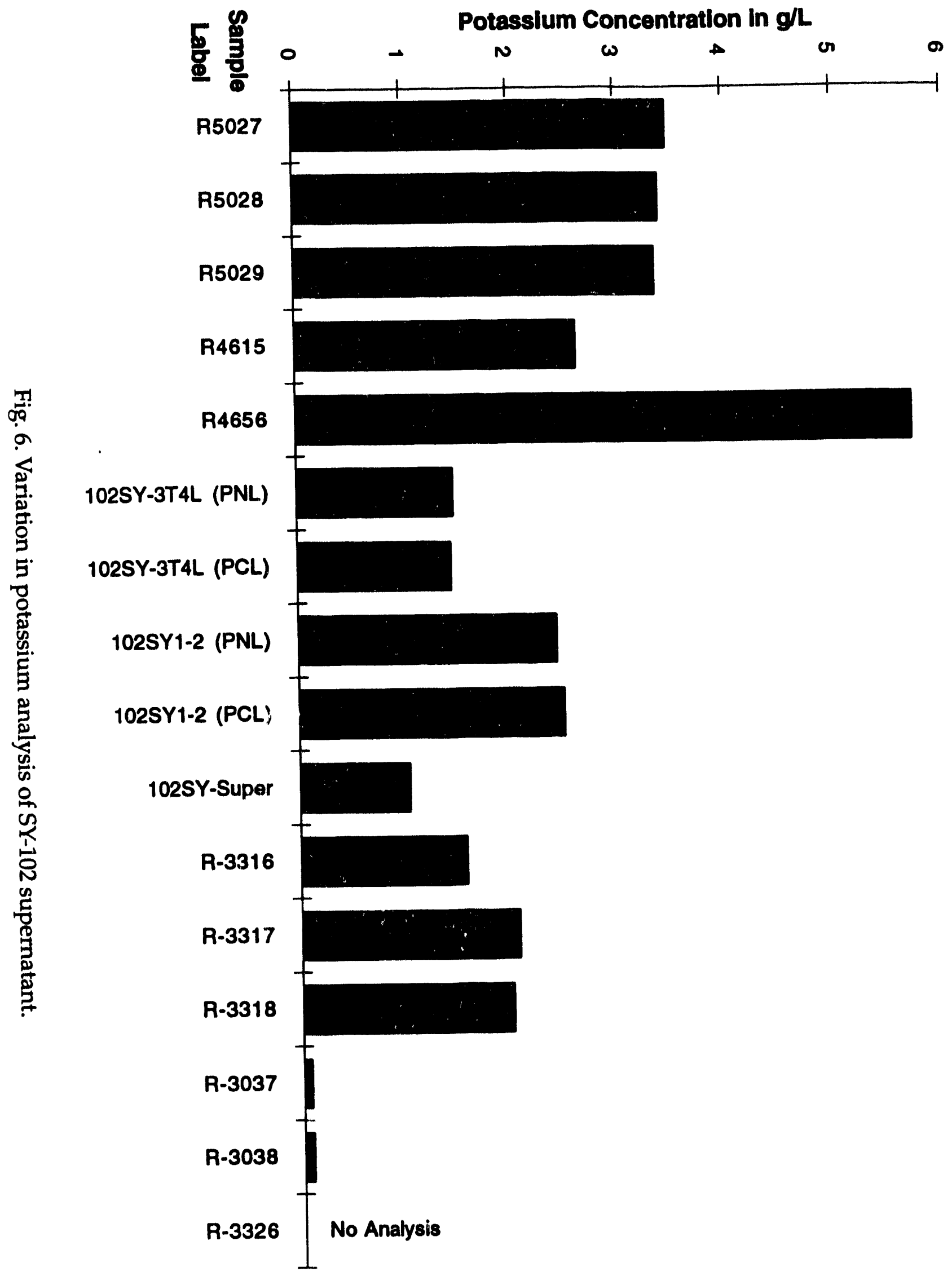


this sample also results from centrifuging and separating the third and fourth segments into a solid and supernatant layer.

An estimate of layering in the supernatant can be made from a consideration of the R502.7, R5028 and R5029 samples which were obtained in June 1989 from three different heights in the tank, but in the same sampling operation. The fact that the analyses reported for aluminum, sodium and potassium are nearly the same for each sample, suggests that, at least in June 1989, there are no major layers present in the supernatant that would lead to different elemental compositions at different depths in the tank. The analytical results for R3037 and R3038, obtained in November of 1984, are also consistent with a lack of layering in the supernatant in the tank.

In contrast, the large difference in the potassium levels that occurs in the June 1989 samples compared to the November 1984 samples suggests that a significant change in the nature of the waste stream occurred in the intervening years. Similar differences between the ratios of the elements on different dates are consistent with a variation in the waste stream flowing into the tank, as expected.

The two samples taken in March 1989 (R4615 and R4656) are of interest since they differ so markedly in their analytical results, but were obtained within five days of each other. The R4615 sample analytical results for these three elements are very similar to those of the June 1989 samples, whereas the analytical results on the R4656 grab sample indicate a much greater concentration of all three elements. Unfortunately, we have no information as to the depth or riser location at which this sample was taken. It may be that the R4656 sample represents an anomaly, either due to a sampling or analytical error. The possibility that sampling occurred shortly after introduction of a 
new waste stream into the tank seems unlikely since the record of tank transfers shows no unusual tank activity during March of 1989.

The variation in the supernatant nitrate levels is shown in Figure 7. As is the case with the metals, there are large differences in nitrate concentrations from sample to sample and the concentration pattern across the chart appears to be different from any of the metal concentration patterns. Although the grab samples obtained in June 1989 at different tank depths have the same nitrate concentrations, the grab samples obtained in November 1984 at two different tank heights have markedly different nitrate levels, with the R3038 sample nearly ten times the concentration of nitrate as the R3037 sample. Unlike the metal data, this large variation suggests that layering, based on the density associated with the nitrate concentration of the supernatant, may occur.

Concentration data for the same set of samples are shown for fluoride, chloride and sulfate in Figure 8. As can be readily seen from this combination chart, there is no consistency to the relative concentrations of the anions in the samples. Sometimes sulfate is present in the greatest concentration (e.g., R3316), sometimes fluoride (e.g., R5027), and sometimes chloride (e.g., R3318). Again it should be pointed out that the set of three June 1989 samples have similar concentrations of the three anions, but the R3037 and R3038 samples from November 1984 have markedly different concentrations of the same three anions. The difference between the behavior of the June 1989 and November 1984 samples may reflect the fact that layering did occur in 1984, but enough mixing occurred prior to the withdrawal of the 1989 samples to prevent layering.

Figure 9 shows the sodium, nitrate and nitrite concentration data together for the samples in which analytical data are reported for all three species. Since it might be expected that sodium and nitrate will track together in the waste stream, roughly 


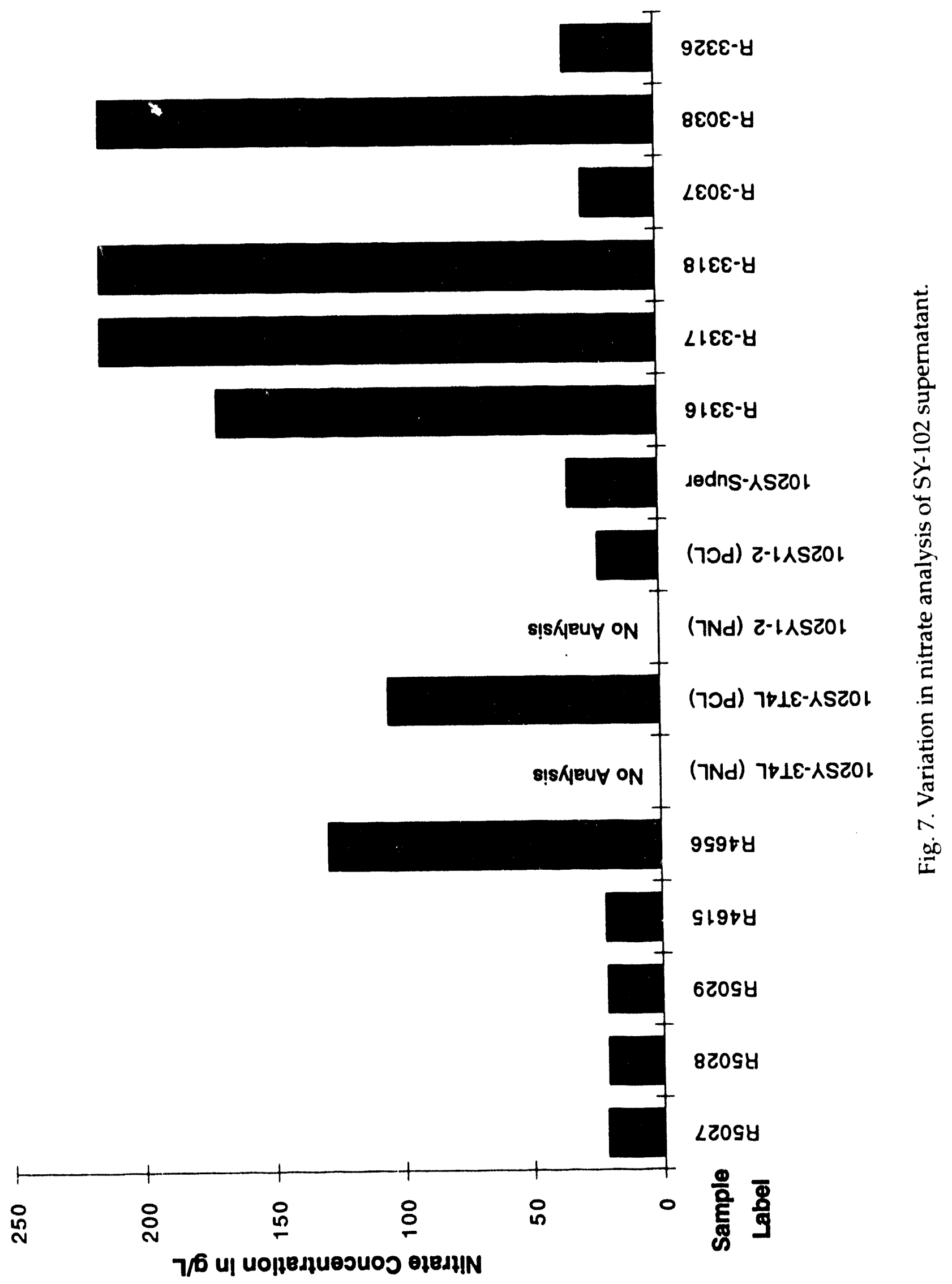




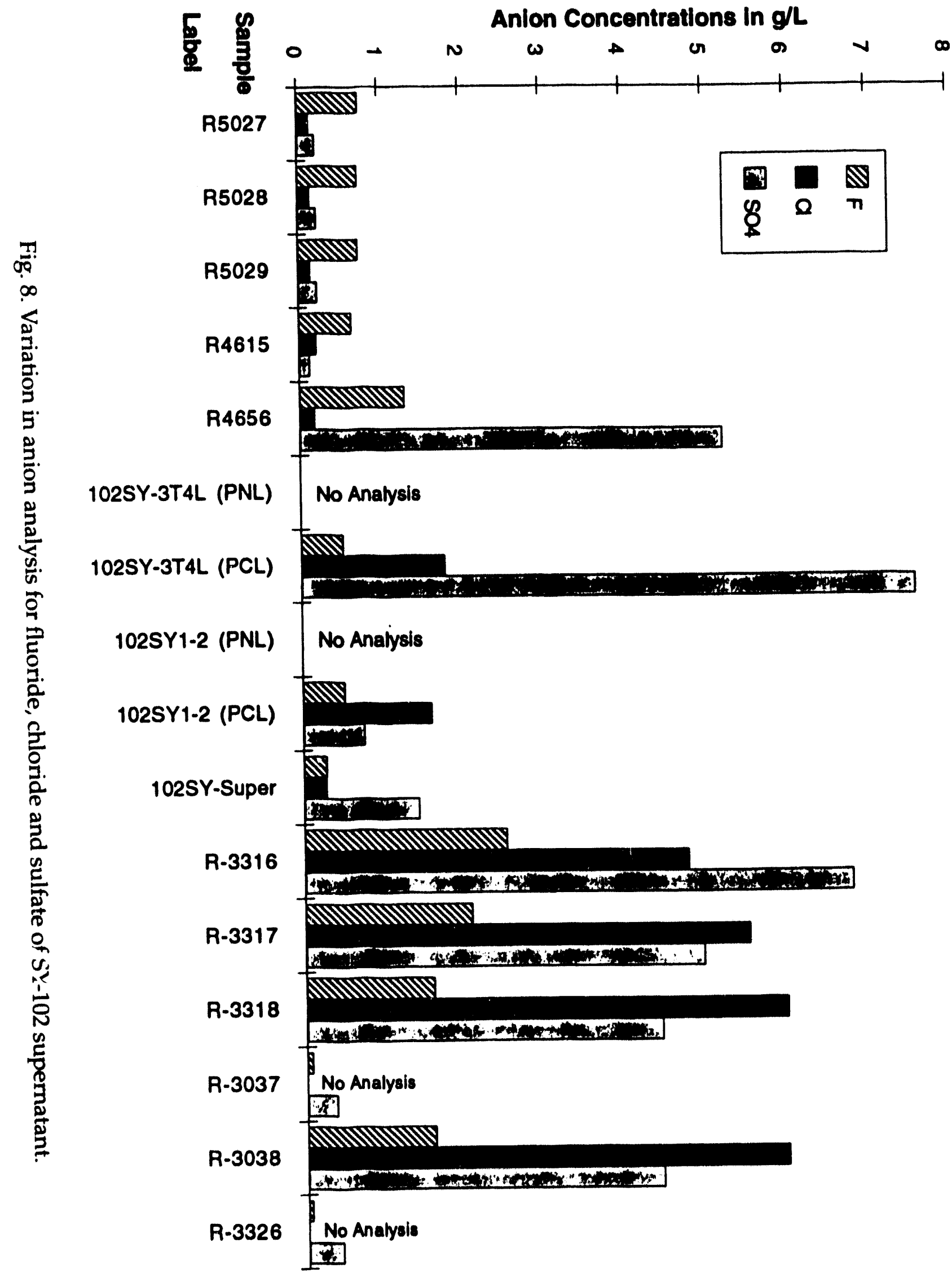



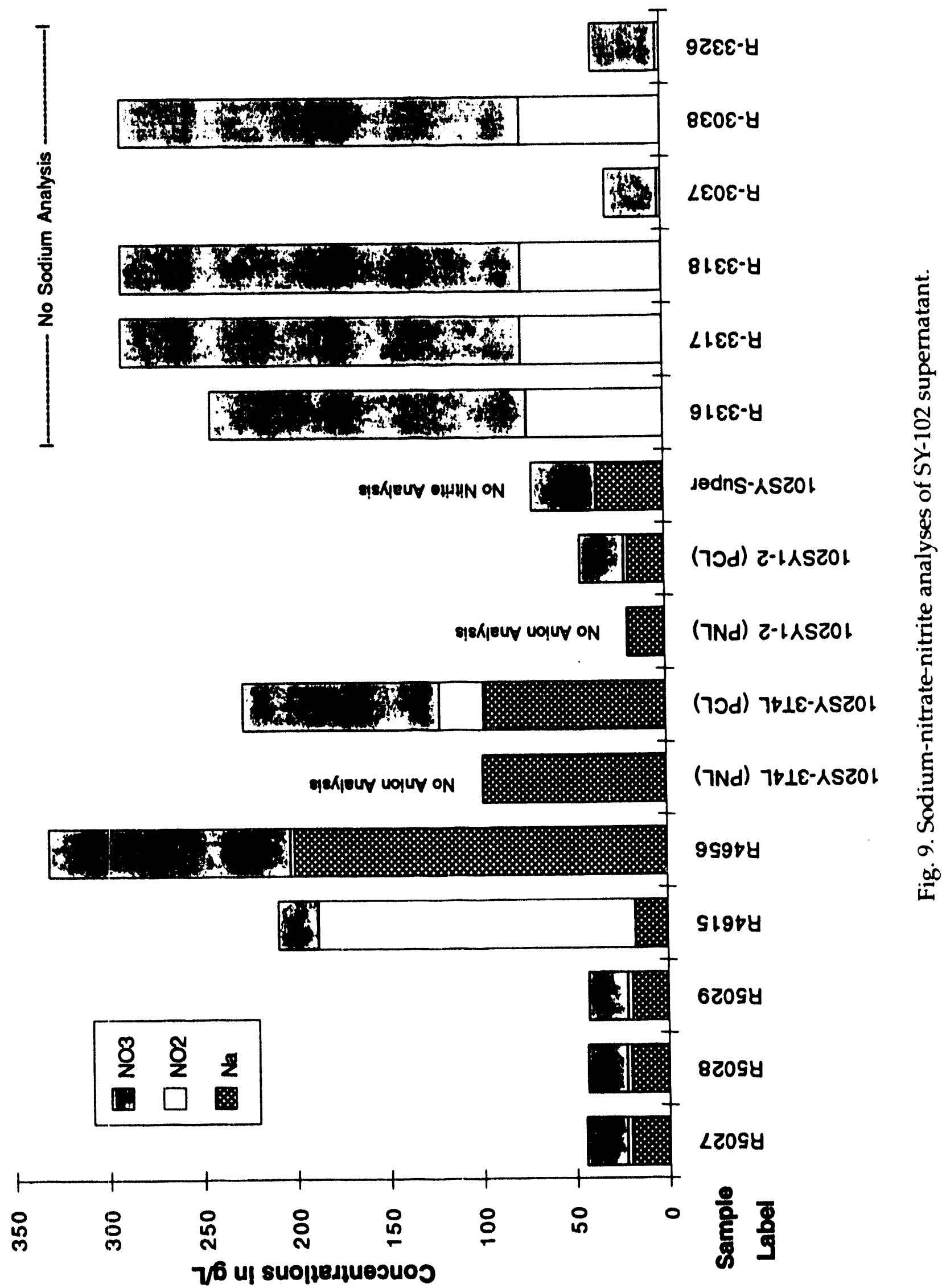
comparable concentrations of these species should be present in each sample. This appears to be the case for all the samples shown in Figure 8 with the exception of R4656, again suggesting that the analytical results for this sample may be an anomaly. Another unusual feature in this chart with no obvious explanation, is the very large nitrite level in R4615.

In general, radiation levels reported for the supernatant grab samples are typically less than one Curie per liter, with Cs-137 responsible for the majority of the activity. In nearly all samples, radiation levels of other radioactive isotopes are one hundred-fold or more lower than the Cs-137 activity level. The variation in the Cs-137 levels reported for the samples is shown in Figure 10. Again we note the large variation in radiation levels, with an especially anomalous value for the R4656 sample. Interestingly, the variation in Cs-137 levels reported follows the same pattern as that observed for the aluminum concentration in the samples (Figure 4), suggesting that the same waste stream may be responsible for the appearance of both cesium and aluminum in the tank supernatant. However, in view of the difference in the chemistries of the two elements, the similarity in behavior may only be a fortuitous occurrence.

\section{Tank Sludge Composition}

As mentioned earlier, there are nine analytical reports available for the 102-SY tank sludge. Three of these reports are on samples from the 1988 core, one is from a grab sample taken in July 1988 (102SY-Solids), and four of the last five are from grab samples taken in November 1984. No date is available for the fifth grab sample (R3036), but it appears to have been taken even earlier, since the analysis date is October 1984. It should also be noted that there are two reports on the analysis of the R3316 sample 


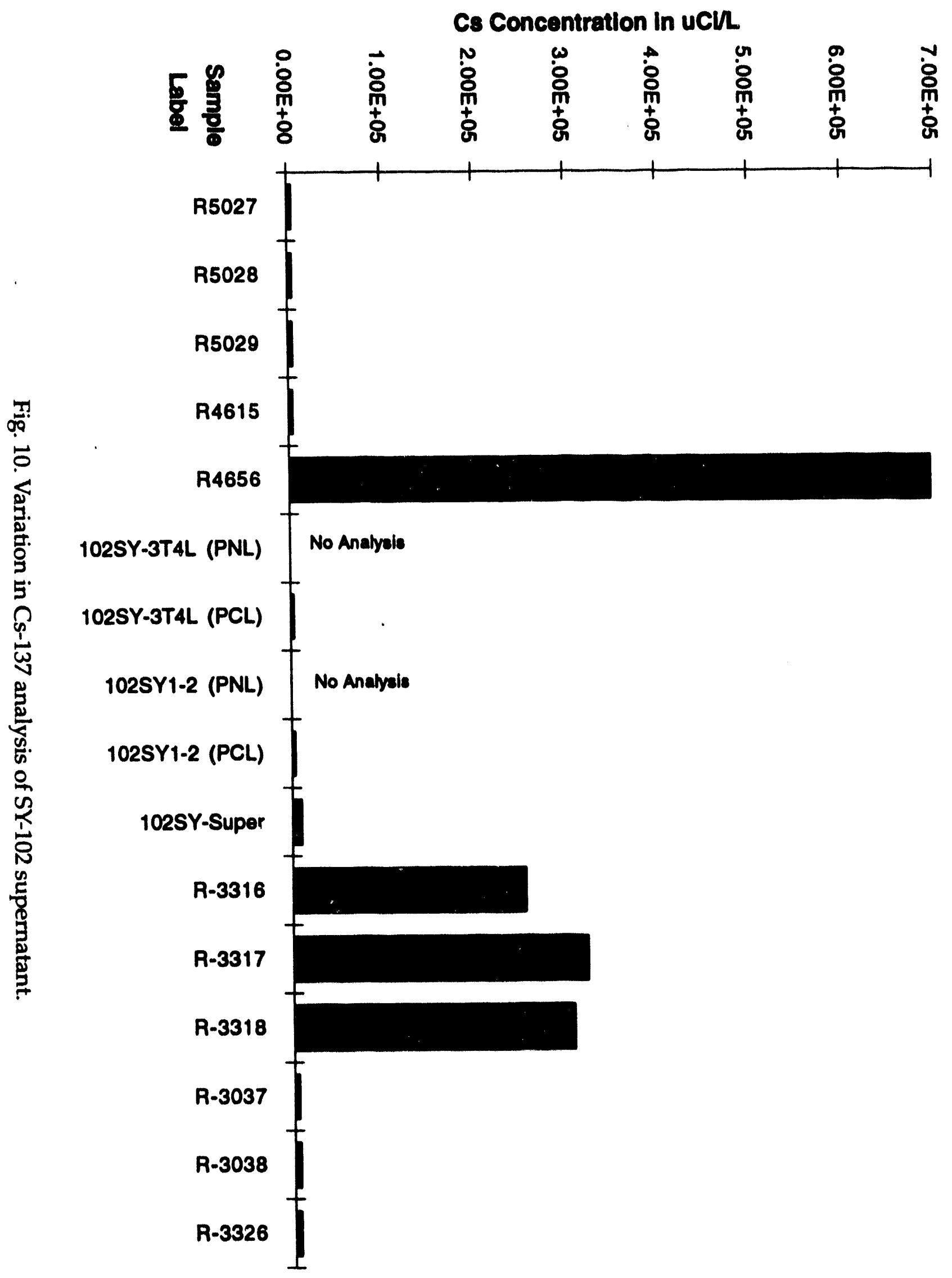


which differ significantly. However, no explanation is available as to what is responsible for the different set of analytical values reported.

The variation in the concentration of aluminum, chromium and iron found in these samples is shown in Figure 11. With the exception of the 3T4S samples and the 102SY-Solids sample, all of the remaining samples have the same relative abundance of the three metals, i.e., $\mathrm{Al}>\mathrm{Cr}>\mathrm{Fe}$. This is consistent with the fact that all of these samples were obtained from near the bottom of the tank, although the location is not available for the R3036 grab sample. In contrast, the $3 \mathrm{~T} 4 \mathrm{~S}$ samples taken from a point higher in the tank have a reduced chromium concentration, compared to the other two metals. The 102SY-Solids sample is a grab sample which also has a reduced chromium concentration, suggesting that this sample, like the 3T4S sample, was obtained from a point higher up in the tank sludge.

If we consider the absolute values of these analytical results, rather than the relative results, we find a large variation in the concentrations of the three elements as a function of the sample. For example, the aluminum concentration varies from a high of $\sim 16 \%$ by weight in the R3036 sample, to a low of $\sim 5 \%$ in the $4 \mathrm{~B}$ sample. Similar fluctuations are present in the analyses of all three metals. The source of these fluctuations could be a result of horizontal inhomogeneities in the tank composition, since the 4B sample and grab samples from the bottom of the tank could have been taken from different locations in the tank. Alternatively, the differences in the analytical results could be due to matrix interferences occurring in the analytical procedure. The presence of matrix interferences could alter the absolute values determined for the metal concentrations, but would be less likely to alter their relative concentrations. The analytical results from the R3036 sample are more than double the values reported for the other grab samples. Since we do not know the location of this grab sample, these 


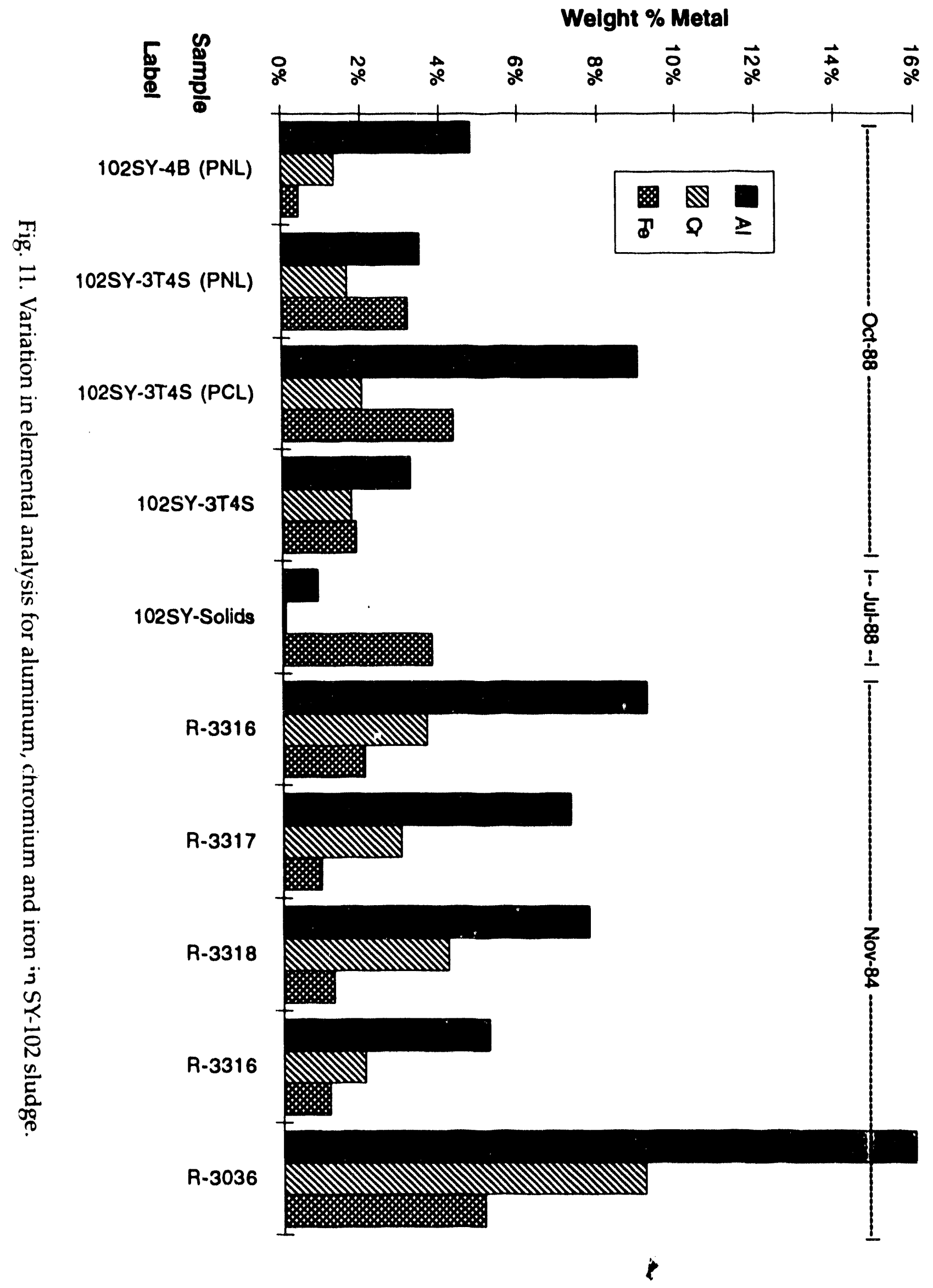


high concentration values may be typical of sludge higher in the tank. Omitting the R3036 sample data from consideration considerably reduces the spread in the analytical values reported for the other sludge analyses.

The 3T4S sludge sample is the only sample for which we have duplicate and independent analytical data. Figure 12 shows sludge concentration values obtained from Scheele and Peterson (PNL) as well as from Herting (PCL) for aluminum, chromium, iron and sodium. In addition, I have included in this chart Kirkbride's estimate, which is presumably based on the PNL and PCL data, as well as the Weiss results on the July 1988 grab sample (102SY-Solids). Values reported by Scheele and Peterson agree reasonably well with those of Herting for chromium, iron and sodium. However, Herting has an aluminum value nearly three times that of Scheele and Peterson. This deviation in the aluminum value can only be assigned to analytical error or to severe matrix interferences, which were accounted for by one analyst but not the other. It is interesting to note that Kirkbride selected the aluminum value from Scheele and Peterson, the chromium and sodium values from Herting, but used an iron estimate which is lower than either analytical value reported.

The iron value from the 102SY-Solids grab sample is similar to those reported for the 3T4S sample, but the aluminum, chromium and sodium values are all much lower. This deviation may reflect the fact that the 3T4S solid sample was obtained by mixing the top of the fourth core segment with the third core segment followed by homogenization and centrifugation. In contrast, the 102SY-Solids grab sample was almost certainly obtained from a much smaller vertical volume of the tank and therefore the metal concentrations reported should reflect much more localized tank conditions. If this is indeed the case, then these results indicate that the concentrations of the various metals vary substantially, depending upon either the horizontal or vertical 


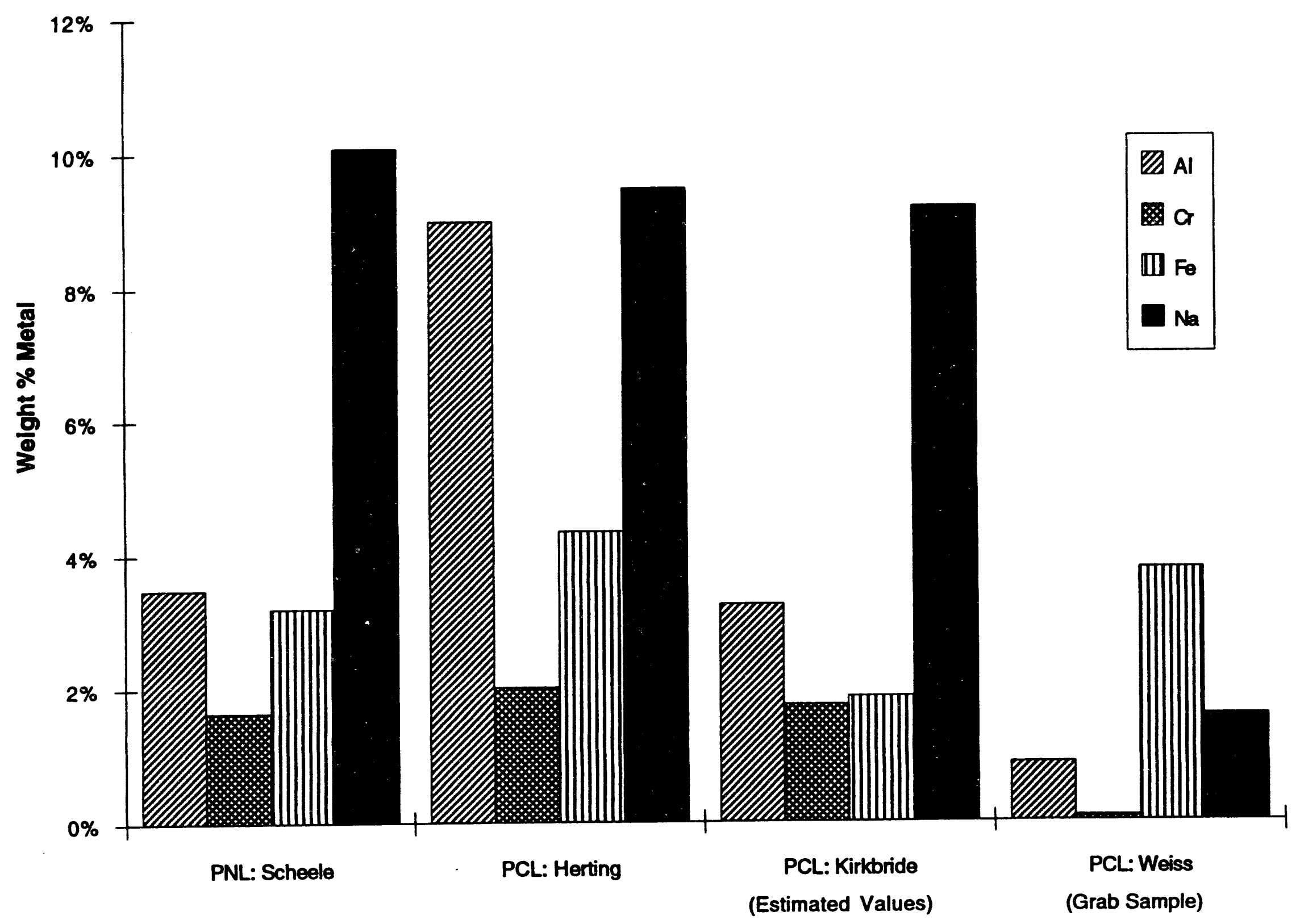

Fig. 12. Variation in elemental analysis for aluminum, chromium, iron and sodium of the $3 \mathrm{~T} 4 \mathrm{~S}$ sample. 
sampling location in the sludge. Additional sampling of the tank will be necessary to answer this question.

In Figure 13 we have shown the variation in the concentrations of aluminum, chromium, iron and manganese for the 3T4S sample reported by Scheele and Peterson, and Herting, as well as the values reported for these elements from three of Lumetta and Swanson's sludge washing experiments, i.e., PFP-1, PFP-3 and PFP-8. All of these analytical results are on a sample from the same composite; however, it should be noted that Lumetta and Swanson's results were obtained at a later date and they reported that the composite from which they obtained their samples was dried out. This would increase the effective concentration of the elements due to the loss of water.

The analyses for the four elements all show similar, albeit not identical, patterns. Aluminum and iron are in greatest abundance in all samples, although the absolute concentrations are not the same. Lumetta and Swanson's results do appear on average to be somewhat higher than the results of Scheele and Peterson as expected from the reduced water content of the PFP samples. They are also greater than Herting's results, with the notable exception of aluminum, for which Herting reports a value nearly double that of any of the other analyses. The range of $\sim 1 \%$ observed in the analytical results on the three PFP samples from the sludge washing experiments is much larger than the deviation one would expect due to normal analytical error. This may indicate the limits of precision possible for such a complex matrix, but it seems more likely that this range reflects the homogenization process originally used to composite the third and fourth segments and prepare the 3T4S sample. The inhomogeneity of the 3T4S sample, reflected in the large analytical range, may be a consequence of uneven settling during the centrifugation step used on the composite to separate the solid sample (3T4S) from the supernatant sample (3T4L). 


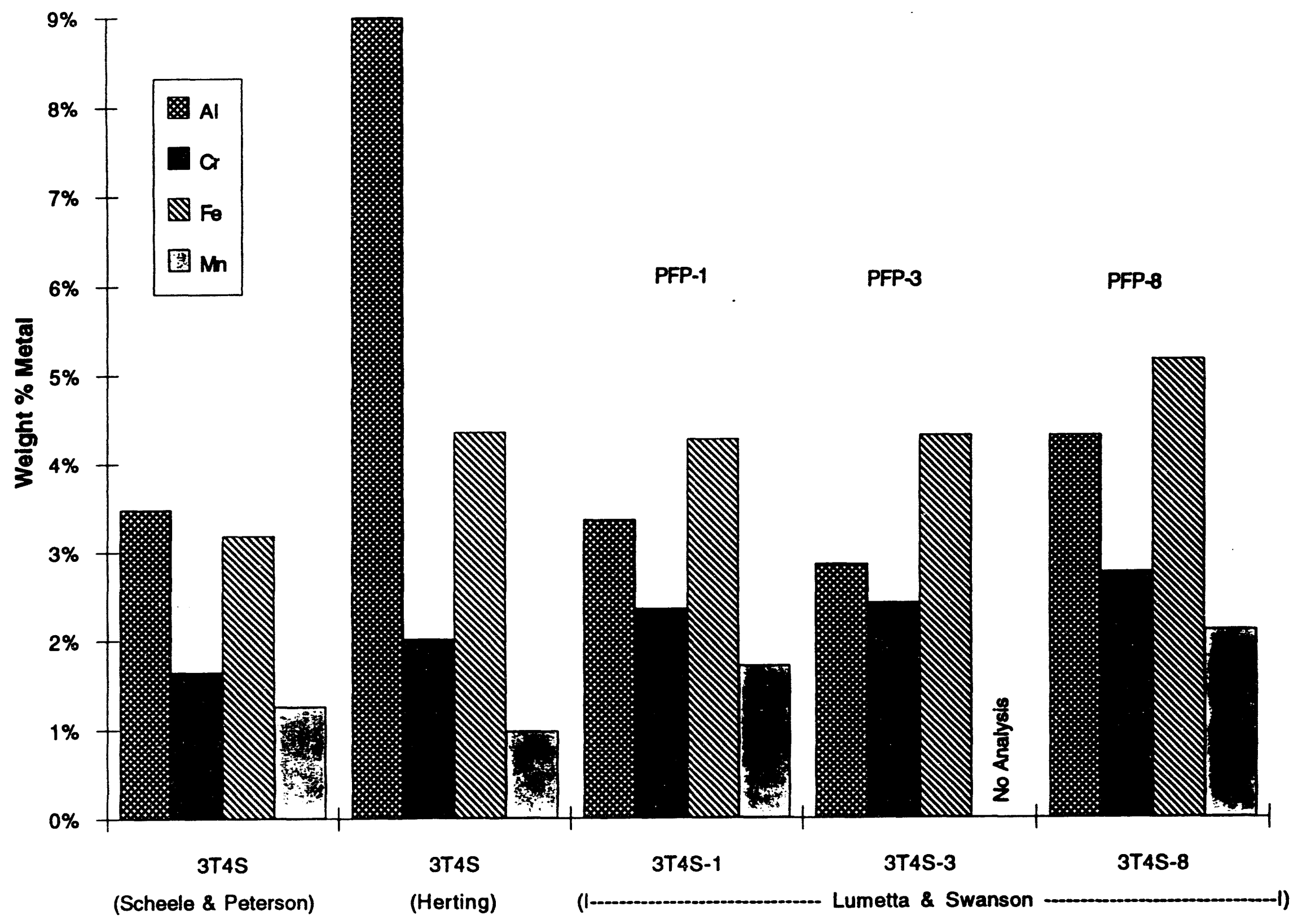

Fig. 13. Variation in elemental analysis for aluminum, chromium, iron and manganese of the 3T4S sample and associated sludge washing experiments. 
Figure 14 shows the variation observed for six of the less abundant elements found in the 3T4S sample, including calcium, potassium, phosphorus, lead, thorium and uranium. Unfortunately, not all elements were analyzed in every analysis, but we can get an indication of the limits on the analytical results and the interpretations that can be drawn from them. There appears to be significantly greater variation in the analytical results reported for these less-abundant elements than for the most-abundant elements. For example, the concentrations of potassium and phosphorus reported by Scheele and Peterson are nearly three times greater than the concentrations reported by Herting. A comparison of the analytical results for the three PFP samples show that most of the elements were found to have similar concentrations in all three samples, with the exception of the calcium level in PFP-8, which is smaller by a factor of nearly twenty. As was observed for the more abundant elements, the ranges observed in these analyses exceed normal analytical expectations, which may also be a result of incomplete homogenization of the 3T4S sample.

The variations in concentration of the radioactive elements americium, plutonium, and cesium are shown in Figure 15. Unfortunately, interpretation of the plutonium data is complicated by the fact that different isotopes are reported for different samples (see Comp.SL.final spreadsheet). In addition, the americium and plutonium data listed for Scheele and Peterson's 3T4S sample were actually determined for the $4 \mathrm{C}$ sample, i.e., sludge from the top of the fourth core segment prior to forming the composite with sample $3 \mathrm{C}$ from the third core segment, rather than sample 3T4S.

If we omit the second $3 \mathrm{~T} 4 \mathrm{~S}$ sample, which is actually the $4 \mathrm{C}$ sample, and the 102SY-Solids sample from consideration, we can see that the activity values for Cs-137 are in reasonable agreement for all of the other samples, averaging roughly $130 \mu \mathrm{Ci} / \mathrm{g}$, 


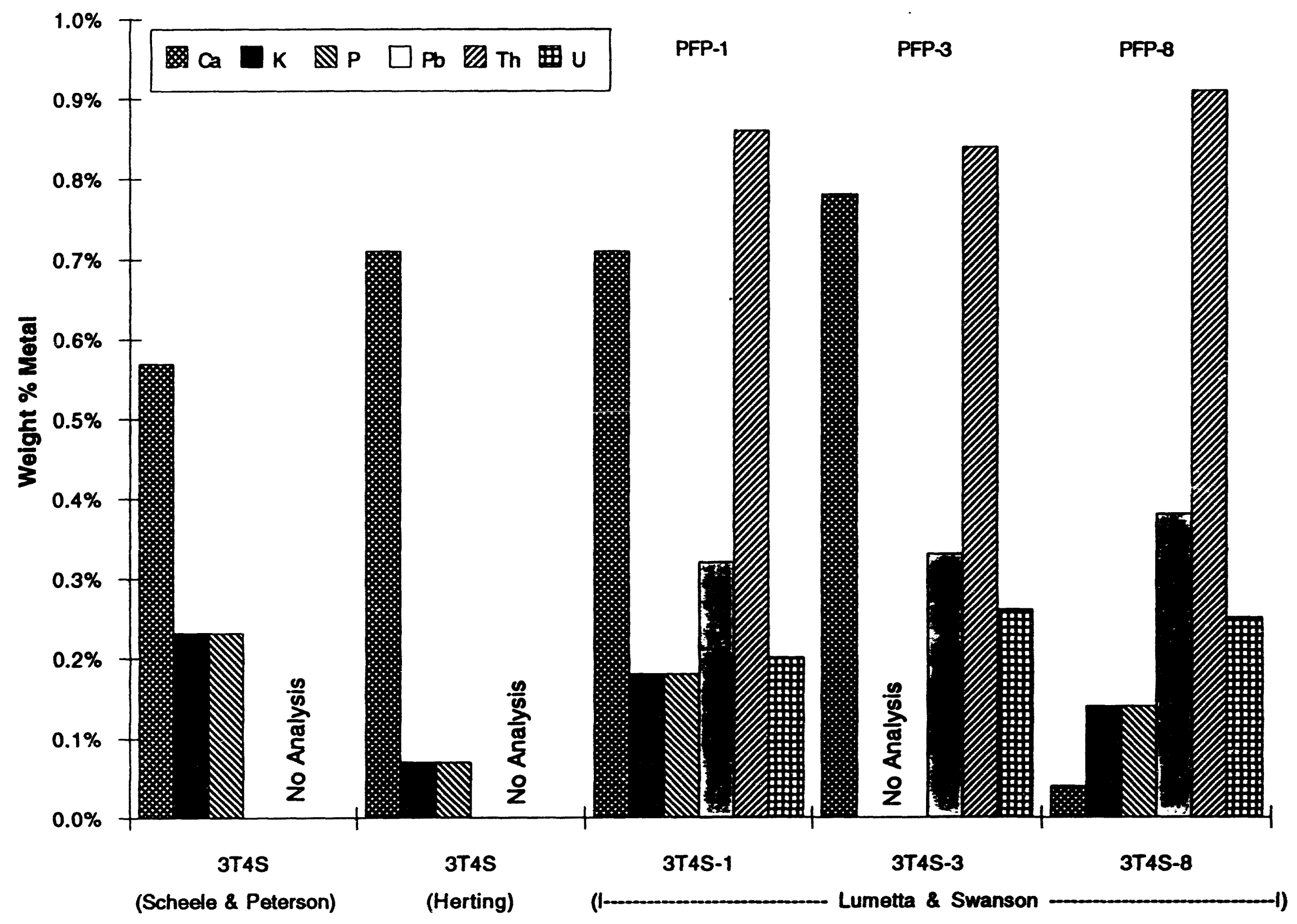

Fig. 14. Variation in elemental analysis for the less abundant calcium, potassium, phosphorus, lead, thorium and uranium of the 3T4S sample. 


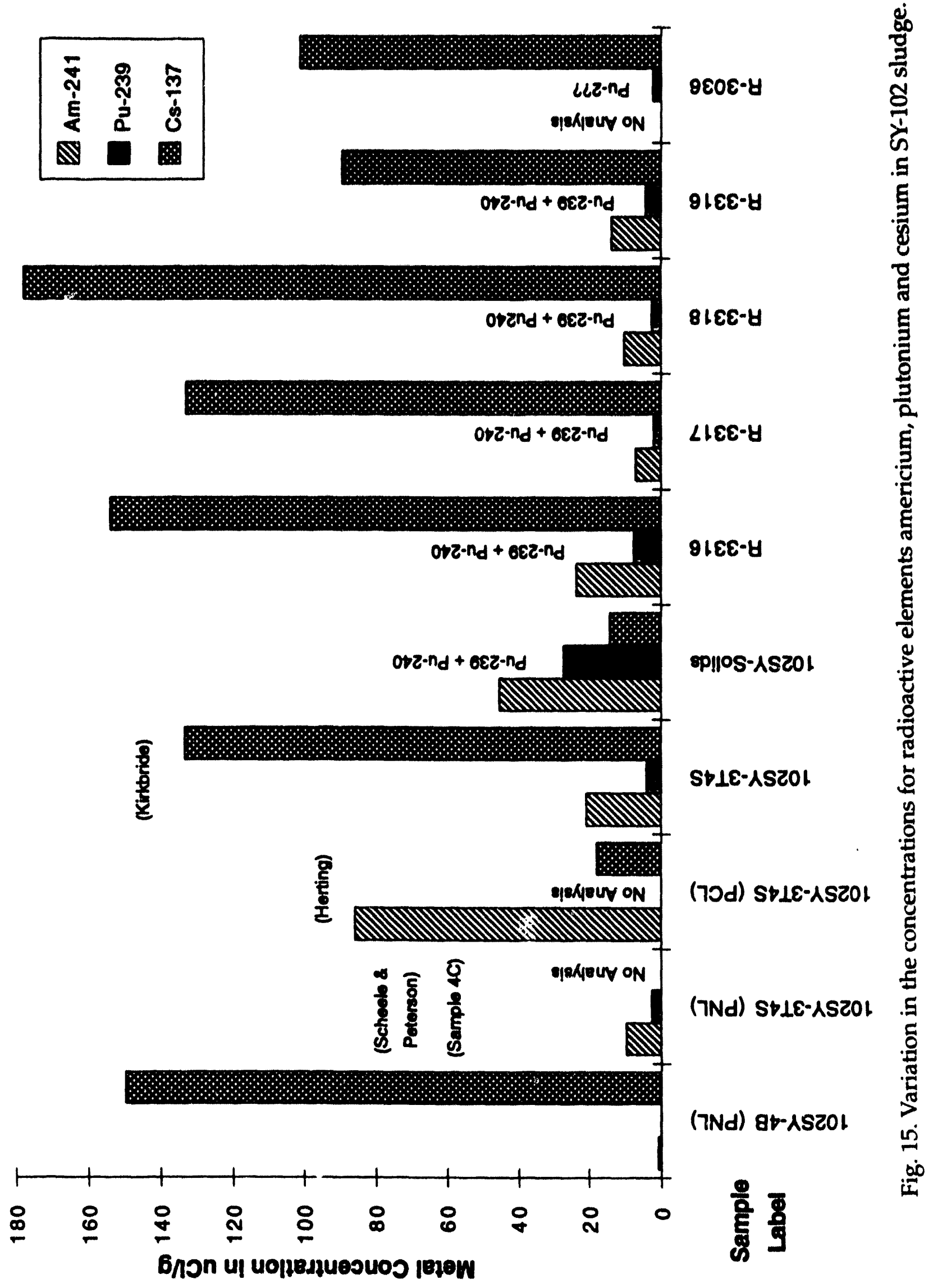


with the largest variation being a factor of two between the R-3318 and R-3316 samples. Since the $4 \mathrm{~B}$ sample and all the grab samples listed were obtained near the bottom of the tank, this value should reflect the cesium content in the residual salt cake left in the tank. The values for the $4 \mathrm{C}$ and $102 \mathrm{SY}$-Solids sample are much lower, consistent with the fact that these samples were obtained at a pnint significantly higher in the tank, i.e., above the salt cake, where we would expect to find a lower Cs-137 content.

In contrast, the americium activities are generally lower than the Cs-137 activities, but show much greater variation from sample to sample. It is unclear at this time what is responsible for the very large fluctuations observed in the Am-241 activity levels reported in these samples. The values from the bottom of the tank, i.e., the 4B sample and the grab samples, appear to be significantly lower than those reported for samples obtained from a point higher in the tank, such as Herting's analysis of the 3T4S sample and the 102SY-Solids sample. Consistent with this observation is the fact that the Am-241 analysis reported for the $4 \mathrm{C}$ sample by Scheele and Peterson also falls in the lower range of activities. We have ignored the value reported by Kirkbride since this value is not an independent analytical result.

Scheele and Peterson's report on the 1988 core samples represents the most complete set of analytical data available for the SY-102 tank sludge. The elemental abundances determined for the $4 \mathrm{~B}$ and $3 \mathrm{~T} 4 \mathrm{~S}$ core samples are shown in Figure 16 . The dominant species in the $4 \mathrm{~B}$ sample have the order: $\mathrm{Na}>\mathrm{Al}>\mathrm{Cr}>\mathrm{P}>\mathrm{As} \sim \mathrm{Se}>\mathrm{Fe}$. The distribution of the dominant species in the $3 \mathrm{~T} 4 \mathrm{~S}$ sample are quite different, with the exception of sodium and aluminum, and have the following order: $\mathrm{Na}>\mathrm{Al} \sim \mathrm{Fe}>\mathrm{Cr}>$ $\mathrm{Mn}>\mathrm{Ca}>\mathrm{P}>\mathrm{Si}$. The difference in the sludge analysis for these two samples presumably reflects the different layers that formed in the tank as the waste stream fed into the tank changed over the years. Due to the compositing and homogenization of 


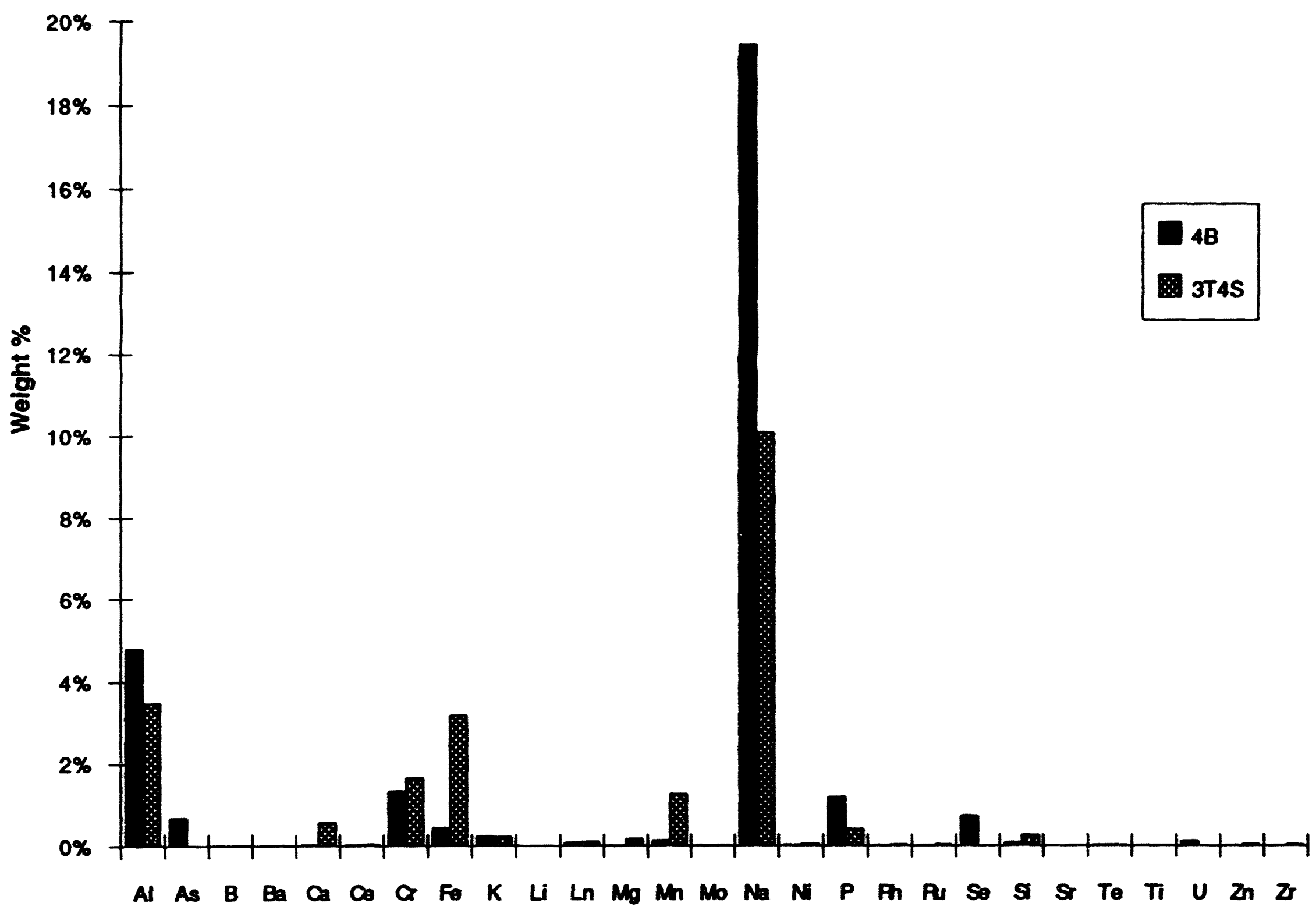

Fig. 16. Elemental abundance in SY-102 solid core samples 4B and 3T4S. 
the core segments, we have converted the many layers that may exist in the tank into only two effective layers, i.e., sample 4B, which represents the sludge in the bottom 8 in. of the tank, and sample 3T4S, which represents the remaining 30 in. of sludge.

The elemental abundances of those elements found at lower concentrations in the 4B and 3T4S samples of the sludge are shown in Figure 17. Again it is clear from a comparison of the results for the two samples that they have a different signature, as would be expected if the waste streams forming the sludge were different. Unfortunately, analytical data for bismuth, thorium, and heavy metals such as lead and mercury are not available for these samples. Uranium data for the 3T4S sample are also missing. These additional data would be useful information since the concentrations of these elements in the sludge will probably affect any tank remediation flow sheet proposed.

The analytical data available for the concentrations of anions in the sludge are relatively sparse. Scheele and Peterson reported the concentrations of several anions in the $4 \mathrm{~B}$ sample but not for the $3 \mathrm{~T} 4 \mathrm{~S}$ sample. As mentioned earlier, these analyses were carried out on aqueous extractions of the sludge and therefore do not detect anions present as insoluble salts. Figure 18 shows a comparison between the anion data available for the $4 \mathrm{~B}$ sample and the data for the 3T4S sample from Herting's analysis. The much larger nitrate concentration found in the $4 \mathrm{~B}$ sample is consistent with the salt cake composition proposed for this sample.

Figure 19 shows the variation in the chloride and sulfate concentrations reported for the sludge samples. These are the only two anions for which analytical data are available for the majority of the sludge samples. The chloride data show relatively little variation in concentration compared to the sulfate data. The large deviation in the 


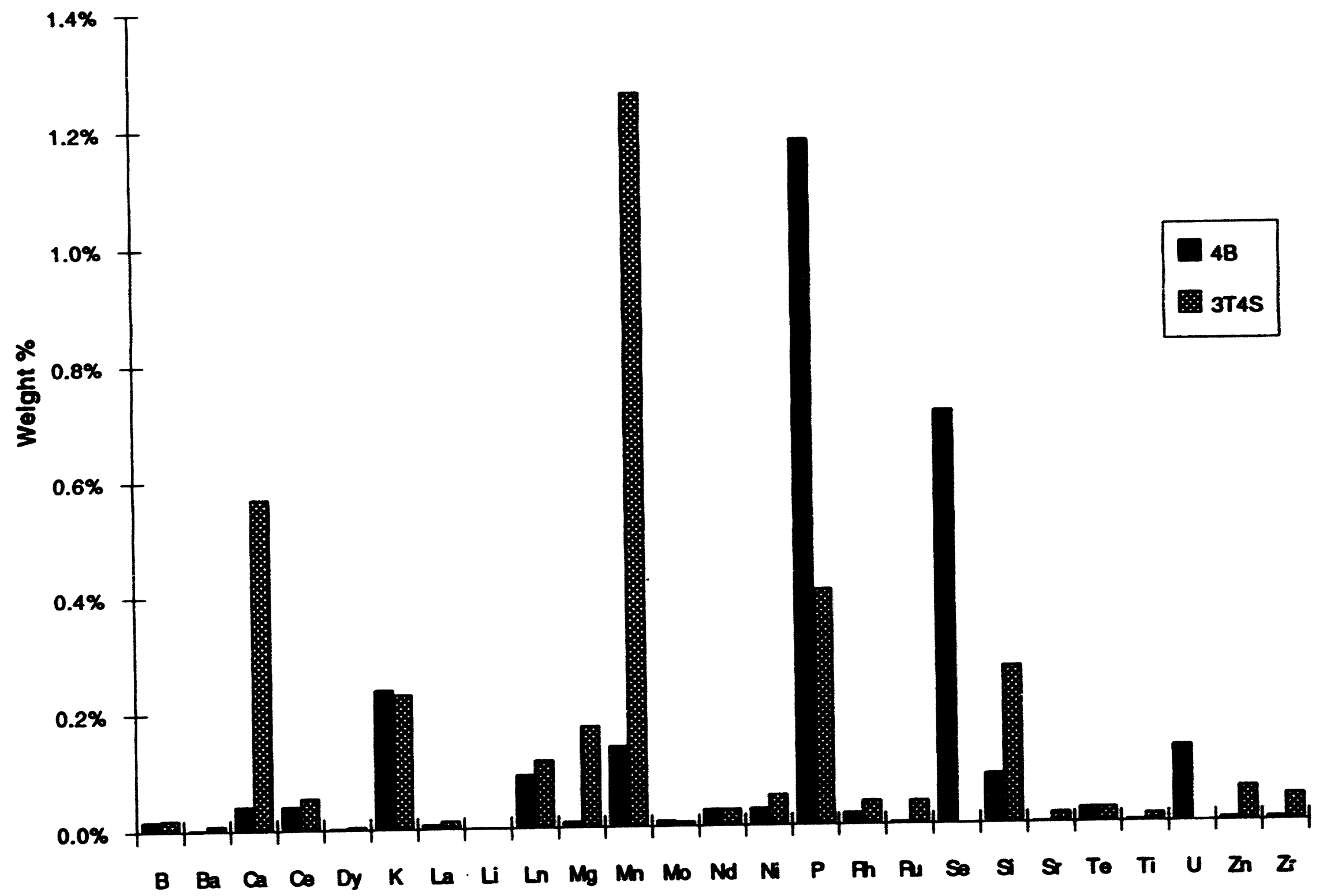

Fig. 17. Elemental abundance of those elements found at lower concentrations in SY-102 solid core samples 4B and 3T4S. 


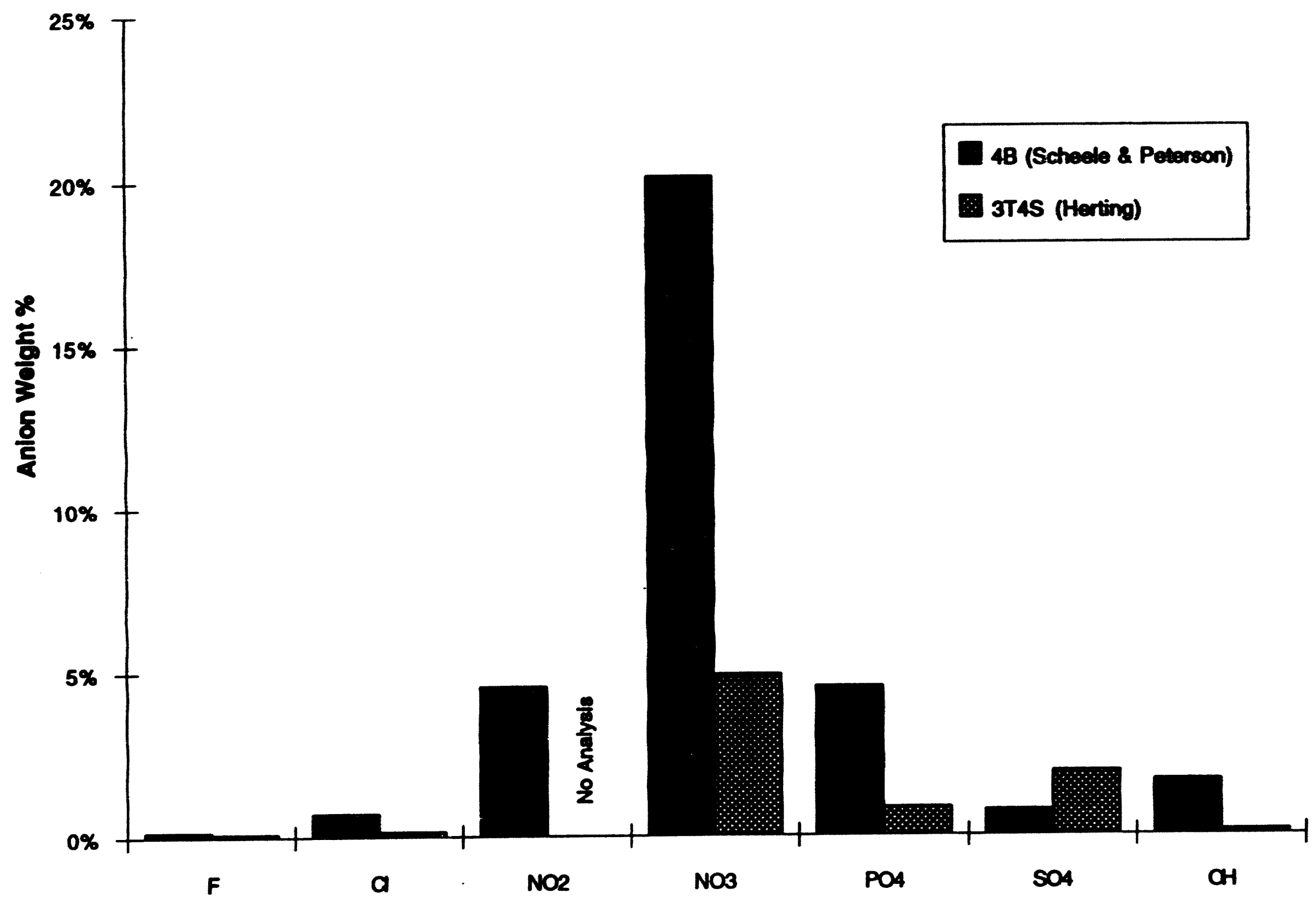

Fig. 18. Anion abundance in SY-102 solid core samples $4 B$ and $3 T 4 S$. 


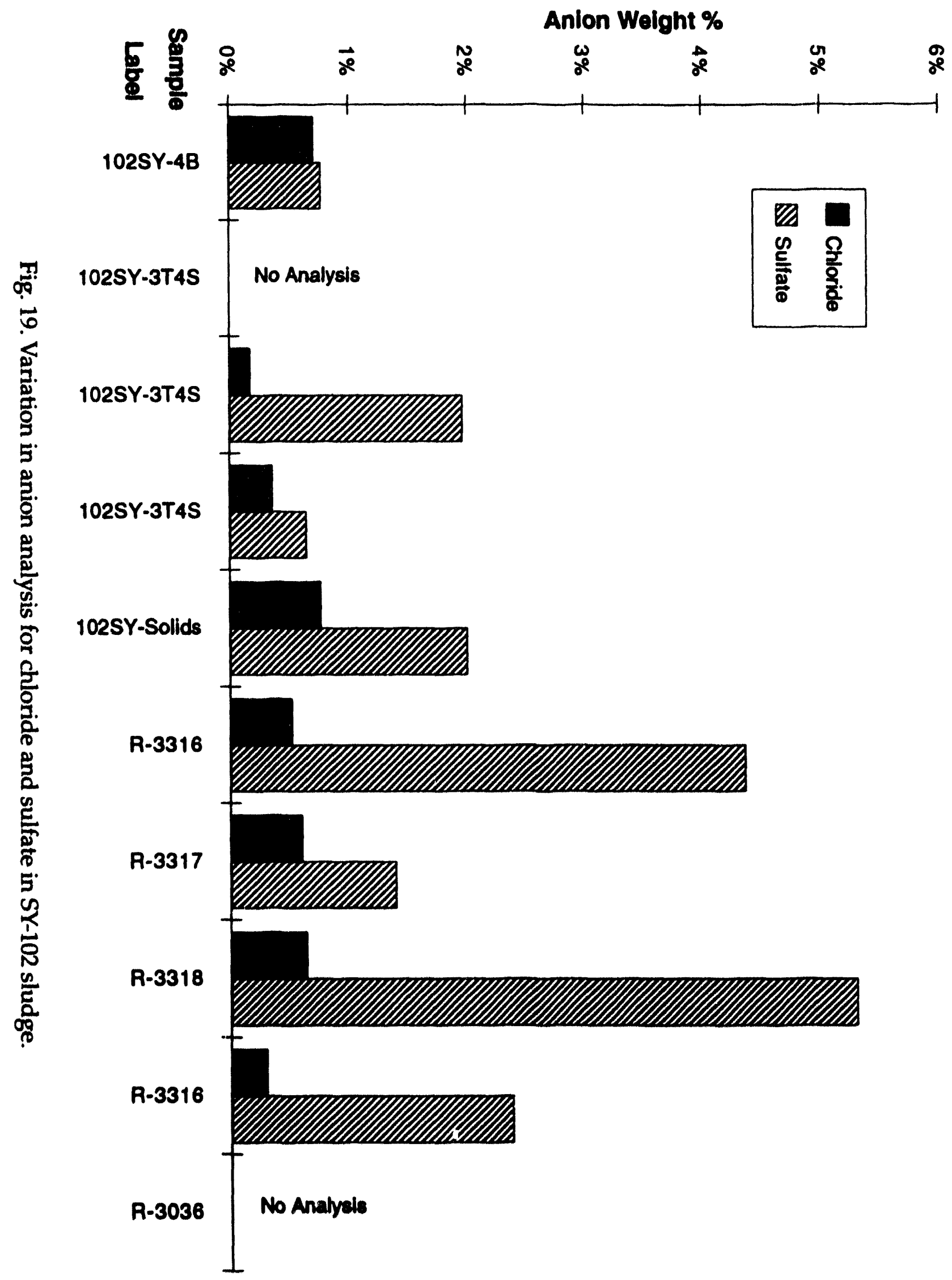


sulfate values reported for the R-3316, R-3317 and R-3318 samples is particularly surprising. The fluctuation may reflect the formation of insoluble, or less soluble salts during the process of extracting the basic solid with water, in preparation for the ion chromatographic method used for the analysis. Mixing of the layers in the sludge may bring together in the liquid phase cations and anions that were separated in the sludge, resulting in the precipitation of new salts. Deviations in the exact method used to carry out the extraction could account for the formation of different amounts of insoluble salts for each sample, and since sulfate salts tend to be less soluble than chloride salts, greater variation in the sulfate results would be expected.

It is of some interest to compare the phosphorus analysis carried out on the 4B sample using ICP with the phosphate analysis carried out on the aqueous extraction of the sample using ion chromatography. Scheele and Peterson report $0.38 \mathrm{mmol} / \mathrm{g}$ of sludge by ICP compared to $0.48 \mathrm{mmol} / \mathrm{g}$ by ion chromatography. If insoluble phosphate salts were not detected by aqueous extraction, we would expect the ICP number to be larger than the ion chromatography number. Since the reverse appears to be the case, we might expect that all of the phosphate present in the $4 \mathrm{~B}$ sludge sample should be capable of being extracted by water. In contrast, for the 3T4S sample, Herting reports $0.181 \mathrm{mmol} / \mathrm{g}$ by ICP and only $0.0917 \mathrm{mmol} / \mathrm{g}$ by ion chromatography, suggesting that nearly half of the phosphate is in the form of water insoluble salts. We can compare this result with Lumetta and Swanson's sludge washing data on the 3T4S sample in which they found that a water wash removed $18.7 \%, 22.1 \%$ and $100 \%$ of the phosphorus from the sludge in three separate experiments. They could give no explanation for the large discrepancy between the three experiments, and unfortunately none of them match the $50 \%$ extraction rate we would expect from the ICP/ion chromatography comparison. Again, we note here that these fluctuations in the 
experimental results may simply be a consequence of inhomogeneities in the 3T4S sample that occurred during the sample preparation.

The interpretation of the Lumetta and Swanson's sludge washing study is further clouded by the method used originally to prepare the 3T4S sample. The 3T4S sample was prepared by mixing the slurry from the third core segment with the upper $11 \mathrm{in.}$ of the fourth core segment, homogenizing and centrifuging the mixture, and then separating the solid (3T4S) from the supernatant (3T4L). Since the phosphate levels in supernatant sample 3T4L are much lower than those found in the solid 3T4S sample, it would seem reasonable to expect that any extractable phosphate would have already been extracted into the supernatant during the sample preparation, leaving no phosphate to be extracted in later sludge washing experiments. However, it may be that differences between the hydroxide content of the supernatant during sample preparation and the later sludge washing experiments can account for this behavior. Alternatively, the larger volume of water used in the sludge washing experiments, compared to the supernatant in the sample preparation, may dissolve more of the poorly soluble transition metal phosphate salts.

\section{Comparison of the 1988 and 1990 Cores}

Information on the 1990 core is available to us from two sources; Lumetta and Swanson's sludge washing experiments (PFP-6 and PFP-7) and Gray's report from the PCL laboratory at Westinghouse. Both sets of analyses are limited to the 34COMP sample, which appears to be the solid sample analogous to the 1988 core 3T4S sample, resulting from homogenization of the third and fourth segments of the core followed by centrifugation. Although we did not receive a detailed description of the 1990 core and sample preparation, the information we do have suggests that a sample analogous to the 4B sample from the 1988 core was not separated out of the 1990 core, implying that 
the bottom 8 in. of the 1990 core sample was included in the homogenization of the third and fourth core segments. This should increase the relative concentrations of the salt cake components (e.g., sodium, nitrate, Cs-137) in the 34COMP sample from the 1990 core compared to the 3 T4S sample from the 1988 core.

Information from Steve Agnew supports risers $1 \mathrm{~B}$ and $13 \mathrm{~A}$ as the locations of the 1988 and 1990 core samples, respectively. Riser 1B is roughly $20 \mathrm{ft} 8 \mathrm{in}$. from the center of the tank, nearly equidistant from the Feed Pump Pit and the Pump Pit. In contrast, riser $13 \mathrm{~A}$ is less than $11 \mathrm{ft}$ from the center of the tank, adjacent to the Pump Pit. The two risers are approximately $15 \mathrm{ft}$ from each other. Figure 20 presents a schematic of the riser locations on tank SY-102 with the core sites indicated (Rockwell, \#SD-RE-TI-093).

The 88/90 CoreComp3 spreadsheet presents the data available for the 34COMP sample from the 1990 core, together with the comparable data for the $4 \mathrm{~B}$ and 3T4S samples from the 1988 core. The concentrations of aluminum, chromium, iron and manganese in these samples are shown in Figure 21. All three of the 34COMP analyses have similar concentrations for these four elements. The results for the 3T4S samples from the 1988 core are all substantially higher. The higher values could reflect the fact that the 3T4S samples contain less water than the 34COMP sample, as suggested by Lumetta and Swanson. However, the fact that the aluminum content of the 3T4S sample is roughly double that of the 34COMP sample while the iron content of the 3T4S sample is more than triple that of the 34COMP sample implies that explanations other than water content must play a role in accounting for the differences in concentrations observed in these two samples.

The relative abundances of the $3 \mathrm{~T} 4 \mathrm{~S}$ and $34 \mathrm{COMP}$ samples are also different. The 3T4S sample has the order $\mathrm{Fe}>\mathrm{Al}>\mathrm{Cr}>\mathrm{Mn}$, whereas the 34COMP sample has the 
TANK SY-102

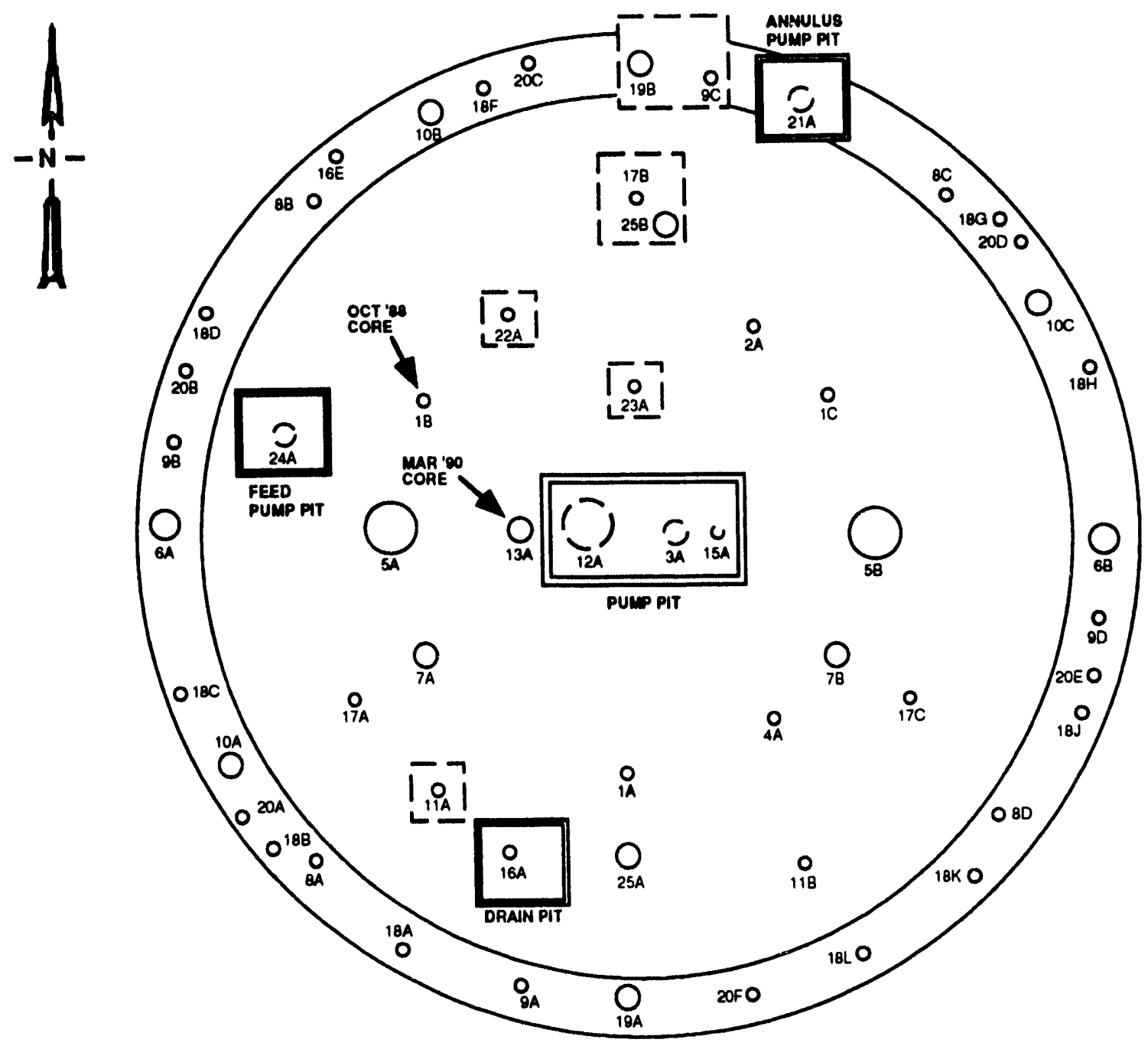

Note: Copied from Rockwell Hanford Operations

Document \#: SD-RE-T1-093

Some labels may be incorrect due to blurring of original.

Fig. 20. Schematic of the riser locations on SY-102 with the core sites indicated. 


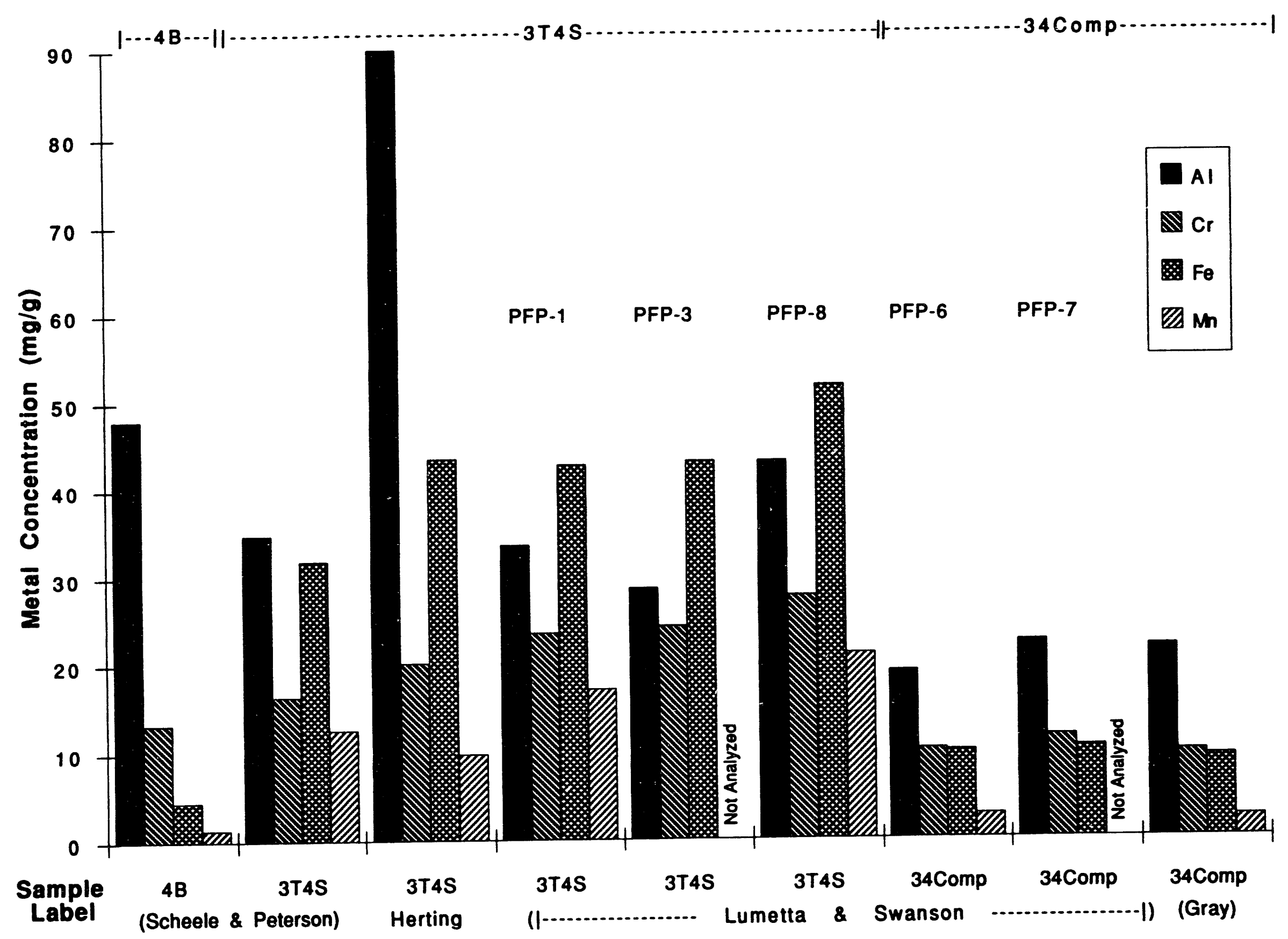

Fig. 21. 1988-1990 core comparison for elements aluminum, chromium, iron and manganese. 
order $\mathrm{Al}>\mathrm{Cr}>\mathrm{Fe}>\mathrm{Mn}$. This difference in relative concentrations in samples taken from similar depths in the tank, but at two different locations, suggests that inhomogeneous mixing of the layers in the tank has probably occurred. However, if the 34COMP sample does contain a significantly larger portion of the salt cake from the bottom of the tank, the presence of this material could explain the difference in the relative concentrations since the order for the $4 \mathrm{~B}$ sample from the 1988 core is the same as that of the 34COMP sample. Thus the combination of greater salt cake and a wetter 34COMP sludge sample may be enough to account for the relative concentration differences observed between the 3T4S and 34COMP samples.

Figure 22 presents the same information for elements present in less abundance in the 34COMP sample, including, calcium, potassium, lead and thorium. There is much greater analytical variation in these results, both for the 3T4S sample and the 34COMP sample. In addition, not all samples were analyzed for all the elements. In particular, the calcium and thorium levels fluctuate by a factors of five and two, respectively. These large fluctuations may represent serious matrix interferences in the analytic method. The combination of missing analyses and poor analytical precision prevents us from making a useful comparison between the 3T4S and 34COMP samples.

\section{Charge Balance}

In an attempt to ascertain the reliability and internal consistency of the analytical results, we have carried out a charge balance analysis on the $4 \mathrm{~B}$ sludge sample from the 1988 core, the sample for which we have the most complete analytical data. These results are presented in the form of two Microsoft Excel spreadsheets (filenames: ChargeBalance and ChargeBalance.complete) in Appendix B. Our initial approach (in ChargeBalance) was to assume that the elements for which the analytical data were obtained by ICP, would be found in the sludge as cations, except for phosphorus, 


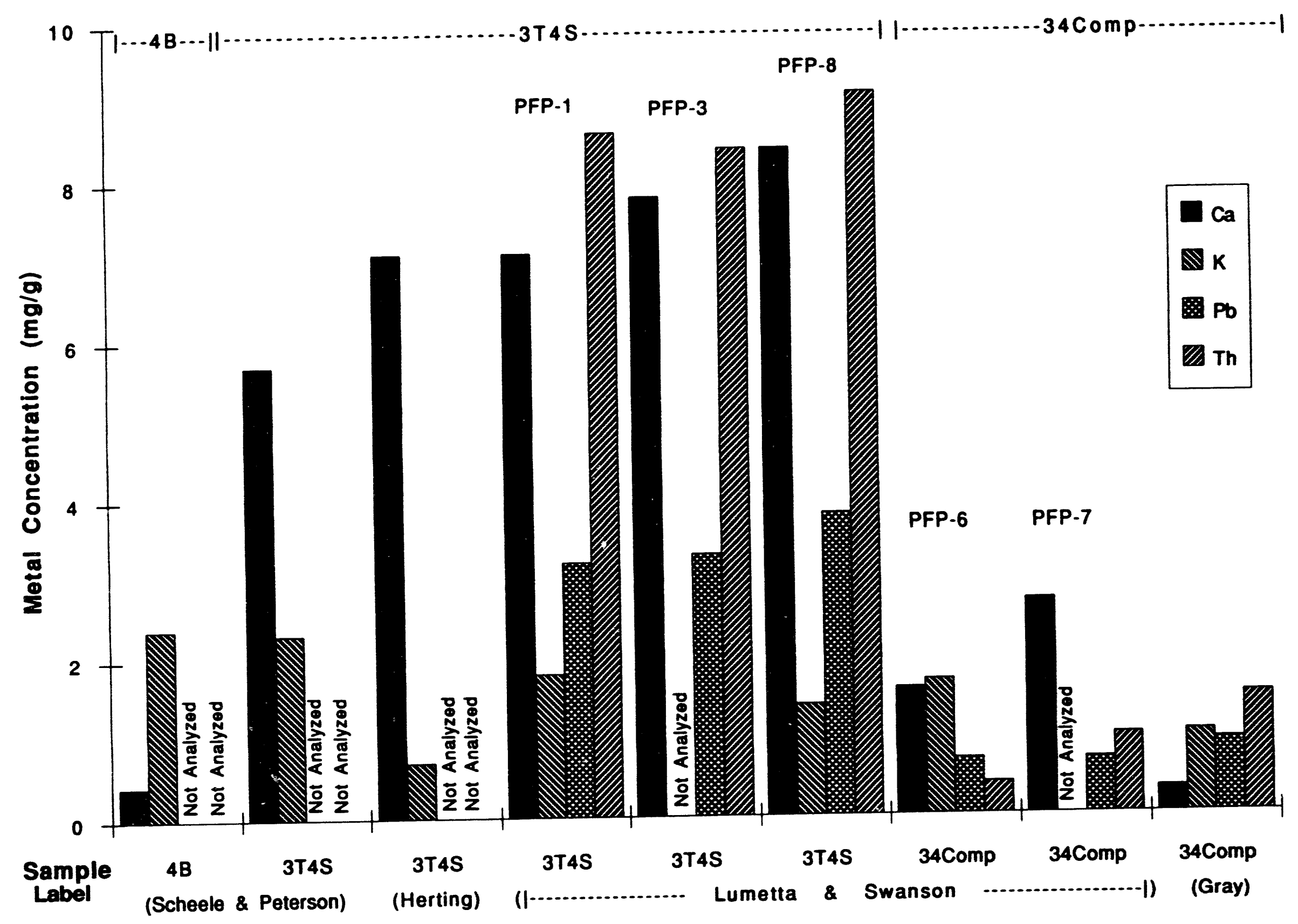

Fig. 22. 1988-1990 core comparisons for less abundant elements calcium, potassium, lead and thorium. 
sulfur, boron, arsenic, selenium, and silicon, which were assumed to exist as the oxyanions, phosphate, sulfate, borate, arsenate, selenate, and silicate, respectively. The total charge for these latter anions was then added to the charges obtained from the ion chromatography results for fluoride, chloride, nitrate, nitrite, and hydroxide. The total cationic and anionic charges were obtained by converting the weight \% values to molar quantities and multiplying by the appropriate charge. For cations that can exist in multiple oxidation states, a charge consistent with the presence of air and at least $0.1 \mathrm{M}$ $\mathrm{NaOH}$ was assumed. For example, iron was assumed to be present as $\mathrm{Fe}(\mathrm{III})$ in $\mathrm{FeOOH}$, chromium as a $\mathrm{Cr}$ (III) salt, and manganese as $\mathrm{Mn}(\mathrm{IV})$ in $\mathrm{MnO}_{2}$. We refer to this case as the Minimum Negative Anion Case. The charge balance that results from these assumptions is not very good, with a net cationic charge of +150.6 compared to a net anionic charge of -80.5 . However, it should be noted that if the counterion for aluminum in the sludge is assumed to be hydroxide instead of nitrate or nitrite, then the hydroxide content needs to be increased, providing an additional 53.4 units of negative charge, resulting in a total anionic content of -133.9.

A second scenario (also in ChargeBalance) assumed that any element capable of existing as an anion under tank conditions, was in fact present in anionic form. This approach was expected to increase the net negative charge and correspondingly decrease the net positive charge. Under this scenario, in addition to the anions already mentioned above, aluminum was assumed to exist as the tetrahydroxyaluminate anion, chromium as chromate, and molybdenum as molybdate. Other potential anions that could exist, but which were not included in this calculation, are tellurium as tellurate, titanium as titanate and zirconium as zirconate. However, since these three elements are present as minor constituents of the sludge, these assumptions do not affect the charge balance calculation significantly. We refer to this scenario as the Maximum Negative Anion Case. The charge balance that results from these assumptions now has 
an excess of negative charge, with a net cationic content of +89.5 and a net anionic content of -103.4. The Minimum and Maximum cases represent the likely extremes of charge balance possible for the sludge composition.

It is clear from a consideration of these two results, that the assumption made as to the speciation of the aluminum ion in the tank is critical to obtaining a reasonable charge balance. Converting all the aluminum present, based on the ICP analysis from $\mathrm{Al}(\mathrm{III})$ to $\mathrm{Al}(\mathrm{OH})_{4}^{-}$, results in a net swing of 71.2 units of charge from plus to minus. $\mathrm{A}$ similar conversion of the chromium from $\mathrm{Cr}(\mathrm{III})$ to $\mathrm{CrO}_{4}=$ results in only a swing of 12.8 units of charge from plus to minus, due to the smaller weight $\%$ abundance and larger atomic mass of chromium relative to aluminum. The imbalance in the net cationic and anionic charge in these two examples can be adjusted by altering the $\mathrm{Cr}(\mathrm{III}) / \mathrm{CrO}_{4}=$ and /or the $\mathrm{Al}\left(\mathrm{NO}_{3}\right)_{3} / \mathrm{Al}(\mathrm{OH})_{3} / \mathrm{Al}(\mathrm{OH})_{4}$ - ratios.

Unfortunately, there is no direct evidence as to the form of the aluminum in the 4B sample. However, Scheele and Peterson, based on a water extraction of the sludge samples, estimate that $\sim 10 \%$ of the chromium in the $4 \mathrm{~B}$ and $3 \mathrm{~T} 4 \mathrm{~S}$ samples is in the form of chromate. Lumetta and Swanson's sludge washing results on the 3T4S sample suggest that between $30 \%$ and $34 \%$ of the chromium is extractable as chromate. We have used Lumetta and Swanson's sludge washing results on the 3T4S sample to make what we believe to be a realistic estimate of the actual charge balance in the sludge. The spreadsheet presenting these results is entitled Realistic Negative Ion Case for SY-1024B in Appendix B (filename: ChargeBalance.complete).

Using Lumetta and Swanson's sludge-washing results we have incorporated both $\mathrm{Cr}$ (III) and chromate into the charge balance spreadsheet using a value of $33 \%$ $\mathrm{Cr}(\mathrm{III})$ and $67 \%$ chromate. The complete charge balance of the tank sludge was then 
obtained by assuming that $30 \%$ of the aluminum is present as $\mathrm{Al}(\mathrm{OH})_{3}$ and $70 \%$ as $\mathrm{Al}(\mathrm{OH})_{4^{-}}$. A cation/anion balance of \pm 110.7 results from these assumptions. Included in this charge balance are the additional hydroxide ions present in $\mathrm{Al}(\mathrm{OH})_{3}$ which are not accounted for in the hydroxide analysis by ion chromatography. In addition, we have included the oxide and hydroxide content that must be present in $\mathrm{MnO}(\mathrm{OH})_{2}$ and $\mathrm{FeOOH}$, the compounds assumed to most likely account for the manganese and iron content of the tank sludge, respectively.

As mentioned earlier, we were concerned that the technique used to carry out the anion analyses might be in error due to the inability of the water extraction method to extract insoluble salts. In order to estimate the effect of such an error, we carried out one additional charge balance in which we arbitrarily assumed that all the aluminum is in the form of $\mathrm{Al}(\mathrm{OH})_{3}$ and the chromium in the form of $\mathrm{Cr}(\mathrm{III})$ (see ChargeBalance.complete). This significantly reduced the anion content of the sludge and we added $8 \%$ additional sulfate in order to reestablish the charge balance. This represents a rough upper limit to the amount of missing anions that could be present in the sludge, although several assumptions affect this value. For example, if fluoride is the ion that is not extracted instead of sulfate, the missing fluoride would correspond to roughly $3.2 \%$ of the solid. Regardless of the exact assumptions made, it is obvious that the anion concentrations can be significantly higher than were determined experimentally without disrupting the charge balance calculation.

\section{Metal Oxide Balance}

An additional piece of information available for the $4 \mathrm{~B}$ sludge sample from the 1988 core, is the result of calcining the sludge at $1000^{\circ} \mathrm{C}$ for one hour. A weight $\%$ oxide of $38.4 \%$ was reported for a sludge sample previously dried at $105^{\circ} \mathrm{C}$ overnight. The difference in the weight of the sample before and after heating represents conversion of 
hydroxides to oxides, and decomposition of nitrates and nitrites to oxides. In addition, the reduction in weight after calcination may represent loss of any remaining hydrated water not removed from the lattice by drying overnight. We have used the sludge composition suggested by our charge balance calculation to estimate the loss of weight we should expect upon calcination. Two calculations were carried out; one in which fluoride and chloride salts remain intact but all oxyanion salts convert to oxides; and a second in which phosphate, sulfate, fluoride and chloride salts remain intact. In either case, a value of $40.6 \%$ by weight is predicted for the calcination process which is in reasonably good agreement with the experimental value of $38.4 \%$. The production of sodium peroxide in the calcination process, rather than sodium oxide, would reduce the calculated weight $\%$ by roughly $1 \%$. Other differences in the form of the oxide produced by the calcination process used could increase or decrease the calculated value. However, the magnitude of the effects resulting from other elements should be much smaller since sodium is by far the most abundant element present in the sludge.

These two calculated values bracket the experimental value; however, we should note that no provision has been made in these calculations to take into account the presence of hydrated water which might remain behind after the drying process at $105^{\circ} \mathrm{C}$. The presence of hydrated water in the sample prior to calcination will result in a larger decrease in the experimental weight \% obtained, which suggests that the $40.6 \%$ calculated value may be the best fit to the lower experimental value.

Using the chromium and aluminum species distribution proposed above from the charge balance calculations, i.e., $30 \% \mathrm{Al}(\mathrm{OH})_{3}$ and $33 \%$ chromate, results in a calculated total weight $\%$ of cations + anions of $74.4 \%$ (see ChargeBalance.complete). Scheele and Peterson report that the $4 \mathrm{~B}$ sample contains $32.7 \%$ water, i.e., $67.3 \%$ of the original sample was left after drying overnight at $105^{\circ} \mathrm{C}$. The calculated value is $\sim 7 \%$ 
too high, which suggests that our assumption that $30 \%$ of the aluminum is in the form of $\mathrm{Al}(\mathrm{OH})_{3}$ is not correct. The inability of Lumetta and Swanson to extract more than $15 \%$ of the aluminum content of the 3T4S sludge sample with $0.1 \mathrm{M} \mathrm{NaOH}$ suggests that a significant part of the aluminum in the sludge may be present as other compounds, such as aluminum phosphate. The less $\mathrm{Al}(\mathrm{OH})_{3}$ present in the sludge, the lower will be the calculated total weight $\%$, since the mass of the additional hydroxide ions from the $\mathrm{Al}(\mathrm{OH})_{3}$ will not need to be added into the total mass.

\section{Recommendations}

Flow sheets proposed for the remediation of waste tanks at the Hanford tank farm can only be evaluated effectively if analytical data for the sludge composition are available, since variation in tank composition can have negative impacts on any process proposed for the cleanup. Attempts at determining tank composition include direct analysis of the sludge currently in the tank via core sampling, as well as the evaluation of the process streams that were fed into, and removed from the tank since 1977 (DREAM project). Since the process stream record for SY-102 is extremely complex, it seems likely that the two sets of SY-102 core samples (1988 and 1990), together with Lumetta and Swanson's sludge washing experiments, constitute the best information available regarding the tank sludge composition.

As discussed in the body of this report, evaluation of the data from these two cores is indicative of significant limitations on our ability to utilize the data to design or evaluate flowsheets proposed to remediate the tank. These limitations include, but are not limited to:

1) the possible presence of severe matrix interferences in the various analyses.

2) uncertainty as to the location of the sampling points in the tank. 
3) incomplete recovery of the core sample.

4) uncertainty as to the homogeneity of the sludge sample.

5) uncertainty as to the effectiveness of the aqueous extraction procedure used for anion analyses.

6) the absence of analytical data for important elements that might affect proposed remediation schemes, such as thorium.

7) the absence of analytical data for radioactive isotopes that might affect proposed remediation schemes, such as Sr-90 and Tc-99.

8) uncertainty as to the isotope distribution for radioactive elements such as plutonium.

9) the lack of attention paid to the material balance of the sample.

10) the lack of attention paid to the radioactivity balance, i.e., total alpha, beta and gamma.

Ideally, a third core should be taken from tank SY-102 in order to eliminate the many uncertainties associated with the two previous cores obtained. In order to improve the utility of the core we have considered the following points.

1) The core should be preferentially taken from a point distant from the tank wall, the pump pits and other risers in the tank previously used to transfer slurry into and out of the tank, since the region close to these risers may exhibit atypical layering of the sludge. Risers labeled $4 \mathrm{~A}, 7 \mathrm{~B}$ and $17 \mathrm{C}$ in the southeast region of the tank may be suitable.

2) All analyses should be obtained both with and without control spikes in order to estimate the extent of matrix interferences of critical concern in such a complex mixture. 
3) The homogeneity of the core samples prepared should be evaluated prior to carrying out duplicate analyses in order to estimate if the observed range is associated with analytical error or inhomogeneity of the sample.

4) Analyses for anions should be carried out on the acid digested sample in order to ensure detection of anions present in the sludge as insoluble salts.

5) Analyses should be carried out for all species (including complexants and other organics) that might interfere with ion exchange, solvent extraction, or vitrification methods that might be proposed as part of a remediation flow sheet.

6) Analyses should be carried out for all radioactive isotopes that might determine the final classification of the remediated waste as class $A$ or $B$ radioactive waste.

7) Analyses for both the radioactive and cold isotopes should be carried out, e.g., total cesium as well as Cs-137, in order to be able to estimate when column overloading might take place.

8) The plutonium isotope distribution should be determined in order to address potential criticality concerns during the remediation process.

9) Care should be taken to obtain a good material balance for the sample to ensure that elements not analyzed do not makeup a significant fraction of the sludge.

10) Similarly, care should be taken to obtain a gond radioactivity balance for the sample to ensure that isotopes not analyzed do not makeup a significant fraction of the total alpha, beta and gamma counts of the sludge.

If a third core is not a practical option, due to cost or due to the long lag time between obtaining a core and the issuance of the analytical report, then priority should be given to reanalyzing the sludge available from the previous two cores, focusing on the issues raised above. Assuming that sufficient material is available from the 1988 and/or 1990 core, new samples should be obtained and analyzed using the guidelines 
indicated above. In particular, items 2, 4, 7, 9 and 10 applied to any future analyses of the older core material will help determine how much reliance can be placed on the analytical data available from the earlier reports for the 1988 (Scheele and Peterson; Herting; Lumetta and Swanson), and 1990 (Lumetta and Swanson; Gray) cores.

Finally, it would be extremely useful to carry out additional sludge washing experiments in order to resolve some of the questions raised by Lumetta and Swanson's earlier experiments. Of critical concern is whether or not the supernatant from a water or $0.1 \mathrm{M} \mathrm{NaOH}$ sludge washing procedure contains sufficient TRUs to render the supernatant a class $B$ or class $C$ waste. In addition, are there any species present in the supernatant that would interfere with the use of standard cesium and technate ion exchange methods that might be used to remove these radioactive isotopes from the supernatant.

In order to provide a firmer basis for evaluating the effectiveness of sludgewashing as a useful pretreatment step for tank remediation, additional sludge washing experiments should be carried out using a) water; b) $0.1 \mathrm{M} \mathrm{NaOH}$; and c) tank supernatant. These experiments should be carried out keeping in mind the same analytical concerns discussed above, e.g., the use of control spikes; analysis for both cold and hot isotopes; material balance and radioactivity balance. 


\section{References}

Agnew, S., DREAM Project, Los Alamos National Laboratory, Los Alamos, New Mexico.

Bensky, M. S., Internal Memo (1988 Core Sampling Description), October 26, 1988.

Bratzel, D. R., "Characterization of Supernatant from Tank 102-SY," Rockwell Internal Letter, \#65453-84-320, October 5, 1984.

Bratzel, D. R., "Characterization of Tk 102-SY Supernatant," Rockwell Internal Letter, \#65453-84-143, November 7, 1984.

Bratzel, D. R., "Characterization of Tk 102-SY Supernatant, R-3326," Rockwell Internal Letter, \#65453-84-374, December 31, 1984.

Bratzel, D. R., "Tank 102-SY Plutonium Settling Study," Rockwell Internal Letter, \#65453-85-006, January 10, 1985.

Bratzel, D. R., "Characterization of Tank 102-SY Waste," Rockwell Internal Letter, \#65453-85-064, March 29, 1985.

Gray, R., "Retrieval and Dissolution of TK 241-SY-102 Waste," Westinghouse Internal Memo, \#28110-PCL91-004, February 22, 1991.

Herting, D. L., "Characterization of Solids from Tank 241-SY-102," Westinghouse Internal Memo, \#16220-PCL90-082, July 6, 1990.

Kirkbride, R. A., "PFP Sludge and Supernate Composition," Westinghouse Internal Memo, \#7K321-92-RAK-02, December 10, 1992.

Jansky, M. T., "Composition of Tank 102SY Waste," Rockwell Internal Letter, \#65453-80-292, October 6, 1993.

Lumetta, G. J., "Simulated Dissolved PFP Sludge Solution," PNL Internal Memo, December 18, 1992.

Lumetta, G. J. and Swanson, J. L., "Pretreatment of Plutonium Finishing Plant (PFP) Sludge: Report for the Period October 1990 - March 1992," PNL Draft Report, March 1993, Richland, Washington.

Scheele, R. D. and Peterson, M. E., "Results of the Characterization of Samples of Waste from Double-Shell Tank 102-SY," PNL Report, January 1990, Richland, Washington.

Wanner, D. D., "Tank 102-SY Core Sample," Westinghouse Internal Memo, \#13316-88-098, November 18, 1988. 
Weiss, R. L., "November 1988 Core Sample from Tank 241-SY-102, Process Chemistry Laboratory Efforts," Westinghouse Internal Memo, \#16500-90-085, November 19, 1990.

Weiss, R. L., "November 1988 Core Sample from Tank 241-SY-102, Process Chemistry Laboratory Efforts," Westinghouse Internal Memo, \#12712-PCL89-050, March 7, 1990.

Weiss, R. L., "Mixing Study: 241-SX-104 Supernate/241-SY-102 Solids," Westinghouse Internal Memo, \#12712-PCL89-060, March 23, 1989.

Weiss, R. L., "Analysis of Liquid Sample from Tank 241-SY-102," Westinghouse Internal Memo, \#12712-PCL89-112, May 2, 1989.

Weiss, R. L., "Analysis of Liquid Sample from Tank 241-SY-102 Taken June 2, 1989," Westinghouse Internal Memo, \#12712-PCL89-149 Rev.1, August 29, 1989. 


\section{APPENDIX A}


TANK SY-102 COMPOSITION-Liquids and Solids Separate Filename: Comp.SL.final 


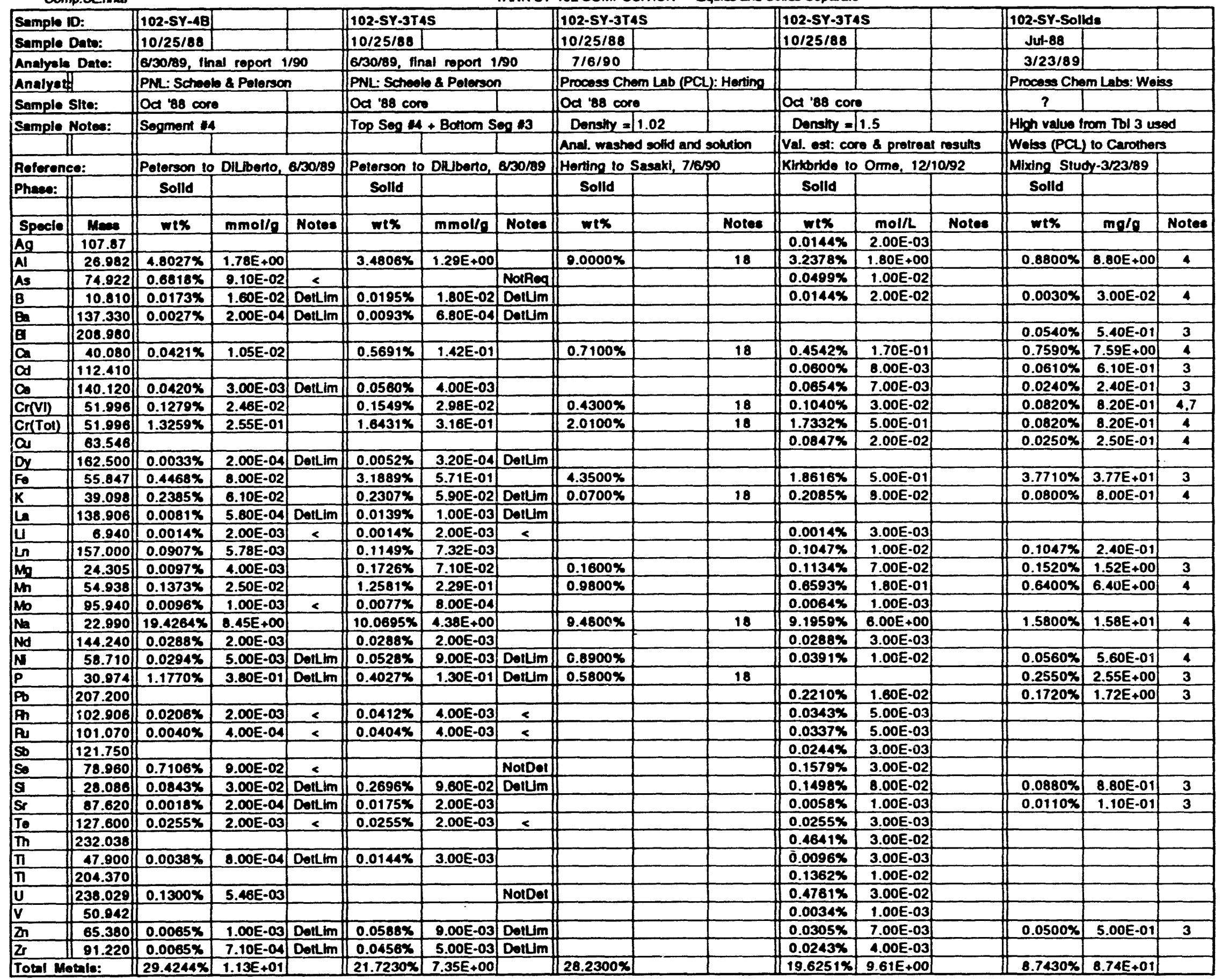


Comp.sefinal

TANK 5Y-102 COMPOSITION - Llquits and Solids Separate

\begin{tabular}{|c|c|c|c|c|c|c|c|c|c|c|c|c|c|c|c|c|}
\hline Somple & & $\mid 102-5 Y-48$ & & & 102-SY-3T & & & 102-SY-3T & & & |102-SY-3T & & & 102-SY-Soll & & \\
\hline Anione & & $w 1 x$ & $\mathrm{mmol} / \mathrm{g}$ & Notes & $w 1 x$ & $\mathrm{mmol} / \mathrm{g}$ & & $w 1 x$ & & & $w+x$ & $\mathrm{~mol} / \mathrm{L}$ & & $w t \%$ & $\mathrm{mg} / \mathrm{g}$ & \\
\hline $\mathbf{F}$ & 18.998 & $0.1653 \%$ & $8.70 E-02$ & & & & & $0.1100 \%$ & & & $0.3000 \%$ & $3.00 E-01$ & & $0.0080 \%$ & $8.00 E-02$ & 8 \\
\hline a & 35.453 & $0.7091 \%$ & $2.00 E-01$ & & & & & $0.1700 \%$ & & & $0.3545 \%$ & $1.50 E-01$ & & $0.7600 x$ & $7.60 E+00$ & 4 \\
\hline NOR & 46.006 & $4.5775 x$ & $9.95 E-01$ & & & & & & & & $2.4536 \%$ & $8.00 E-01$ & & & & \\
\hline No3 & 62.005 & $20.1516 \%$ & $3.25 E+\infty$ & & & & & $4.8300 \%$ & & & $12.4010 \%$ & $3.00 E+00$ & & & & \\
\hline POA & 94.971 & $4.5586 x$ & $4.80 E-01$ & & & & & $0.8800 \%$ & & & $3.7989 \%$ & $6.00 E-01$ & & $2.0000 x$ & $2.00 E+01$ & 4,5 \\
\hline SO4 & 96.058 & $0.7685 \%$ & $8.00 E-02$ & & & & & $1.8600 \%$ & & & $0.6404 \%$ & $1.00 E-01$ & & $2.0000 \%$ & $2.00 E+01$ & 4.5 \\
\hline$\infty$ & 60.009 & $0.0000 \%$ & $0.00 E+\infty 0$ & & & & & & & & $2.4004 \%$ & $6.00 E-01$ & & & & \\
\hline OH & 17.007 & $1.7007 \%$ & $1.00 E+00$ & & & & & $0.1500 \%$ & & pH calc & $1.7007 \%$ & $1.50 E+00$ & & & & \\
\hline Total A & Ions: & $32.6313 \%$ & $6.09 E+00$ & & $0.0000 x$ & & & $8.2000 \%$ & & & $24.1294 \times$ & $7.05 E+00$ & & $4.7680 \%$ & $4.77 E+01$ & \\
\hline & & & & & & & & & & & & & & & & \\
\hline Total Or & C: & $0.8700 x$ & & & & & & & & & & & & $0.7550 \%$ & $7.55 E+00$ & 3 \\
\hline & & & & & & & & & & & & & & & & \\
\hline Total C & mp: & $62.9257 \%$ & $1.74 E+01$ & & $21.7230 x$ & $7.35 E+00$ & & $36.4300 \%$ & & & $43.7545 \%$ & $1.67 E+01$ & & $14.2660 \%$ & $1.43 E+02$ & \\
\hline & & & & & & & & & & & & & & & & \\
\hline Trate & & $0 / 0$ & $u \mathrm{CI} / 0$ & & $0 / 2$ & $\mathrm{uCl} / \mathrm{g}$ & & $0 / 9$ & $\mathrm{uCl} / \mathrm{g}$ & & 210 & CUL & $a \Omega$ (21) & $9 / 0$ & uCV/g & \\
\hline Am-241 & 241.057 & $2.81 E-07$ & $9.73 E-01$ & & 2.83E-06 & $9.82 E+00$ & 5 & $2.48 E-05$ & $8.60 E+01$ & $?$ & $6.00 E-08$ & $3.12 E-02$ & $9.00 E-03$ & $1.31 \mathrm{E}-05$ & $4.53 E+01$ & \\
\hline Cm-243 & 243.000 & & & & & & & & & & & & & & & \\
\hline Cm-244 & 244.000 & & & & & & & & & & 6.67E-10 & $8.19 E-05$ & $1.00 E-06$ & & & \\
\hline Cm-24x & 243.560 & 6.84E-10 & 4.30E-02 & 2 & $3.02 E-10$ & $1.00 \mathrm{E}-02$ & 5 & & & & & & & & & \\
\hline Np-237 & 237.048 & $8.28 E-07$ & $5.90 E-04$ & & $1.14 E-08$ & $8.10 E-04$ & 5 & & & & $1.33 E-06$ & $1.43 E-06$ & $2.00 \mathrm{E}-03$ & & & \\
\hline Pu-230 & 238.050 & $2.14 E-09$ & $3.70 E-02$ & & $4.55 E-08$ & $7.88 E-01$ & 5 & & & & & & & & & \\
\hline Pu-230 & 239.052 & 2.07E-08 & $1.30 E-01$ & & $4.49 E-05$ & $2.82 E+00$ & 5 & & & & 6.67E-05 & $6.28 E-03$ & $1.00 E-01$ & $4.32 E-04$ & $2.71 E+01$ & 4.9 \\
\hline Pu-240 & 240.054 & $1.70 E-07$ & $3.00 E-02$ & & $5.18 E-06$ & $1.19 E+00$ & 5 & & & & $6.67 E-08$ & $2.30 E-03$ & $1.00 E-02$ & & & \\
\hline$P_{u-241}$ & 241.057 & $1.17 E-00$ & $1.22 E+00$ & & 3.44E-07 & $3.58 E+01$ & 5 & & & & & & & & & \\
\hline$P_{U}-242$ & 242.000 & & & & & & & & & & & & & & & \\
\hline$P_{u-244}$ & 244.000 & & & & & & & & & & & & & & & \\
\hline n-TALS & & $9 / 9$ & $\mathrm{uCl} / \mathrm{Q}$ & & $9 / 0$ & $\mathrm{uCl} / \mathrm{q}$ & & o/a & uCl/s & & $9 / 0$ & CI/L & & $9 / 9$ & $\mathrm{uCu}_{\mathrm{g}}$ & \\
\hline $\mathrm{H}-\mathbf{3}$ & 3.016 & $1.33 E-13$ & $1.30 \mathrm{E}-03$ & $\leq$ & 6.34E-14 & $6.20 E-04$ & $<$ & & & & & & & & & \\
\hline C.14 & 14.000 & $3.99 E-10$ & $1.80 \mathrm{E}-03$ & & & & NotPeg & & & & $4.44 E-10$ & $3.00 E-06$ & & & & \\
\hline $1-129$ & 129.000 & $1.34 E-06$ & 2.40E-04 & $<$ & $1.34 E-06$ & $2.40 E-04$ & & & & & $1.49 E-06$ & $4.00 E-07$ & & & & \\
\hline Nb-94 & 94.000 & $2.13 E-08$ & $4.10 E-03$ & $\leq$ & $1.20 \mathrm{E}-08$ & $2.30 \mathrm{E}-03$ & $\leq$ & & & & & & & & & \\
\hline $\mathrm{N} 1-63$ & 83.000 & $5.05 E-08$ & $2.90 E+00$ & $<$ & $9.58 E-08$ & $5.50 E+00$ & $\leq$ & & & & $6.97 \mathrm{E}-08$ & $6.00 E-03$ & & & & \\
\hline $50-79$ & 79.000 & $4.52 E-09$ & $3.18 E-04$ & & $2.56 E-09$ & $1.80 \mathrm{E}-04$ & $<$ & & & & & & & & & \\
\hline Sr-90 & 90.000 & $4.90 E-07$ & $6.76 E+01$ & & & & NotReg & $1.52 E-06$ & $2.10 E+02$ & & 4.83E-07 & $1.00 \mathrm{E}-01$ & & & & \\
\hline Tc-99 & 99.000 & $1.18 E=05$ & $2.02 E-01$ & & $1.28 E-05$ & $2.20 E-01$ & & & & & $1.17 E-05$ & $3.00 E-04$ & & $2.33 E-06$ & 4.00E-02 & 4 \\
\hline Co-144 & 144.000 & $3.42 E-10$ & $1.10 E+\infty 0$ & $<$ & & & NotReg & & & & $4.14 E-10$ & $2.00 E-03$ & & & & \\
\hline$C_{0}-60$ & 60.000 & $9.62 E-11$ & $1.10 E-01$ & & & & NotPeg & & & & $1.17 E-10$ & $2.00 E-04$ & & & & \\
\hline Cs-134 & 134.000 & $4.90 E-11$ & $6.40 \mathrm{E}-02$ & & & & NotReg & & & & $5.10 E-11$ & $1.00 E-04$ & & & & \\
\hline Cs-137 & 137.000 & $1.71 E-06$ & $1.50 E+02$ & & & & NotReg & $2.06 E-07$ & $1.80 E+01$ & & $1.52 E-06$ & $2.00 E-01$ & & $1.64 \mathrm{E}-07$ & $1.44 E+01$ & 3 \\
\hline$E u-152$ & 152.000 & $8.50 E-10$ & $1.50 E-01$ & & & & NotReg & & & & $7.56 \mathrm{E}-10$ & $2.00 E-04$ & & & & \\
\hline Eu-154 & 154.000 & $5.49 E-09$ & $1.50 E+00$ & 4 & & & Notieg & & & & $0.76 E-09$ & $4.00 E-03$ & 1 & & & \\
\hline Eu-155 & 155.000 & & & & & & & & & & & & & & & \\
\hline Ru-106 & 108.000 & $4.78 E-10$ & $1.60 E+00$ & $<$ & & & Notieg & & & & $3.99 E-10$ & $2.00 E-03$ & & & & \\
\hline$S b-125$ & 125.000 & $1.53 \mathrm{E}-09$ & $1.60 E+00$ & $<$ & & & NotReg & & & & $1.27 \mathrm{E}-09$ & $2.00 E-03$ & & & & \\
\hline Zr-95 & 91.220 & & & & & & & & & & & & & & & \\
\hline Tot TAU & & $3.36 \mathrm{E}-06$ & $2.44 E+\infty 0$ & & $5.45 E-05$ & $5.04 E+01$ & & $2.48 E-05$ & $8.60 E+01$ & & $0.07 E-05$ & $3.99 E-02$ & & $4.45 E-04$ & $7.24 E+01$ & \\
\hline Tot Nion & Rue & 1.54E-05 & $2.27 E+02$ & & $1.43 E-05$ & $5.72 E+00$ & & $1.73 E-06$ & $2.20 E+02$ & & $1.52 E-05$ & $3.17 E-01$ & & $2.50 E-06$ & $1.44 E+01$ & \\
\hline Tol Red & lonuellide & $1.88 E-05$ & $2.29 E+02$ & & $6.88 E-05$ & $5.62 E+01$ & & 2.65E-05 & $3.14 E+02$ & & 9.59E-0.5 & $3.57 \mathrm{E}-01$ & & $4.47 E-04$ & $8.68 E+01$ & \\
\hline
\end{tabular}


Comp.SLinal Sample IA-3316-Solld

Sample I Nov-84

Anatyele 3/29/85

Anelyas: Rockswel AL: Bntzel

Sample 86 trom botiom

Semple INoce: Contriluped solids

Date also reponted, 1/10/05

Aelerene Bratzol to Gale, 3/29/05

\begin{tabular}{l|l|l}
\hline Phween: & Solld \\
\hline
\end{tabular}

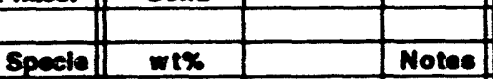

Ag

Al

A

B

B

E

a

a

$3.6300 \%$

Cr(Tof) $3.6300 \times$

a

Dy

\begin{tabular}{l|l}
\hline Fo & $2.0600 \%$ \\
\hline
\end{tabular}

\begin{tabular}{l|l}
\hline & $0.0830 x$ \\
\hline
\end{tabular}

는

\begin{tabular}{l|l|l}
\hline Ln & $0.0000 \times$ & $0.00 E+00$ \\
\hline
\end{tabular}

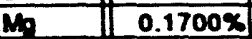

\begin{tabular}{l|l}
$\mathrm{in}$ & $0.7000 x$ \\
\hline
\end{tabular}

in

Ned

$\mathrm{P}$
$\mathrm{PB}$

Ph

PI

S

Sr

To

$\frac{\pi}{n}$

$\frac{v}{v}$

2

Total Mo 15.8917x
TANK SY-102 COMPOSITION - Lquits and Sollds Separate

\begin{tabular}{|c|c|c|c|c|c|c|c|c|}
\hline \multicolumn{2}{|c|}{ R-3316-Solld } & & \multicolumn{2}{|c|}{ R-3316-Solld } & & \multicolumn{2}{|c|}{ A-3036-Solld } & \\
\hline Nov-84 & & & Nov-84 & & & $?$ & & \\
\hline $3 / 20 / 85$ & & & $1 / 10 / 85$ & & & $10 / 5 / 84$ & & \\
\hline \multicolumn{2}{|c|}{ Rockmell AL: Bntzel } & & \multicolumn{2}{|c|}{ Rockmoll AL: Bratzel } & & \multicolumn{2}{|c|}{ Rorkmel AL: Brated } & \\
\hline \multicolumn{2}{|c|}{$\sigma$ trom bottom } & & \multicolumn{3}{|c|}{6 trom bonom, Centill. solits } & bonom (?) & & \\
\hline \multicolumn{3}{|c|}{ Nove: Contultured solids } & Densithy & 1.54 & & Donaly = & 2.65 & \\
\hline & & & \multicolumn{3}{|c|}{ Denta aboo reponed, 3rapes } & \multicolumn{3}{|c|}{ Donoly 100 hiom 1.65 used } \\
\hline \multicolumn{3}{|c|}{ Bratzel to Gab, 329/55 } & \multicolumn{3}{|c|}{ Bretrel to Gab, 1/10/5 } & \multicolumn{3}{|c|}{ Bratzel to Tubarg, 105/84 } \\
\hline Solld & & & Solld & & & Solld & & \\
\hline 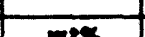 & & Mnen & $-m$ & III & Moto- & $=8$ & & Mote \\
\hline & & & & 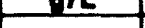 & & & & now \\
\hline $7.7500 x$ & & & $5.2013 x$ & $0.01 E+01$ & 16 & $16.0000 \%$ & & \\
\hline & & & & & & & & \\
\hline & & & & & & & & \\
\hline & & & & & & & & \\
\hline & & & & & & & & \\
\hline & & & & & & $0.4500 \%$ & & \\
\hline $0.0164 x$ & & & $0.0183 x$ & 2.82E-01 & & $0.2200 \times$ & & \\
\hline & & & & & & & & \\
\hline $4.1900 x$ & & 7 & $2.0584 \%$ & $3.17 E+01$ & 7 & $9.1700 \%$ & & Crain \\
\hline $4.1900 x$ & & & $2.0584 x$ & $3.17 E+01$ & & $9.1700 \%$ & & \\
\hline $0.0053 x$ & & & $0.0035 x$ & $5.46 E-02$ & & & & \\
\hline & & & & & & & & \\
\hline $1.2700 \%$ & & & $1.1682 x$ & $1.80 E+01$ & & $5.1000 x$ & & \\
\hline $0.0466 \%$ & & & $0.0470 \%$ & $7.24 E-01$ & & & & \\
\hline & & & & & & & & \\
\hline & & & & & & & & \\
\hline $0.0000 x$ & $0.00 E+00$ & & $0.0000 x$ & $0.00 E+00$ & & $0.0000 \%$ & & \\
\hline $0.0804 \times$ & & & $0.0987 x$ & $1.52 E+00$ & $\leq$ & $0.2500 x$ & & \\
\hline $0.4400 \%$ & & & $0.3935 x$ & $6.06 E+\infty 0$ & & $1.9800 \%$ & & \\
\hline & & & & & & & & \\
\hline & & & & & & & & \\
\hline & & & & & & & & \\
\hline & & & & & & $0.0700 x$ & & \\
\hline & & & & & & $0.4800 \%$ & & \\
\hline & & & & & & & & \\
\hline & & & & & & & & \\
\hline & & & & & & & & \\
\hline & & & & & & & & \\
\hline & & & & & & & & \\
\hline & & & & & & & & \\
\hline & & & & & & & & \\
\hline & & & & & & & & \\
\hline & & & & & & & & \\
\hline & & & & & & & & \\
\hline & & & & & & & & \\
\hline & & & & & & & & \\
\hline & & & & & & & & \\
\hline & & & & & & & & \\
\hline & & & & & & & & \\
\hline 13.80778 & & & $8.9896 \%$ & $1.30 E+02$ & & $33.7200 x$ & & \\
\hline
\end{tabular}


Comp.sumel

TANK SY-102 COMPOSITION - Uquids and Sollits Seperente

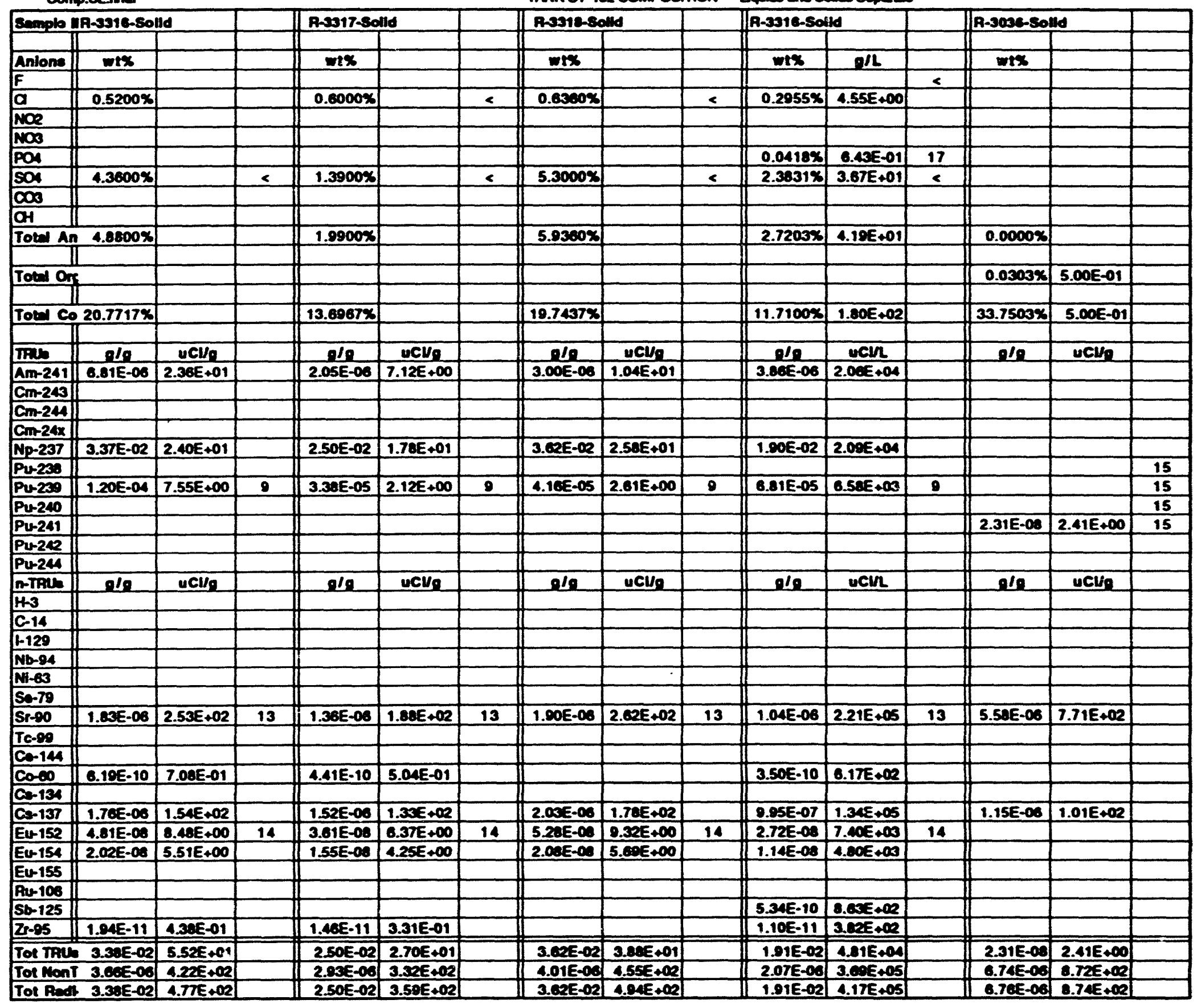




\begin{tabular}{|c|c|c|c|c|c|c|c|c|c|c|c|c|c|c|c|c|}
\hline \multirow{2}{*}{\multicolumn{2}{|c|}{$\begin{array}{l}\text { Semple 1D: } \\
\text { Semple Den: }\end{array}$}} & \multirow{2}{*}{\multicolumn{2}{|c|}{ 102-SY-3TAL }} & & \multicolumn{2}{|l|}{$102-5 Y-1-2$} & & A5027 & & & A5020 & & & \multicolumn{3}{|l|}{ A5022 } \\
\hline & & $10 / 25 / 88$ & & & $10 / 25 / 88$ & & & $6 / 2 / 89$ & & & $6 / 2189$ & & & 0/2109 & & \\
\hline Ancirele & Dete: & \multicolumn{3}{|c|}{ arsopes, thel repon $1 / 20$} & \multicolumn{3}{|c|}{ 6/30/29, hinal repon $1 / 90$} & $8 / 29 / 80$ & & & $8 / 29 / 89$ & & & $8 / 29 / 89$ & & \\
\hline Analyset: & & \multicolumn{3}{|c|}{ 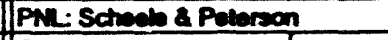 } & \multicolumn{3}{|c|}{ 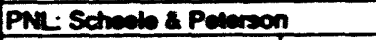 } & \multicolumn{3}{|c|}{ Procaes Chem Lab (PCL): Weles } & \multicolumn{3}{|c|}{ Proceas Chem Lob (PCL): Welas } & \multicolumn{3}{|c|}{ Process Chem Lo (PCL) Woies } \\
\hline Somple: & She: & $0 a^{20} \mathrm{cos}$ & & & Oa 28 cone & & & \multicolumn{3}{|c|}{ 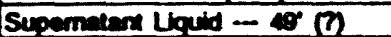 } & \multicolumn{3}{|c|}{ Supementer Lquid - 40 (1) } & \multicolumn{3}{|c|}{ 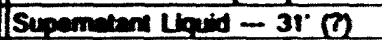 } \\
\hline Semple : & Notes: & \multicolumn{3}{|c|}{ Toe $\operatorname{Ser} 4+$ Bollom $\operatorname{seg} 13$} & Sermen is & 82 Compo & aine & & & & & & & & & \\
\hline & & & & & & & & Sp.Gr. = & 1.025 & & Sp.Gr. & 1.016 & & Se.G. $=$ & 1.012 & \\
\hline Rolerene & & Potereon to & Dabento, & 63009 & Pcereon 10 & Dilbanto, & ero/00 & Wales $10 \mathrm{~S}$ & vereasio, 8 & seseg & Wdias lo S & yemeain, 8 & 909 & Wales 10 Se & anows. 8 & 2909 \\
\hline Pheoe: & & \begin{tabular}{|l|} 
Lquild \\
\end{tabular} & & & Llquild & & & Lould & & & Llould & & & Llould & & \\
\hline Specte & $\ln 20$ & $w 1 \%$ & mmol/s & Notes & $w t x$ & mmol/s & Notes & $w t \%$ & $m$ & Motee & $w+x$ & $\mathbf{M}$ & Notes & $\omega t x$ & $\mathbf{m}$ & Notes \\
\hline $\mathrm{Ag}$ & 107.07 & & & & & & & & & & & & & & & \\
\hline $\mathbf{A}$ & 26.082 & $0.2590 x$ & $9.00 E-02$ & & $0.1184 \%$ & $4.30 E-02$ & & $0.1100 x$ & $4.20 E-02$ & & 0.10898 & $4.10 E-02$ & & $0.1066 x$ & $4.00 E-02$ & \\
\hline As & 74.922 & & & Notinea & & & Notinges & & & & & & & & & \\
\hline $\mathbf{B}$ & 10.810 & $0.0032 \pi$ & $3.00 E-03$ & Detim & $0.0011 \%$ & $1.00 E-03$ & Dolim & & & & & & & & & \\
\hline Ba & 137.330 & $0.0011 \%$ & $8.00 E-05$ & $<$ & $0.0000 \%$ & $3.00 E-07$ & Detum & & & & & & & & & \\
\hline E & 208.980 & & & & & & & & & & & & & & & \\
\hline a & 40.080 & 0.00308 & $9.70 E-04$ & & 0.00037 & $7.00 E-05$ & & $0.0002 x$ & $6.00 E-05$ & & 0.00035 & $0.00 E-05$ & & $0.0002 x$ & $5.00 E-05$ & \\
\hline $\boldsymbol{\alpha}$ & 112.410 & & & & & & & & & & & & & & & \\
\hline$\infty$ & 140.120 & $0.0280 x$ & $2.00 E-03$ & $\leq$ & $0.0006 x$ & $4.00 E-05$ & $\leq$ & & & & & & & & & \\
\hline Crr(V) & 51.996 & $0.0040 x$ & $7.70 E-04$ & & $0.0012 \%$ & $2.37 E-04$ & & & & & & & & & & \\
\hline Cr(Tol) & 51.998 & $0.0312 x$ & $0.00 E-03$ & & $0.0009 x$ & $1.00 E-04$ & & $0.0010 x$ & 1.90E-04 & & $0.0010 x$ & $1.90 E-06$ & & $0.0010 x$ & $1.00 E-04$ & \\
\hline$a$ & 03.546 & & & & & & & & & & & & & & & \\
\hline Dy & 162.500 & $0.0013 \%$ & $8.00 E-05$ & $<$ & $0.0000 x$ & $1.00 E-08$ & $\leq$ & & & & & & & & & \\
\hline$F_{0}$ & \begin{tabular}{|l|}
55.847 \\
\end{tabular} & $0.0003 x$ & 0.00E-0S & Defim & $0.0002 x$ & 4.00E-05 & & & & & & & & & & \\
\hline $\mathbf{K}$ & 39.098 & $0.1212 x$ & $3.10 E-02$ & & $0.2346 x$ & $6.00 E-02$ & & $0.3395 x$ & $8.00 E-02$ & & $0.3340 x$ & $8.70 E-02$ & & $0.3323 x$ & $0.60 \mathrm{E}-02$ & \\
\hline La & 138.908 & $0.0028 x$ & $2.00 E-04$ & $\leq$ & $0.0000 x$ & $2.00 E-06$ & 5 & & & & & & & & & \\
\hline U & 6.940 & $0.0021 x$ & $3.00 E-03$ & $\leq$ & $0.0000 x$ & $1.00 E-06$ & Domin & & & & & & & & & \\
\hline In & 157.000 & $0.0452 x$ & 2.08E-03 & & $0.0008 x$ & $5.20 E-05$ & & & & & & & & & & \\
\hline$M_{2}$ & 24.305 & $0.0007 \%$ & $3.00 E-04$ & $<$ & $0.0000 x$ & $5.00 E-06$ & Detura & & & & & & & & & \\
\hline$m_{m}$ & 54.938 & $0.0016 \%$ & $3.00 E-04$ & $<$ & 0.00008 & $5.00 E-07$ & Doum & & & & & & & & & \\
\hline$M_{0}$ & 95.940 & $0.0019 x$ & $2.00 E-04$ & Dedin & $0.0001 x$ & $1.00 E-05$ & Dochen & & & & & & & & & \\
\hline$m$ & 22.990 & $8.2763 x$ & $3.00 E+\infty 0$ & & $2.0162 x$ & $0.77 \mathrm{E}-01$ & & $2.0180 x$ & $9.00 E-01$ & & $2.0130 x$ & $8.90 E-01$ & & $1.9310 x$ & D.SOE-01 & \\
\hline $\mathbf{N e d}$ & 144.240 & $0.0007 x$ & $8.00 E-04$ & $<$ & $0.0001 x$ & $0.00 E-00$ & $\leq$ & & & & & & & & & \\
\hline $\boldsymbol{M}$ & 58.710 & $0.0041 x$ & $7.00 E-04$ & Detim & $0.0000 x$ & $5.00 \mathrm{E}-06$ & Donen & & & & & & & & & \\
\hline $\mathbf{P}$ & 30.974 & & & NotDal & $0.0093 x$ & $3.00 E-03$ & & $0.0004 x$ & $3.10 E-\infty 3$ & & $0.0005 x$ & $3.10 E-03$ & & $0.0000 x$ & $2.00 E-03$ & \\
\hline $\mathbf{P B}$ & 207.200 & & & & & & & & & & & & & & & \\
\hline F & 102.906 & $0.0309 x$ & $3.00 E-03$ & $\leq$ & $0.0031 x$ & $3.00 E-04$ & $\leq$ & & & & & & & & & \\
\hline $\mathbf{P y}$ & 101.070 & $0.0505 x$ & $5.00 E-03$ & $\leq$ & $0.0020 x$ & $2.00 E-04$ & $\leq$ & & & & & & & & & \\
\hline 50 & 121.750 & & & & & & & & & & & & & & & \\
\hline So & 78.000 & & & Notons & & & NolDed & & & & & & & & & \\
\hline $\mathbf{s}$ & 28.088 & $0.0022 x$ & $8.00 E-04$ & Dectin & $0.0129 x$ & $4.60 E-03$ & Deven & & & & & & & & & \\
\hline Sr & 87.620 & $0.0018 \%$ & $2.005-04$ & $<$ & $0.0000 x$ & 6.00E-07 & Doning & & & & & & & & & \\
\hline$T e$ & 127.600 & $0.0255 x$ & $2.00 E-03$ & $\leq$ & $0.0003 x$ & $2.00 E-05$ & $<$ & & & & & & & & & \\
\hline $\mathbf{T h}$ & 232.038 & & & & & & & & & & & & & & & \\
\hline$\pi$ & 47.900 & 0.00148 & $3.00 E-04$ & $\leq$ & $0.0000 x$ & $2.00 E-06$ & Doving & & & & & & & & & \\
\hline$\pi$ & 204.370 & & & & & & & & & & & & & & & \\
\hline U & 238.020 & & & NotDel & & & NotDen & & & & & & & & & \\
\hline $\mathbf{v}$ & 50.942 & & & & & & & & & & & & & & & \\
\hline$\underline{\mathbf{n}}$ & 85.380 & $0.0131 x$ & $2.00 E-00$ & $\leq$ & $0.0002 x$ & $3.00 E-05$ & & & & & & & & & & \\
\hline $\mathbf{Z}$ & 01.220 & 0.00648 & $7.00 E-04$ & $<$ & 0.00008 & $1.00 E-08$ & Dopin & & & & & & & & & \\
\hline Tord & :alo: & $8.0794 x$ & $3.70: E+00$ & & 2.40048 & D.SOE-01 & & 2.47022 & $1.03 E+\infty 0$ & & $2.4093 x$ & $1.02 E+00$ & & $2.3790 \mathrm{~s}$ & $0.79 E-01$ & \\
\hline & & & & & & & & & & & & & & & & \\
\hline
\end{tabular}


Compsetind

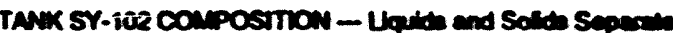

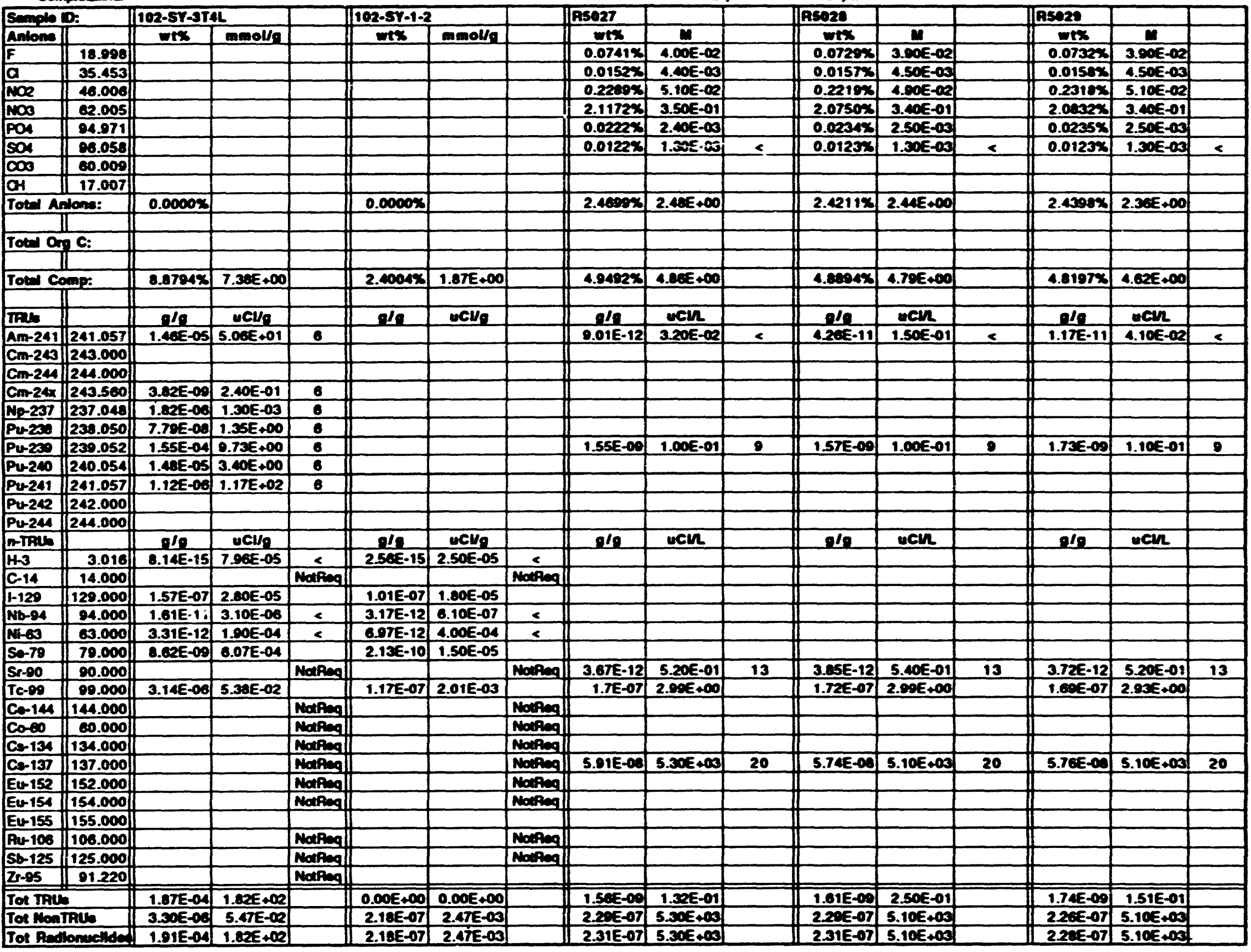




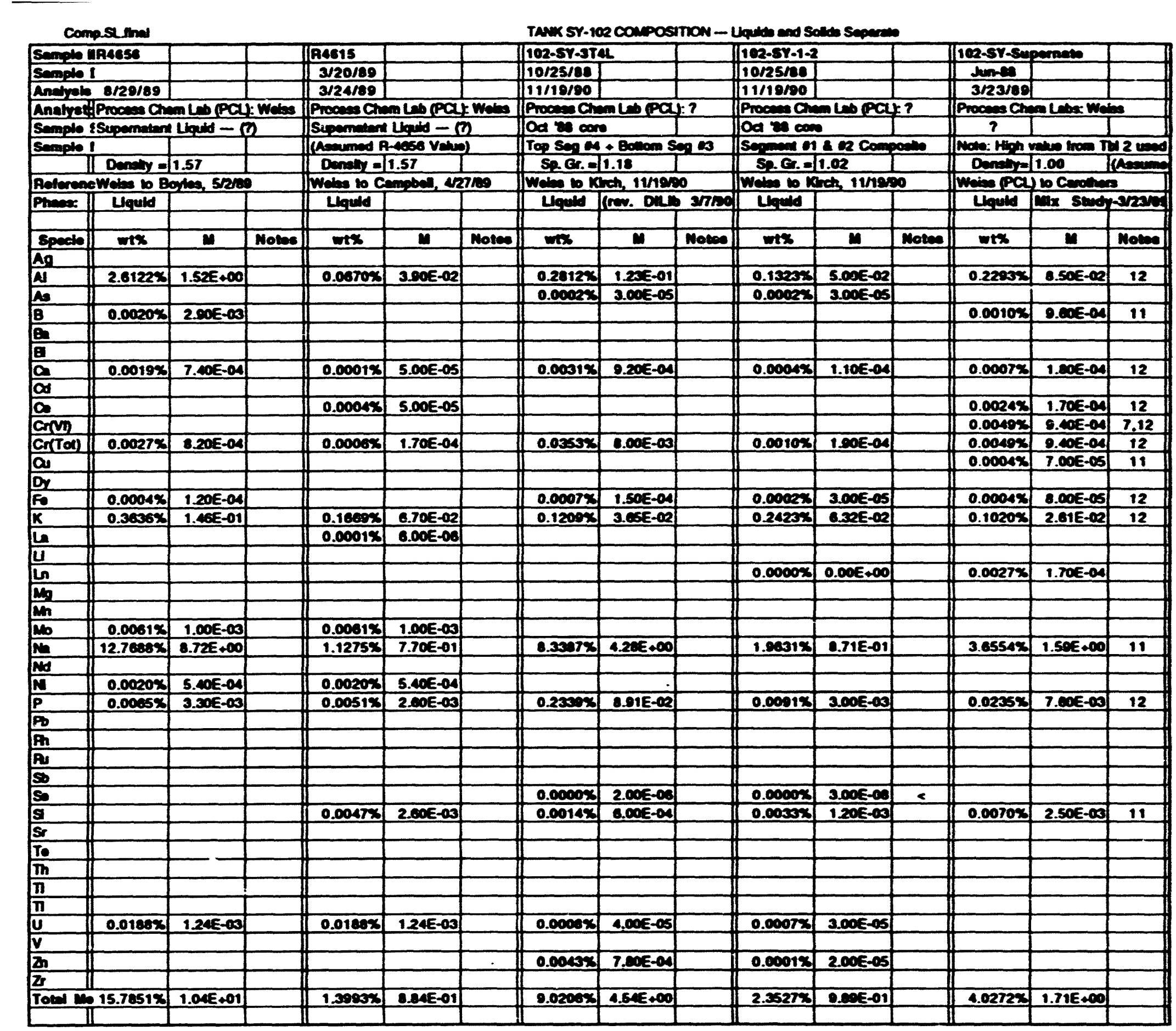


Compserinel

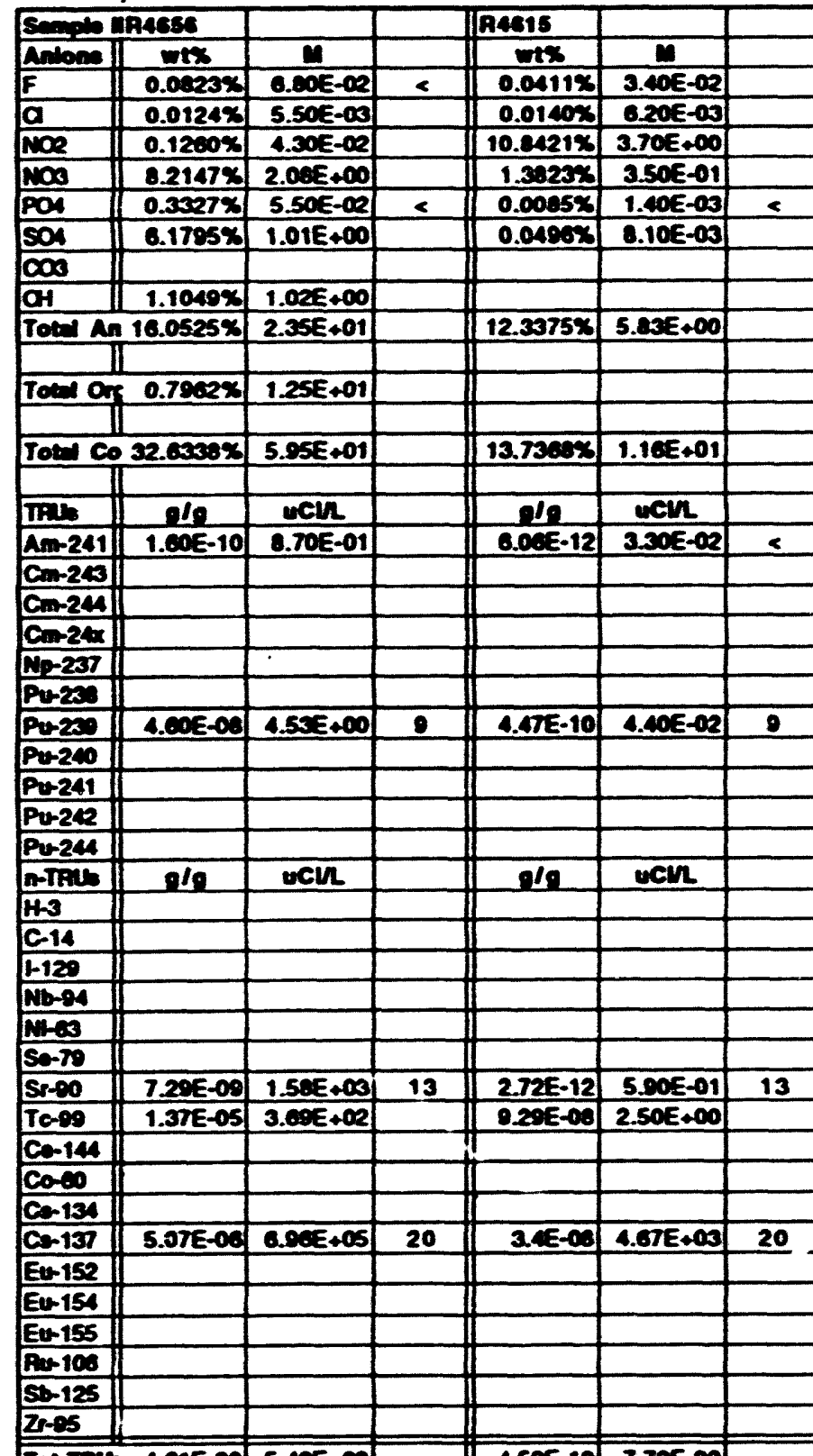

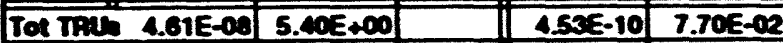

Tot Hont tere-05 a exe 00 .

\begin{tabular}{|l|l|}
\hline Tot Rad 1.00E-05 $6.00 E+05$ \\
\hline
\end{tabular}

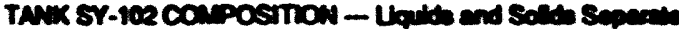

\begin{tabular}{|c|c|c|c|c|c|c|c|c|}
\hline \multicolumn{2}{|c|}{ 10R-st-3Tah } & & \multicolumn{2}{|l|}{$192-57-1-2$} & & \multicolumn{2}{|c|}{ 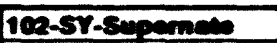 } & \\
\hline wer & $\boldsymbol{m}$ & & wetx & $\boldsymbol{m}$ & & $w x$ & $n$ & \\
\hline $0.0435 x$ & $2.70 E-02$ & $\leq$ & 0.05057 & $2.70 E-\infty 2$ & $\leq$ & 0.02058 & $1.50 E-\infty 2$ & 12 \\
\hline $0.1502 x$ & $5.00 E-\infty 2$ & & $0.15 \operatorname{sen} x$ & ASCE-CR & & $0.0200 \%$ & $7.00=-\infty$ & 12 \\
\hline $2.0000 x$ & $5.14 E-01$ & & $0.1070 x$ & $1306-02$ & & & & \\
\hline $8.0320 x$ & $1.70 E+\infty 0$ & & $2.2970 x$ & $3.70 E-01$ & & 3.49718 & S.CAE-O1 & 12 \\
\hline $0.6407 x$ & $7.00 E-02$ & & $0.0745 x$ & $8.005-00$ & $\leq$ & 0.14258 & $1.50 E-02$ & 12.4 \\
\hline $0.5530 x$ & 6.00E-02 & & 0.07553 & $000-0$ & $\leq$ & 0.14418 & $1.50=-63$ & 10,5 \\
\hline $2.1800 x$ & $4.306-01$ & & $0.3700 x$ & 6.3AE-02 & & $0.2700 x$ & $4.01 E-\infty 2$ & 10 \\
\hline $1.0054 x$ & $7.00 E-01$ & & $0.0080 \%$ & $4.01 E-01$ & & $0.9015 \%$ & $5.2 x=-01$ & 11 \\
\hline $15.0000 x$ & $1.20 E+01$ & & $3.0012 x$ & $2.00 E+\infty 00$ & & $5.1077 x$ & $4.50 E+00$ & \\
\hline 0.1804 & $2205 \times 00$ & & $0.0200 x$ & $2.12=-01$ & & $0.04 \times 2 \times 3$ & $4.02 \leq-01$ & 12 \\
\hline & & & & & & & & \\
\hline $24.8140 x$ & $2.72 E+01$ & & $0.2047 x$ & S.SEE+00 & & $0.1011 \%$ & $0.00=00$ & \\
\hline & & & & & & & & \\
\hline $9 / 0$ & men & & $9 / 2$ & $\operatorname{con}$ & & g/g & ECL & \\
\hline & & & & & & $3.005-10$ & 1206000 & 12 \\
\hline & & & & & & & & \\
\hline & & & & & & & & \\
\hline & & & & & & & & \\
\hline & & & & & & & & \\
\hline $2.18 \leq-0$ & $1.00 E-01$ & 922 & $2.50=-00$ & $1.00 \leq-01$ & 0.22 & $1.505-00$ & $1.005+60$ & 9.12 \\
\hline & & & & & & & & \\
\hline & & & & & & & & \\
\hline & & & & & & & & \\
\hline & & & & & & & & \\
\hline 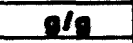 & man & & en & men & & $e^{1 / n}$ & $\operatorname{con}$ & \\
\hline & & & & & & & & \\
\hline $4.325-12$ & $2.30 E-02$ & & $5.00 E-12$ & $2.30 E-02$ & & & & \\
\hline & & & & & & & & \\
\hline & & & & & & & & \\
\hline & & & & & & & & \\
\hline & & & & & & & & \\
\hline $1.07 E-11$ & $1.75 E+00$ & 13,2 & $124 E-11$ & $1.75 E+00$ & 13,22 & & & \\
\hline & & & & & & 5.e3E-07) & $1.00 E+01$ & 12 \\
\hline & & & & & & & & \\
\hline & & & & & & & & \\
\hline & & & & & & & & \\
\hline $3.79 E-\infty$ & $300=+00$ & 22 & A.3TE- 00 & $300 E+03$ & 22 & 1.1TE-07 & $1.02 E+04$ & 12 \\
\hline & & & & & & & & \\
\hline & & & & & & & & \\
\hline & & & & & & & & \\
\hline & & & & & & & & \\
\hline & & & & & & & & \\
\hline & & & & & & & & \\
\hline $2.10 E-00$ & $1.00=-01$ & 22 & $2.50 E-\infty$ & $1.00 E-01$ & 22 & $1.05=-00$ & $2.20 \leqslant+\infty 0$ & \\
\hline $3.70 E-\infty$ & $3005+\infty$ & 22 & $437 E-\infty$ & $3005+03$ & 22 & $7.00=-07$ & $1.02 \leq+04$ & \\
\hline $4.00=-00$ & $3005+00$ & 22 & 4ere-00 & 3ces+es & 22 & $7.14 \leq-07$ & $1.02=04$ & \\
\hline
\end{tabular}




\begin{tabular}{|c|c|c|c|c|c|c|c|c|c|c|c|c|c|c|c|c|c|c|}
\hline \multicolumn{3}{|c|}{ Semple UA-331C-Supernato } & & \multicolumn{2}{|c|}{ A-3017-Suparnets } & & \multicolumn{2}{|c|}{ | A } & & \multicolumn{2}{|c|}{ A-3037-Seporneste } & & \multicolumn{2}{|c|}{ IA-3032-supernate } & & \multicolumn{2}{|c|}{ A-3326-Sepomente } & \\
\hline Semple & Nov-84 & & & Now-84 & & & Mov-84 & & & Nov-84 & & & Nov-84 & & & $?$ & & \\
\hline Andyels & $3 / 29 / 85$ & & & $3 / 29 / 05$ & & & \multirow{2}{*}{\multicolumn{2}{|c|}{ Bockno AL: Brizal }} & & $10 / 5 / 84$ & & & $10 / 5 / 84$ & & & $12 / 31 / 84$ & & \\
\hline \multicolumn{3}{|c|}{ 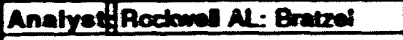 } & & \multicolumn{2}{|c|}{ Rockonal AL: Bread } & & & & & \multicolumn{2}{|c|}{ Aockoneli AL: Brated } & & \multicolumn{2}{|c|}{ Poodomell AL: Bretel } & & \multicolumn{2}{|c|}{ Pockenell AL: Breted } & \\
\hline \multicolumn{3}{|c|}{ Semple if from bottom } & & \multicolumn{2}{|c|}{ To trom bollom } & & $\sigma \operatorname{trom} \infty$ & Dnom & & 100 & & & andese & & & & & \\
\hline Sepple & Danstis $=$ & 1.41 & & Denaly $=$ & 1.44 & & Densiye & 1.42 & & SeGe & 1.03 & & Se.Gi= & 1.08 & & Se.cr. & 1.06 & \\
\hline & 9 & & & & & & & & & & & & & & & loemoned A & A-3003 Vane & \\
\hline Rolerence & Brated to C & Gelo, 328/05 & & Bretzel $10 \mathrm{C}$ & Geb, 3290: & & Erened to & Gede, 3/293 & & Breal to & Tulown tos & 504 & Bined to 1 & Troen, 10 & $5 / 24$ & Boneal to & Tubers. 128: & $31 / \mathrm{en}$ \\
\hline Phee: & Lould & & & Llouid & & & Urquid & & & Leuld & & & Uould & & & Llepeld & & \\
\hline & & & & & & & -8 & & & & & & 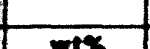 & & & $=0$ & & \\
\hline Specio & $w+x$ & $\mathbf{u}$ & Notee & $w+x$ & $\mathbf{u}$ & Notes & $\mathbf{m t x}$ & $\mathbf{m}$ & Noles & $w+x$ & 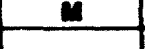 & Notes & $w$ & $m$ & Notes & $w t x$ & 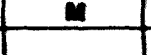 & Notee \\
\hline$\frac{A q}{N}$ & 0.46698 & 2.44E-01 & & $0.6727 x$ & $3.50 E-01$ & & $0.7125 x$ & $3.75 E-01$ & & $0.1300 x$ & $5.10 E-02$ & & $0.1604 x$ & $5.30 E-02$ & & $0.1055 x$ & $6.50 E-02$ & \\
\hline As & & & & & & & & & & & & & & & & & & \\
\hline B & & & & & & & & & & & & & & & & & & \\
\hline Ba & & & & & & & & & & & & & & & & & & \\
\hline B & & & & & & & & & & & & & & & & & & \\
\hline a & & & & & & & & & & 0.00018 & $2.25 E-05$ & & & & & & & \\
\hline 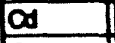 & $0.0042 x$ & $5.26 E-04$ & & $0.0024 x$ & 3.13E-0.4 & & $0.0018 x$ & $220 E-04$ & & $0.0006 \pi$ & 5.87E-05 & & $0.0000 x$ & $7.30 E-05$ & & $0.0010 x$ & $9.24 E-05$ & \\
\hline$\infty$ & & & & & & & & & & & & & & & & & & \\
\hline crivn & $0.0810 x$ & $2.22 E-02$ & 7 & $0.0812 \pi$ & $2.25 \mathrm{E}-02$ & 7 & $0.0042 x$ & $2.30 E-02$ & 7 & 0.00348 & $6.73 E-04$ & Crotin & $0.0041 x$ & - $.46 E-04$ & $\cos (1)$ & & & \\
\hline Cr(Ta) & $0.0810 x$ & $2.22 E-02$ & & $0.0812 x$ & $2.25 E-02$ & & $0.0842 x$ & $2.30 E-02$ & & 0.00348 & $6.73 E-04$ & & $0.0041 x$ & $8.46 E-04$ & & $0.0040 x$ & $9.79 E-04$ & \\
\hline $\mathbf{a}$ & $0.0003 x$ & $5.73 E-05$ & $<$ & $0.0002 \pi$ & $5.15 E-05$ & & $0.0002 \%$ & 3.62E-05 & & & & & & & & & & \\
\hline Dy & & & & & & & & & & & & & & & & & & \\
\hline $\mathbf{F}_{\mathbf{0}}$ & $0.0003 x$ & 6.52E-05 & $<$ & $0.0004 x$ & $1.07 E-04$ & & $0.0004 x$ & $1.12 E-04$ & & $0.0002 x$ & 3.04E-05 & & $0.0003 x$ & $5.01 E-05$ & & $0.0000 x$ & $1.08 E-04$ & \\
\hline $\mathbf{K}$ & $0.1101 x$ & $3.97 E-02$ & & 0.14127 & $5.20 E-02$ & & $0.1305 x$ & $5.03 E-02$ & & $0.0073 x$ & $1.02 E-03$ & & $0.0005 x$ & $2.30 E-03$ & & & & \\
\hline 느 & & & & & & & & & & & & & & & & & & \\
\hline$\underline{u}$ & & & & & & & & & & & & & & & & & & \\
\hline Ln & $0.0000 x$ & $0.00 E+00$ & & $0.0000 x$ & $0.00 E+00$ & & $0.0000 x$ & $0.00 E+00$ & & $0.0000 \%$ & $0.00 E+00$ & & 0.00008 & $0.00 E+00$ & & & & \\
\hline$M_{2}$ & $0.0003 x$ & $1.50 E-04$ & $\leq$ & $0.0002 x$ & $1.23 E-04$ & $\leq$ & $0.0002 x$ & $0.49 E-05$ & $\leq$ & $0.0000 x$ & $4.11 E-00$ & $\leq$ & $0.0000 x$ & $4.52 E-06$ & & & & \\
\hline$m$ & $0.0003 x$ & 6.62E-05 & $\leq$ & $0.0002 x$ & $0.45 E-05$ & & $0.0002 x$ & $5.72 E-05$ & & $0.0000 \%$ & $1.02 E-00$ & $\leq$ & $0.0000 \%$ & $1.82 E-06$ & $<$ & $0.0001 \%$ & 1.84E-05 & $\leq$ \\
\hline$M_{0}$ & & & & & & & & & & & & & & & & & & \\
\hline $\mathbf{m}$ & & & & & & & & & & & & & & & & & & \\
\hline Ned & & & & & & & & & & & & & & & & & & \\
\hline N & & & & & & & & & & $0.0000 x$ & $5.11 E-08$ & $\leq$ & $0.0000 x$ & 5.11E-06 & $\leq$ & $0.3700 x$ & $6.60 E-02$ & \\
\hline $\mathbf{P}$ & & & & & & & & & & $0.0116 \%$ & $3.67 E-03$ & & $0.0141 x$ & $4.84 E-03$ & & & & \\
\hline $\boldsymbol{P}_{\mathbf{D}}$ & & & & & & & & & & & & & & & & & & \\
\hline $\mathbf{f n}$ & & & & & & & & & & & & & & & & & & \\
\hline $\mathbf{A I}_{\mathbf{I}}$ & & & & & & & & & & & & & & & & & & \\
\hline 5 & & & & & & & & & & & & & & & & & & \\
\hline 50 & & & & & & & & & & & & & & & & & & \\
\hline $\mathbf{s}$ & & & & & & & & & & & & & & & & & & \\
\hline Sr & & & & & & & & & & & & & & & & & & \\
\hline To & & & & & & & & & & & & & & & & & & \\
\hline $\mathrm{m}$ & & & & & & & & & & & & & & & & & & \\
\hline$n$ & & & & & & & & & & & & & & & & & & \\
\hline$\pi$ & & & & & & & & & & & & & & & & & & \\
\hline $\mathbf{U}$ & & & & & & & & & & & & & & & & & & \\
\hline $\mathbf{v}$ & & & & & & & & & & & & & & & & & & \\
\hline $\mathbf{z n}$ & & & & & & & & & & & & & & & & & & \\
\hline $\mathbf{z}$ & & & & & & & & & & & & & & & & & & \\
\hline Toted Me & $0.6641 x$ & $3.07 E-01$ & & $0.0000 x$ & 4.34E-01 & & $0.0390 x$ & 4.40E-01 & & $0.1592 x$ & 5.05E-0.2 & & $0.1002 x$ & $7.11 E-02$ & & 0.54198 & $1.33 E-01$ & \\
\hline & & & & & & & & & & & & & & & & & & \\
\hline
\end{tabular}


Comp.sentrel

\begin{tabular}{|c|c|c|c|c|c|c|c|c|c|}
\hline \multicolumn{3}{|c|}{ Somplo UA-3316-Sugarnate } & & \multicolumn{2}{|c|}{ R-3317-8cremente } & & \multicolumn{2}{|c|}{ A-3316-Supanets } & \\
\hline Anlone & \begin{tabular}{|c|}
$w 1 s$ \\
\end{tabular} & $\mu$ & & \begin{tabular}{|c|}
$+x$ \\
\end{tabular} & 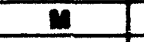 & & \begin{tabular}{|l|}
$w+x$ \\
\end{tabular} & $M$ & \\
\hline $\mathbf{F}$ & $0.1779 x$ & $1.32 E-01$ & $<$ & $0.1430 x$ & $1.00 E-01$ & & $0.1110 x$ & $0.30 E-02$ & \\
\hline$a$ & 0.33698 & $1.34 E-01$ & & 0.38163 & $1.55 E-01$ & & 0.41048 & $1.03 E-01$ & \\
\hline noe & $5.2205 x$ & $1.00 E+00$ & & $5.3034 x$ & $1.00 E+00$ & & $5.3457 \times$ & $1.65 E+00$ & \\
\hline 100 & $12.0932 x$ & $2.75 E+00$ & & $14.8984 x$ & $3.46 E+00$ & & $15.1002 x$ & $3.40 E+00$ & \\
\hline POA & 0.47908 & $7.12 E-02$ & & $0.3430 x$ & $5.20 E-02$ & & $0.3110 x$ & 4.05E-02 & \\
\hline son & 3.27008 & $4.80 E-01$ & $\leq$ & $1.4342 \%$ & $2.15 E-01$ & $\leq$ & $1.1162 x$ & 1.65E-01 & \\
\hline $\mathbf{\infty}$ & $2.3001 \times$ & 5.63E-01 & & $2.5970 x$ & $6.21 E-01$ & & $3.0250 x$ & 7.10E-01 & \\
\hline CH & $1.1423 \times$ & $=.47 E-01$ & & 1.724458 & $1.46 E+00$ & & 1.64008 & $1.37 \mathrm{E}+00$ & \\
\hline Toth An ? & $25.1164 x$ & $7.02 E+00$ & & $26.0160 \%$ & $8.22 E+00$ & & $27.0701 \times$ & $8.16 E+00$ & \\
\hline & & & & & & & & & \\
\hline Tow or & & & & & & & & & \\
\hline & & & & & & & & & \\
\hline Tot $\mathrm{Co}:$ & $25.7805 \times$ & $1.40 E+01$ & & $27.7153 \times$ & 1.64E+01 & & $28.0171 \%$ & $1.03 E+01$ & \\
\hline & & & & & & & & & \\
\hline IF & $n / 0$ & ucn & & ele & uch & & $9 / 2$ & waln & \\
\hline Am-241 & $2.00 \mathrm{E}-00$ & $1.02 E+01$ & & & & & $3.06 E-00$ & $1.00 E+01$ & \\
\hline$C m-243$ & & & & & & & & & \\
\hline$C m-244$ & & & & & & & & & \\
\hline Cm-24x & & & & & & & & & \\
\hline N9-237 & & & & & & & & & \\
\hline Pu-2as & & & & & & & & & \\
\hline Pu-20 & 2.17E-00 & $1.02 E+00$ & $\boldsymbol{0}$ & $7.81 E-00$ & $7.00 E+00$ & 8 & $1.04 E-07$ & $0.27 E+\infty$ & 9 \\
\hline Pu-240 & & & & & & & & & \\
\hline Pu-241 & & & & & & & & & \\
\hline Pu-242 & & & & & & & & & \\
\hline Pu-244 & & & & & & & & & \\
\hline n-TRES & $0 / 0$ & ucu & & $0 / 0$ & ucul & & $g / 2$ & $\mathrm{UCL}$ & \\
\hline H-3 & & & & & & & & & \\
\hline C-14 & & & & & & & & & \\
\hline 1.129 & & & & & & & & & \\
\hline No-94 & & & & & & & & & \\
\hline$M-6$ & & & & & & & & & \\
\hline So-70 & & & & & & & & & \\
\hline Sr-e0 & 4.54E-09 & $8.84 E+02$ & 13 & $8.4 E-00$ & $1.67 E+03$ & 13 & $9.13 E-09$ & $1.70 E+03$ & 13 \\
\hline Te-9s & & & & & & & & & \\
\hline Co-144 & & & & & & & & & \\
\hline Co-en & & & & & & & & & \\
\hline Co-134 & & & & & & & & & \\
\hline Cs-137 & $2.00 E-00$ & $2.54 E+05$ & & $2.55 E-00$ & $3.21 E+05$ & & $2.46 E-06$ & $3.06 E+05$ & \\
\hline Eu-152 & & & & & & & & & \\
\hline Eu-154 & & & & & & & & & \\
\hline Eu-155 & & & & & & & & & \\
\hline Ru-106 & & & & & & & & & \\
\hline$S b-125$ & & & & & & & & & \\
\hline Z-95 & & & & & & & & & \\
\hline Tot IPU & $2.30 E-00$ & $121 \mathrm{E}+01$ & & $7.81 E-00$ & $7.06 E+00$ & & $1.00 E-07$ & $2.03 E+01$ & \\
\hline Tot NonT & $2.00 E-00$ & $2.55 E+05$ & & 2.5eE-00 & $3.22 \leq+05$ & & $2.47 E-00$ & $3.00 \varepsilon+05$ & \\
\hline Tot Red & $2.00 E-00$ & $2.55 E+05$ & & $2.03 E-06$ & $3.23 E+05$ & & $2.50 E-00$ & $3.00 E+05$ & \\
\hline
\end{tabular}

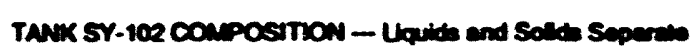

\begin{tabular}{|c|c|c|c|c|c|c|c|c|}
\hline R-3037-5u & erneces & & Asasaser & pernete & & p-3028-Su & 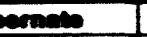 & \\
\hline wrs & $M$ & & wet & $\boldsymbol{n}$ & & \begin{tabular}{|l|} 
wtx \\
\end{tabular} & $M$ & \\
\hline 0.00718 & $3.06 E-03$ & & $0.1400 x$ & O.30E-02 & & $0.0049 x$ & $2.72 E-03$ & $\leq$ \\
\hline & & & $0.5619 x$ & 1.00E-01 & & & & \\
\hline $0.1740 x$ & $3.01 E-02$ & & 7.16124 & 1.65E,00 & & $0.2079 x$ & 4.79E-02 & \\
\hline $2.7752 x$ & $4.61 E-01$ & & $20.2393 x$ & $3.40 E+\infty 0$ & & $3.3342 x$ & $5.70 E-01$ & \\
\hline $0.0356 x$ & $3.26 E-03$ & & $0.4166 x$ & $4.65 E-02$ & & $0.0404 x$ & $4.51 E-03$ & \\
\hline $0.0374 x$ & $4.01 E-03$ & & 1.40527 & 1.65E-01 & & $0.0306 \%$ & $3.30 E-03$ & \\
\hline & & & $4.0535 x$ & $7.16 E-01$ & & $0.2100 x$ & $3.71 E-02$ & \\
\hline $0.6704 x$ & $4.00 E-01$ & & $2.1981 \%$ & $1.37 E+\infty 0$ & & $0.7573 x$ & $4.72 E-01$ & \\
\hline $3.7003 x$ & $0.02 E-01$ & & $36.2757 x$ & $7.74 E+\infty 0$ & & $4.5054 x$ & $1.34 E+00$ & \\
\hline & & & & & & & & \\
\hline & & & 0.02304 & $2.53 E-01$ & & 0.02208 & $2.42 E-01$ & \\
\hline & & & & & & & & \\
\hline $3.0595 \%$ & $1.00 E+\infty 0$ & & $30.4978 \%$ & $1.57 E \cdot 01$ & & $5.1501 x$ & $2.92 E+00$ & \\
\hline & & & & & & & & \\
\hline $9 / 9$ & ven & & $9 / 9$ & UCM & & $g / n$ & ucn & \\
\hline $3.02 E-10$ & $1.00 E+00$ & & $7.51 E-00$ & $2.76 E+01$ & & & & \\
\hline & & & & & & & & \\
\hline & & & & & & & & \\
\hline & & & & & & & & \\
\hline & & & & & & & & \\
\hline & & 15 & & & 15 & & & \\
\hline & & 15 & & & 15 & & & \\
\hline & & 15 & & & 15 & & & \\
\hline $2.00 E-10$ & $3.00 E+01$ & 15 & C.11E-10 & $6.75 E+01$ & 15 & $1.91 \mathrm{E}-10$ & $2.11 E+01$ & \\
\hline & & & & & & & & \\
\hline $9 / 0$ & ucn & & 0 & uCL & & 0 & ucn & \\
\hline SW & & & & & & & & \\
\hline & & & & & & & & \\
\hline & & & & & & & & \\
\hline & & & & & & & & \\
\hline & & & & & & & & \\
\hline & & & & & & & & \\
\hline & & & & & & $8.01 \mathrm{E}-12$ & $1.20 E+00$ & 13 \\
\hline & & & & & & & & \\
\hline & & & & & & & & \\
\hline & & & & & & & & \\
\hline $504 E-00$ & $5365+03$ & & $700-6-9$ & $6.55 E+03$ & & $7.135-00$ & $6.61 E+03$ & \\
\hline & & & & & & & & \\
\hline & & & & & & & & \\
\hline & & & & & & & & \\
\hline & & & & & & & & \\
\hline & & & & & & & & \\
\hline & & & & & & & & \\
\hline $5.02 E-10$ & $3.11 E_{-01}$ & & $0.12 E-00$ & $0.51 E+01$ & & $1.91 E-10$ & $2.11 E+01$ & \\
\hline 5.04E-00 & $5.35 E .03$ & & $7.00 E-00$ & 6.55E+03 & & $7.13 E-00$ & C.61E+03 & \\
\hline $0.00 E-00$ & $5.30 E+03$ & & $7.00 E-000$ & $0.65 E+03$ & & $7.15 E-\infty 0$ & 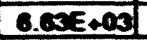 & \\
\hline
\end{tabular}




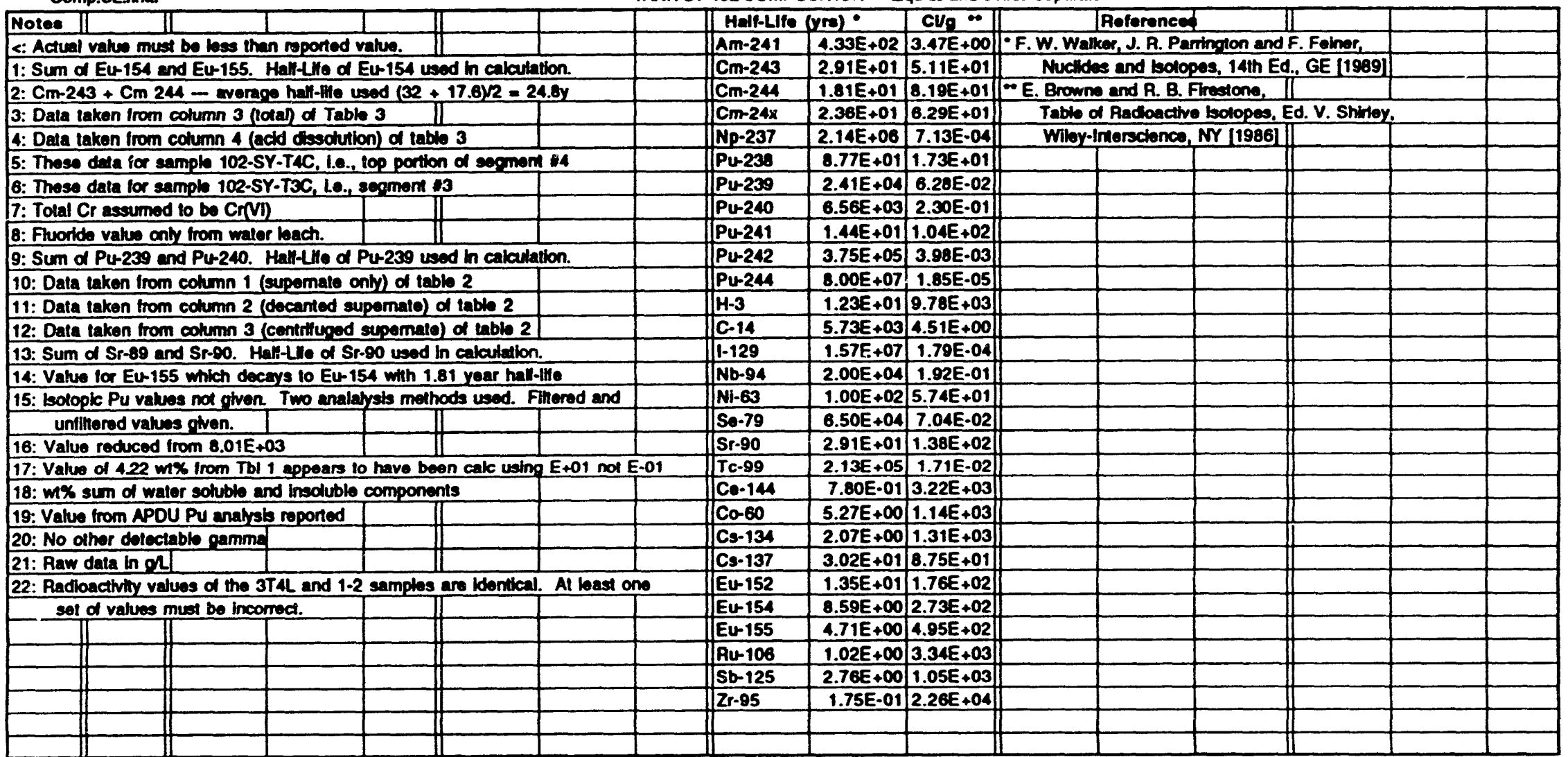




\section{SY-102 LIQUID COMPOSITIONS}

Filename: Liquid.Values 


\begin{tabular}{|c|c|c|c|c|c|c|c|c|c|}
\hline \multirow{2}{*}{\multicolumn{2}{|c|}{\begin{tabular}{|l|} 
Sample ID: \\
Sample Date: \\
\end{tabular}}} & 102SY3T4L & $102 S Y 1-2$ & R5027 & A5028 & R5029 & P4656 & A4615 & 102SY3T4L \\
\hline & & $10 / 25 / 88$ & $10 / 25 / 88$ & $6 / 2 / 89$ & $6 / 2 / 89$ & $6 / 2 / 89$ & $3 / 14 / 89$ & $3 / 20 / 89$ & $10 / 25 / 88$ \\
\hline \multicolumn{2}{|c|}{ Analyels Date: } & $6 / 30 / 89$, final & $6 / 30 / 89$, fing & $8 / 29 / 89$ & $8 / 29 / 89$ & $8 / 29 / 89$ & $8 / 29 / 89$ & $3 / 24 / 89$ & $11 / 19 / 90$ \\
\hline \multirow[t]{2}{*}{ Analyes: } & & \begin{tabular}{|l|} 
PNL:Scheole \\
\end{tabular} & PNL:Sche日le & PCL & PCL & $P C L$ & PCL & PCL & $P Q$ \\
\hline & & \&Peterson & \&Peterson & Welss & Wolss & Wolss & Welss & Wolss & $?$ \\
\hline \multicolumn{2}{|c|}{ Sample SHe: } & Oct'88core & Oct'88core & $49^{\prime}(?)$ & $40^{\prime}(?)$ & $31^{\prime}(?)$ & Super (?) & Super-(?) & Oct'88core \\
\hline \multicolumn{2}{|c|}{ Sample Noter: } & Comp 3/4 & Comp 1/2 & & & & & & Comp 3/4 \\
\hline \multicolumn{2}{|c|}{ Sp.Gr./Den.: } & & & $8 g=1.025$ & $8 g=1.016$ & $8 g=1.012$ & $d=1.57$ & $d=1.57$ & $8 g=1.18$ \\
\hline \multicolumn{2}{|c|}{ Reference: } & Peterson to & Peterson to & Weiss to & Welss to & Welss to & Woiss to & Wolss to & Woiss to \\
\hline & & DiLIberto & DILIberto & Saueressig & Saueressig & Saueressig & Boyles & Campbell & KIrch" \\
\hline & & $6 / 30 / 89$ & $6 / 30 / 89$ & $8 / 29 / 89$ & $8 / 29 / 89$ & $8 / 29 / 89$ & $5 / 2 / 89$ & $4 / 27 / 89$ & $11 / 19 / 90$ \\
\hline Phase: & & Llquid & Llquild & Llquild & Llquild & Llquild & Liquild & Llquild & Llquild \\
\hline Specle & Mass & $w t \%$ & wt\% & $w t \%$ & wt\% & wt\% & $w t \%$ & $w t \%$ & $w t \%$ \\
\hline $\mathrm{Ag}$ & 107.87 & & & & & & & & \\
\hline Al & 26.98 & $0.2590 \%$ & $0.1184 \%$ & $0.1106 \%$ & $0.1089 \%$ & $0.1066 \%$ & $2.6122 \%$ & $0.0670 \%$ & $0.2812 \%$ \\
\hline As & 74.92 & & & & & & & & $0.0002 \%$ \\
\hline $\mathbf{B}$ & 10.81 & $0.0032 \%$ & $0.0011 \%$ & & & & $0.0020 \%$ & & \\
\hline $\mathrm{Ba}$ & 137.33 & $0.0011 \%$ & $0.0000 \%$ & & & & & & \\
\hline$B i$ & 208.98 & & & & & & & & \\
\hline $\mathrm{Ca}$ & 40.08 & $0.0039 \%$ & $0.0003 \%$ & $0.0002 \%$ & $0.0003 \%$ & $0.0002 \%$ & $0.0019 \%$ & $0.0001 \%$ & $0.0031 \%$ \\
\hline$\infty$ & 112.41 & & & & & & & & \\
\hline$C_{\theta}$ & 140.12 & $0.0280 \%$ & $0.0006 \%$ & & & & & $0.0004 \%$ & \\
\hline $\mathrm{Cr}(\mathrm{V} I)$ & 52.00 & $0.0040 \%$ & $0.0012 \%$ & & & & & & \\
\hline $\mathrm{Cr}(\mathrm{TOt})$ & 52.00 & $0.0312 \%$ & $0.0009 \%$ & $0.0010 \%$ & $0.0010 \%$ & $0.0010 \%$ & $0.0027 \%$ & $0.0006 \%$ & $0.0353 \%$ \\
\hline$a_{1}$ & 63.55 & & & & & & & & \\
\hline Dy & 162.50 & $0.0013 \%$ & $0.0000 \%$ & & & & & & \\
\hline $\mathrm{Fo}$ & 55.85 & $0.0003 \%$ & $0.0002 \%$ & & & & $0.0004 \%$ & & $0.0007 \%$ \\
\hline$K$ & 39.10 & $0.1212 \%$ & $0.2346 \%$ & $0.3395 \%$ & $0.3348 \%$ & $0.3323 \%$ & $0.3636 \%$ & $0.1669 \%$ & $0.1209 \%$ \\
\hline La & 138.91 & $0.0028 \%$ & $0.0000 \%$ & & & & & $0.0001 \%$ & \\
\hline $\mathrm{LI}$ & 6.94 & $0.0021 \%$ & $0.0000 \%$ & & & & & & \\
\hline $\operatorname{Ln}$ & 157.00 & $0.0452 \%$ & $0.0008 \%$ & & & & & & \\
\hline $\mathrm{Mg}$ & 24.31 & $0.0007 \%$ & $0.0000 \%$ & & & & & & \\
\hline $\mathrm{Mn}$ & 54.94 & $0.0016 \%$ & $0.0000 \%$ & & & & & & \\
\hline Mo & 95.94 & $0.0019 \%$ & $0.0001 \%$ & & & & $0.0061 \%$ & $0.0061 \%$ & \\
\hline $\mathrm{Na}$ & 22.99 & $8.2763 \%$ & $2.0162 \%$ & $2.0186 \%$ & $2.0139 \%$ & $1.9310 \%$ & $12.7688 \%$ & $1.1275 \%$ & $8.3387 \%$ \\
\hline $\mathrm{Nd}$ & 144.24 & $0.0087 \%$ & $0.0001 \%$ & & & & & & \\
\hline $\mathrm{Ni}$ & 58.71 & $0.0041 \%$ & $0.0000 \%$ & & & & $0.0020 \%$ & $0.0020 \%$ & \\
\hline $\mathbf{P}$ & 30.97 & & $0.0093 \%$ & $0.0094 \%$ & $0.0095 \%$ & $0.0089 \%$ & $0.0065 \%$ & $0.0051 \%$ & $0.2339 \%$ \\
\hline $\mathbf{P b}$ & 207.20 & & & & & & & & \\
\hline $\mathbf{F}$ & 102.91 & $0.0309 \%$ & $0.0031 \%$ & & & & & & \\
\hline $\mathrm{Ru}$ & 101.07 & $0.0505 \%$ & $0.0020 \%$ & & & & & & \\
\hline $\mathbf{S b}$ & 121.75 & & & & & & & & \\
\hline Se & 78.96 & & & & & & & & $0.0000 \%$ \\
\hline$S$ & 28.09 & $0.0022 \%$ & $0.0129 \%$ & & & & & $0.0047 \%$ & $0.0014 \%$ \\
\hline Sr & 87.62 & $0.0018 \%$ & $0.0000 \%$ & & & & & & \\
\hline$T_{\theta}$ & 127.60 & $0.0255 \%$ & $0.0003 \%$ & & & & & & \\
\hline Th & 232.04 & & & & & & & & \\
\hline $\mathrm{TI}$ & 47.90 & $0.0014 \%$ & $0.0000 \%$ & & & & & & \\
\hline $\mathrm{TI}$ & 204.37 & & & & & & & & \\
\hline$U$ & 238.03 & & & & & & $0.0188 \%$ & $0.0188 \%$ & $0.0008 \%$ \\
\hline $\mathrm{V}$ & 50.94 & & & & & & & & \\
\hline $\mathrm{Zn}$ & 65.38 & $0.0131 \%$ & $0.0002 \%$ & & & & & & $0.0043 \%$ \\
\hline $\mathrm{Zr}$ & 91.22 & $0.0064 \%$ & $0.0000 \%$ & & & & & & \\
\hline \multicolumn{2}{|c|}{ Tot Metals: } & $8.8794 \%$ & $2.4004 \%$ & $2.4792 \%$ & $2.4683 \%$ & $2.3799 \%$ & $15.7851 \%$ & $1.3993 \%$ & $9.0206 \%$ \\
\hline & & & & & & & & & \\
\hline
\end{tabular}


Llquid.Values

SY-102 LIQUID COMPOSITIONS

\begin{tabular}{|c|c|c|c|c|c|c|c|c|c|}
\hline \multicolumn{2}{|c|}{ Sample ID: } & \multirow{2}{*}{$\frac{\text { 102SY3TAL }}{\text { WI\% }}$} & \multirow{2}{*}{$\frac{102 S Y 1-2}{w t \%}$} & \multirow{2}{*}{$\frac{R 5027}{w 1 \%}$} & \multirow{2}{*}{$\frac{R 5028}{w+\%}$} & \multirow{2}{*}{$\frac{\text { P5029 }}{\text { wi\% }}$} & \multirow{2}{*}{$\frac{R 4656}{w t \%}$} & \multirow{2}{*}{$\begin{array}{r}\text { P4615 } \\
\text { w1\% } \\
\end{array}$} & \multirow{2}{*}{$\frac{102 S Y 3 T 4 L}{w t \%}$} \\
\hline Anlons & & & & & & & & & \\
\hline $\mathbf{F}$ & 19.00 & & & $0.0741 \%$ & \begin{tabular}{|l|}
$0.0729 \%$ \\
\end{tabular} & \begin{tabular}{|l|}
$0.0732 \%$ \\
\end{tabular} & $0.0823 \%$ & $0.0411 \%$ & $0.0435 \%$ \\
\hline a & 35.45 & & & $0.0152 \%$ & $0.0157 \%$ & $0.0158 \%$ & $0.0124 \%$ & $0.0140 \%$ & $0.1502 \%$ \\
\hline $\mathrm{NO2}$ & 46.01 & & & $0.2289 \%$ & $0.2219 \%$ & $0.2318 \%$ & $0.1260 \%$ & $10.8421 \%$ & $2.0040 \%$ \\
\hline NO3 & 62.00 & & & $2.1172 \%$ & $2.0750 \%$ & $2.0832 \%$ & $8.2147 \%$ & $1.3823 \%$ & $8.9329 \%$ \\
\hline PO4 & 94.97 & & & $0.0222 \%$ & $0.0234 \%$ & $0.0235 \%$ & $0.3327 \%$ & $0.0085 \%$ & $0.6407 \%$ \\
\hline $\mathrm{SO}_{4}$ & 96.06 & & & $0.0122 \%$ & $0.0123 \%$ & $0.0123 \%$ & $6.1795 \%$ & $0.0496 \%$ & $0.5536 \%$ \\
\hline$\infty$ & 60.01 & & & & & & & & $2.1868 \%$ \\
\hline CH & 17.01 & & & & & & $1.1049 \%$ & & $1.0954 \%$ \\
\hline \multicolumn{2}{|c|}{ Tot Anlons: } & $0.0000 \%$ & $0.0000 \%$ & $2.4699 \%$ & $2.4211 \%$ & $2.4398 \%$ & $16.0525 \%$ & $12.3375 \%$ & $15.6069 \%$ \\
\hline \multicolumn{2}{|c|}{ Tot Org C: } & & & & & & $0.7962 \%$ & & $0.1864 \%$ \\
\hline & & & & & & & & & \\
\hline \multicolumn{2}{|c|}{ Tot Comp: } & $8.8794 \%$ & $2.4004 \%$ & $4.9492 \%$ & $4.8894 \%$ & $4.8197 \%$ & $32.6338 \%$ & $13.7368 \%$ & $24.8140 \%$ \\
\hline TAUs & & $g / g$ & $9 / 9$ & $g / g$ & $\mathrm{~g} / \mathrm{g}$ & $g / g$ & $9 / 9$ & $9 / 9$ & $9 / g$ \\
\hline Am-241 & 241.06 & 1.46E-05 & & $9.01 E-12$ & $4.26 \mathrm{E}-11$ & $1.17 \mathrm{E}-11$ & $1.60 E-10$ & $6.06 \mathrm{E}-12$ & \\
\hline $\mathrm{Cm}-243$ & 243.00 & & & & & & & & \\
\hline $\mathrm{Cm}-244$ & 244.00 & & & & & & & & \\
\hline Cm-24x & \begin{tabular}{|l|}
243.56 \\
\end{tabular} & $3.82 E-09$ & & & & & & & \\
\hline Np-237 & 237.05 & $1.82 E-06$ & & & & & & & \\
\hline Pu-238 & 238.05 & $7.79 \mathrm{E}-08$ & & & & & & & \\
\hline Pu-239 & 239.05 & $1.55 E-04$ & & 1.55E-09 & 1.57E-09 & 1.73E-09 & 4.60E-08 & 4.47E-10 & $2.16 E-09$ \\
\hline Pu-240 & 240.05 & $1.48 E-05$ & & & & & & & \\
\hline Pu-241 & 241.06 & $1.12 E-06$ & & & & & & & \\
\hline Pu-242 & 242.00 & & & & & & & & \\
\hline Pu-244 & 244.00 & & & & & & & & \\
\hline n-TRUs & & $9 / 2$ & $9 / 9$ & $0 / 9$ & $9 / 9$ & $9 / 9$ & $9 / 9$ & $9 / 9$ & $9 / 9$ \\
\hline $\mathrm{H}-3$ & 3.02 & $8.14 \mathrm{E}-15$ & $2.56 \mathrm{E}-15$ & & & & & & \\
\hline C-14 & 14.00 & & & & & & & & 4.32E-12 \\
\hline $1-129$ & 129.00 & 1.57E-07 & 1.01E-07 & & & & & & \\
\hline $\mathrm{Nb}-94$ & \begin{tabular}{|c|}
94.00 \\
\end{tabular} & $1.61 \mathrm{E}-11$ & $3.17 E-12$ & & & & & & \\
\hline NI-63 & 63.00 & $3.31 E-12$ & $6.97 \mathrm{E}-12$ & & & & & & \\
\hline Se-79 & 79.00 & B.62E-09 & $2.13 E-10$ & & & & & & \\
\hline Sr-90 & 90.00 & & & $3.67 E-12$ & $3.85 E-12$ & $3.72 E-12$ & $7.29 \mathrm{E}-09$ & $2.72 E-12$ & 1.07E-11 \\
\hline TC-99 & $\begin{array}{r}99.00 \\
\end{array}$ & $3.14 E-06$ & 1.17E-07 & $1.70 \mathrm{E}-07$ & $1.72 \mathrm{E}-07$ & $1.69 E-07$ & 1.37E-05 & $9.29 \mathrm{E}-08$ & \\
\hline Co-144 & 144.00 & & & & & & & & \\
\hline Co-60 & 60.00 & & & & & & & & \\
\hline C8-134 & 134.00 & & & & & & & & \\
\hline C8-137 & 137.00 & & & $5.91 E-08$ & $5.74 \mathrm{E}-08$ & $5.76 \mathrm{E}-08$ & 5.07E-06 & $3.40 \mathrm{E}-08$ & $3.78 \mathrm{E}-08$ \\
\hline Eu-152 & 152.00 & & & & & & & & \\
\hline Eu-154 & 154.00 & & & & & & & & \\
\hline Eu-155 & 155.00 & & & & & & & & \\
\hline Ru-106 & 106.00 & & & & & & & & \\
\hline Sb-125 & 125.00 & & & & & & & & \\
\hline$Z r-95$ & \begin{tabular}{|l|}
81.22 \\
\end{tabular} & & & & & & & & \\
\hline & & & & & & & & & \\
\hline \multicolumn{2}{|c|}{ Tot TRUS } & $1.87 E-04$ & $0.00 E+00$ & $1.56 \mathrm{E}-09$ & 1.61E-09 & $1.74 E-09$ & $4.61 \mathrm{E}-08$ & 4.53E-10 & 2.16E-09 \\
\hline \multirow{2}{*}{\multicolumn{2}{|c|}{\begin{tabular}{|l|} 
Tot n-TRUs \\
Tot Radlonucllde
\end{tabular}}} & 3.30E-06 & $2.18 E-07$ & $2.29 E-07$ & 2.29E-07 & 2.26E-07 & $1.88 \mathrm{E}-05$ & 1.27E-07 & $3.78 E-08$ \\
\hline & & 1.91E-04 & $2.18 \mathrm{E}-07$ & 2.31E-07 & 2.31E-07 & $2.28 \mathrm{E}-07$ & $1.88 E-05$ & $1.27 E-07$ & 4.00E-08 \\
\hline & & & & & & & & & \\
\hline
\end{tabular}


Llquild.Values

SY-102 LIQUID COMPOSITIONS

\begin{tabular}{|c|c|c|c|c|c|c|c|c|}
\hline \multicolumn{2}{|c|}{ Sample ll102SY1-2 } & 102 SYSuper & R-3316 & R-3317 & R-3318 & A-3037 & A-3038 & R-3326 \\
\hline \multicolumn{2}{|c|}{ Sample I $10 / 25 / 88$} & $6 / 1 / 88$ & $11 / 1 / 84$ & $11 / 1 / 84$ & $11 / 1 / 84$ & $11 / 1 / 84$ & $11 / 1 / 84$ & $?$ \\
\hline \multirow{2}{*}{\multicolumn{2}{|c|}{ Analyet $1: P Q$}} & $3 / 23 / 89$ & $3 / 29 / 85$ & $3 / 29 / 85$ & $3 / 29 / 85$ & $10 / 5 / 84$ & $10 / 5 / 84$ & $12 / 31 / 84$ \\
\hline & & PCL & Rockwell & Rockwell & Rockwell & Rockwell & Rockwell & Rockwell \\
\hline & $\| ?$ & Welss & Bratzel & Bratzel & Bratzel & Bratzel & Bratzel & Bratzol \\
\hline \multicolumn{2}{|c|}{ Sample SOct'88core } & $?$ & 6",boltom & 6", bottom & 6",bottom & $10 p$ & middle & $?$ \\
\hline \multicolumn{2}{|c|}{ Sample IComp 1/2 } & Hligh value & & & & & & \\
\hline \multirow{2}{*}{\multicolumn{2}{|c|}{$\begin{array}{l}\text { Sp.Gr.JDi } \quad 1.02 \\
\text { Referenc Weiss to }\end{array}$}} & $d=1(?)$ & $d=1.41$ & $d=1.44$ & $d=1.42$ & $8 g=1.03$ & $8 g=1.06$ & $8 g=1.06$ \\
\hline & & Weiss(PCL) to & deratzel to & Bratzel to & Bratzel to & Bratzel to & Bratzol to & Bratzel to \\
\hline & Kirch* & Carothers & Gale & Gale & Galo & Tulberg & Tulberg & Tulberg \\
\hline & $11 / 19 / 90$ & $3 / 23 / 89$ & $3 / 29 / 85$ & $3 / 29 / 85$ & $3 / 29 / 85$ & $10 / 5 / 84$ & $10 / 5 / 84$ & $12 / 31 / 84$ \\
\hline Phase: & Llquild & Llquid & Llquild & Llquild & Llguid & Llquid & Llquild & Llquild \\
\hline Specle & $w t \%$ & $w t \%$ & $w 1 \%$ & $w t \%$ & $w 1 \%$ & $w t \%$ & $w+\%$ & $w t \%$ \\
\hline \multicolumn{9}{|l|}{ Ag } \\
\hline Al & $0.1323 \%$ & $0.2293 \%$ & $0.4669 \%$ & $0.6727 \%$ & $0.7125 \%$ & $0.1360 \%$ & $0.1604 \%$ & $0.1655 \%$ \\
\hline As & $0.0002 \%$ & & & & & & & \\
\hline $\mathbf{B}$ & & $0.0010 \%$ & & & & & & \\
\hline \multicolumn{9}{|l|}{$\mathrm{Ba}$} \\
\hline \multicolumn{9}{|l|}{ Bi } \\
\hline $\mathbf{C a}$ & $0.0004 \%$ & $0.0007 \%$ & & & & $0.0001 \%$ & & \\
\hline$\infty$ & & & $0.0042 \%$ & $0.0024 \%$ & $0.0018 \%$ & $0.0006 \%$ & $0.0008 \%$ & $0.0010 \%$ \\
\hline$C_{\theta}$ & & $0.0024 \%$ & & & & & & \\
\hline $\operatorname{Cr}(\mathrm{VI})$ & & $0.0049 \%$ & $0.0819 \%$ & $0.0812 \%$ & $0.0842 \%$ & $0.0034 \%$ & $0.0041 \%$ & \\
\hline $\mathrm{Cr}\left(T \circ t_{)}\right.$ & $0.0010 \%$ & $0.0049 \%$ & $0.0819 \%$ & $0.0812 \%$ & $0.0842 \%$ & $0.0034 \%$ & $0.0041 \%$ & $0.0048 \%$ \\
\hline ar & & $0.0004 \%$ & $0.0003 \%$ & $0.0002 \%$ & $0.0002 \%$ & & & \\
\hline \multicolumn{9}{|l|}{ Dy } \\
\hline $\mathrm{Fe}$ & $0.0002 \%$ & $0.0004 \%$ & $0.0003 \%$ & $0.0004 \%$ & $0.0004 \%$ & $0.0002 \%$ & $0.0003 \%$ & $0.0006 \%$ \\
\hline $\mathbf{K}$ & $0.2423 \%$ & $0.1020 \%$ & $0.1101 \%$ & $0.1412 \%$ & $0.1385 \%$ & $0.0073 \%$ & $0.0085 \%$ & \\
\hline \multicolumn{9}{|l|}{ La } \\
\hline \multicolumn{9}{|l|}{$\mathrm{LI}$} \\
\hline $\operatorname{Ln}$ & $0.0000 \%$ & $0.0027 \%$ & $0.0000 \%$ & $0.0000 \%$ & $0.0000 \%$ & $0.0000 \%$ & $0.0000 \%$ & \\
\hline $\mathrm{Mg}$ & & & $0.0003 \%$ & $0.0002 \%$ & $0.0002 \%$ & $0.0000 \%$ & $0.0000 \%$ & \\
\hline Mn & & & $0.0003 \%$ & $0.0002 \%$ & $0.0002 \%$ & $0.0000 \%$ & $0.0000 \%$ & $0.0001 \%$ \\
\hline \multicolumn{9}{|l|}{ Mo } \\
\hline $\mathrm{Na}$ & $1.9631 \%$ & $3.6554 \%$ & & & & & & \\
\hline \multicolumn{9}{|l|}{ Nd } \\
\hline $\mathrm{NI}$ & & & & & & $0.0000 \%$ & $0.0000 \%$ & $0.3700 \%$ \\
\hline $\mathbf{P}$ & $0.0091 \%$ & $0.0235 \%$ & & & & $0.0116 \%$ & $0.0141 \%$ & \\
\hline$P_{b}$ & & & & & & & & \\
\hline Fh & & & & & & & & \\
\hline$P_{u}$ & & & & & & & & \\
\hline So & & & & & & & & \\
\hline Se & $0.0000 \%$ & & & & & & & \\
\hline$s$ & $0.0033 \%$ & $0.0070 \%$ & & & & & & \\
\hline Sr & & & & & & & & \\
\hline To & & & & & & & & \\
\hline Th & & & & & & & & \\
\hline$T I$ & & & & & & & & \\
\hline$T I$ & & & & & & & & \\
\hline$U$ & $0.0007 \%$ & & & & & & & \\
\hline $\mathrm{v}$ & & & & & & & & \\
\hline $\mathrm{Zn}$ & $0.0001 \%$ & & & & & & & \\
\hline $\mathrm{Zr}$ & & & & & & & & \\
\hline Tot Mete & $2.3527 \%$ & $4.0272 \%$ & $0.6641 \%$ & $0.8986 \%$ & $0.9380 \%$ & $0.1592 \%$ & $0.1882 \%$ & $0.5419 \%$ \\
\hline & & & & & & & & \\
\hline
\end{tabular}


Liquid.Values

SY-102 LIQUID COMPOSITIONS

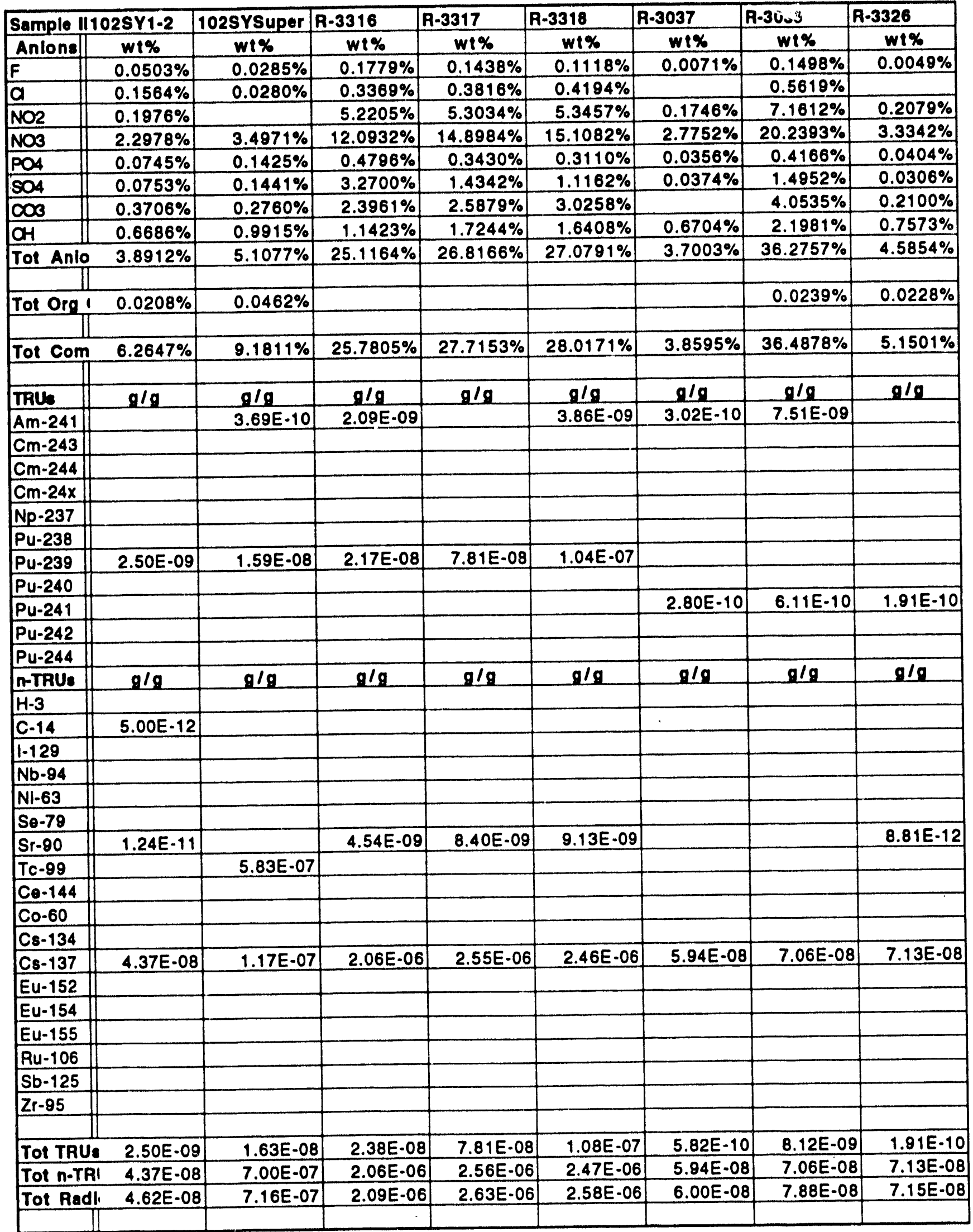


Liquild.Values

SY-102 LIOUID COMPOSITIONS

\begin{tabular}{|c|c|c|c|c|c|c|c|c|c|}
\hline \multicolumn{2}{|c|}{ Sample 1D: } & 102SY3T4L & $102 S Y 1-2$ & R5027 & R5028 & R5029 & R4656 & R4615 & 102SY3T4L \\
\hline \multicolumn{2}{|c|}{ Sample Date: } & $10 / 25 / 88$ & $10 / 25 / 88$ & $6 / 2 / 89$ & $6 / 2189$ & $6 / 2 / 89$ & $3 / 14 / 89$ & $3 / 20 / 89$ & $10 / 25 / 88$ \\
\hline \multicolumn{2}{|c|}{ Analyole Date: } & $6 / 30 / 89$, final & $6 / 30 / 89$, fing & $8 / 29 / 89$ & $8 / 29 / 8 \theta$ & $8 / 29 / 89$ & $8 / 29 / 89$ & $3 / 24 / 80$ & $11 / 18 / 90$ \\
\hline \multirow[t]{2}{*}{ Analyes: } & & PNL:Scheole & PNL:Schoole & PCL & $P C L$ & $\begin{array}{ll}P C L \\
C L\end{array}$ & PCL & PCL & $P Q$ \\
\hline & & EPoterson & \&Peterson & Wolss & Wolss & Woiss & Welss & Wolss & $?$ \\
\hline \multicolumn{2}{|c|}{ Semple Stte: } & Oct'8score & Oct'88core & $49^{\prime}(?)$ & $40^{\prime}(?)$ & $31^{\prime}(?)$ & Super (?) & Supor-(?) & Oct'88core \\
\hline \multicolumn{2}{|c|}{ Sample Notes: } & Comp 3/4 & Comp 1/2 & & & & & & Comp 3/4 \\
\hline \multicolumn{2}{|c|}{ Sp.Gr.JDen.: } & & & $8 g=1.025$ & $g g=1.016$ & $8 g=1.012$ & $d=1.57$ & $d=1.57$ & $s 9=1.18$ \\
\hline \multicolumn{2}{|c|}{ Reference: } & Poterson to & Poterson to & Welss to & Weiss to & Woiss to & Welss to & Wolss to & Woiss to \\
\hline & & DiLIberto & DILIberto & Saueressig & Saueressig & Saueressig & Boyles & Campbell & Klrch ${ }^{\circ}$ \\
\hline & & $6 / 30 / 89$ & $6 / 30 / 89$ & $8 / 29 / 89$ & $8 / 29 / 89$ & $8 / 29 / 89$ & $5 / 2 / 89$ & $4 / 27 / 89$ & $11 / 19 / 90$ \\
\hline Phase: & & Llquild & LIquild & Llquild & Llquild & Llquild & Llquild & Llquild & Llquld \\
\hline Specle & Mase & $g / L$ & $9 / 2$ & $g / L$ & $g / L$ & $g / L$ & g/L & $g / L$ & g/L \\
\hline $\mathrm{Ag}$ & 107.87 & & & $1.21 E+00$ & & & & & \\
\hline Al & 26.98 & $3.11 E+00$ & $1.21 E+00$ & $1.13 E+00$ & $1.11 E+00$ & $1.08 E+00$ & $4.10 E+01$ & $1.05 E+00$ & $3.32 E+00$ \\
\hline As & 74.92 & & & & & & & & 2.25E-03 \\
\hline B & 10.81 & $3.89 \mathrm{E}-02$ & $1.11 \mathrm{E}-02$ & & & & $3.13 \mathrm{E} \cdot 02$ & & \\
\hline $\mathrm{Ba}$ & 137.33 & $1.32 E-02$ & $4.22 E-05$ & & & & & & \\
\hline$B$ & 208.98 & & & & & & & & \\
\hline a & 40.08 & 4.67E-02 & $2.88 \mathrm{E}-03$ & $2.40 \mathrm{E}-03$ & $3.21 E-03$ & $2.00 \mathrm{E}-03$ & 2.97E-02 & $2.00 E-03$ & $3.69 \mathrm{E} \cdot 02$ \\
\hline$\infty$ & 112.41 & & & & & & & & \\
\hline$C_{0}$ & 140.12 & $3.36 \mathrm{E}-01$ & $5.74 E-03$ & & & & & 7.01E-03 & \\
\hline$C_{r}(V I)$ & 52.00 & $4.84 E-02$ & $1.26 \mathrm{E}-02$ & & & & & & \\
\hline Cr(Tol) & 52.00 & $3.74 E-01$ & 9.59E-03 & $9.88 \mathrm{E}-03$ & $9.88 \mathrm{E}-03$ & $9.88 \mathrm{E}-03$ & $4.26 \mathrm{E}-02$ & $8.84 E-03$ & $4.16 \mathrm{E}-01$ \\
\hline a & 63.55 & & & & & & & & \\
\hline Dy & 162.50 & $1.56 \mathrm{E}-02$ & $1.67 E-04$ & & & & & & \\
\hline Fo & 55.85 & $4.02 E-03$ & $2.29 E-03$ & & & & $6.70 \mathrm{E}-03$ & & $8.38 \mathrm{E}-03$ \\
\hline $\mathbf{K}$ & 39.10 & $1.45 E+00$ & $2.40 E+00$ & $3.48 E+00$ & $3.40 \mathrm{E}+00$ & $3.36 E+00$ & $5.71 E+00$ & $2.62 E+00$ & $1.43 E+00$ \\
\hline La & 138.91 & $3.33 \mathrm{E}-02$ & $2.85 \mathrm{E}-04$ & & & & & 8.33E-04 & \\
\hline LI & 6.94 & $2.50 \mathrm{E}-02$ & $7.11 \mathrm{E}-06$ & & & & & & \\
\hline $\operatorname{Ln}$ & 157.00 & 5.43E-01 & $8.37 E-03$ & & & & & & \\
\hline $\mathrm{Mg}$ & 24.31 & $8.75 E-03$ & 1.25E-04 & & & & & & \\
\hline $\mathrm{Mn}$ & 54.94 & $1.98 E-02$ & 2.82E-05 & & & & & & \\
\hline Mo & 95.94 & $2.30 E-02$ & 9.83E-04 & & & & $9.59 \mathrm{E}-02$ & 9.59E-02 & \\
\hline $\mathrm{Na}$ & 22.99 & $9.93 E+01$ & $2.07 E+01$ & 2.07E+01 & 2.05E+01 & $1.95 E+01$ & $2.00 E+02$ & $1.77 E+01$ & $9.84 E+01$ \\
\hline Nd & 144.24 & $1.04 E-01$ & $1.33 E-03$ & & & & & & \\
\hline $\mathrm{Ni}$ & 58.71 & 4.93E-02 & 3.01E-04 & & & & $3.17 \mathrm{E}-02$ & $3.17 E-02$ & \\
\hline$P$ & 30.87 & & 9.52E-02 & $9.60 \mathrm{E}-02$ & $9.60 E-02$ & 8.98E-02 & $1.02 E-01$ & $8.05 E-02$ & $2.76 E+00$ \\
\hline$P_{0}$ & 207.20 & & & & & & & & \\
\hline Ph & 102.91 & $3.70 E-01$ & $3.16 \mathrm{E}-02$ & & & & & & \\
\hline $\mathrm{Au}_{\mathrm{u}}$ & 101.07 & $6.06 \mathrm{E}-01$ & 2.07E-02 & & & & & & \\
\hline So & 121.75 & & & & & & & & \\
\hline$S_{\theta}$ & 78.96 & & & & & & & & $1.58 \mathrm{E}-04$ \\
\hline$\underline{s i}$ & 28.09 & $2.70 \mathrm{E}-02$ & $1.32 E-01$ & & & & & 7.30E-02 & 1.69E-02 \\
\hline Si & 87.62 & $2.10 E-02$ & $5.39 \mathrm{E}-05$ & & & & & & \\
\hline$T_{e}$ & 127.60 & $3.06 \mathrm{E}-01$ & $2.62 E-03$ & & & & & & \\
\hline Th & 232.04 & & & & & & & & \\
\hline$\pi$ & 47.90 & $1.72 E-02$ & $9.82 E-05$ & & & & & & \\
\hline TI & 204.37 & & & & & & & & \\
\hline$U$ & 238.03 & & & & & & $2.95 \mathrm{E}-01$ & $2.85 E-01$ & $0.52 E-03$ \\
\hline v & 50.94 & & & & & & & & \\
\hline $\mathrm{Zn}$ & 65.38 & $1.57 E-01$ & 2.01E-03 & & & & & & $5.10 E-02$ \\
\hline $\mathbf{z}$ & 91.22 & $7.66 \mathrm{E}-02$ & $9.35 E-05$ & & & & & & \\
\hline \multicolumn{2}{|c|}{ Tot Metale: } & $1.07 E+02$ & $2.46 \mathrm{E}+01$ & $2.54 E+01$ & $2.51 E+01$ & $2.41 E+01$ & $2.48 E+02$ & $2.20 E+01$ & $1.06 E+02$ \\
\hline & & & & & & & & & \\
\hline
\end{tabular}


Llquid.Values

SY-102 LIOUID COMPOSITIONS

\begin{tabular}{|c|c|c|c|c|c|c|c|c|c|}
\hline \multirow{2}{*}{\multicolumn{2}{|c|}{\begin{tabular}{|l|} 
Sample 1D: \\
Anlone
\end{tabular}}} & \multirow{2}{*}{$\frac{102 S Y 3 T 4 L}{g / L}$} & \multirow{2}{*}{$\begin{array}{c}102 S Y 1-2 \\
g / L\end{array}$} & \multirow{2}{*}{$\frac{R 5027}{g / L}$} & \multirow{2}{*}{$\frac{\mathrm{A5028}}{\mathrm{Q} / \mathrm{L}}$} & \multirow{2}{*}{$\frac{\mathrm{A5029}}{\mathrm{g} / \mathrm{L}}$} & \multirow{2}{*}{$\frac{R 4656}{9 / 2}$} & \multirow{2}{*}{$\frac{R 4615}{9 / L}$} & \multirow{2}{*}{\begin{tabular}{|c|} 
1028Y3TAL \\
$\mathrm{g} / \mathrm{L}$ \\
\end{tabular}} \\
\hline & & & & & & & & & \\
\hline$F$ & 19.00 & & & \begin{tabular}{|l|}
$7.60 \mathrm{E}-01$ \\
\end{tabular} & \begin{tabular}{|l|}
$7.41 \mathrm{E}-01$ \\
\end{tabular} & \begin{tabular}{|l|}
$7.41 \mathrm{E} .01$ \\
\end{tabular} & $1.29 E+00$ & \begin{tabular}{|l|}
$0.46 E-01$ \\
\end{tabular} & 5.13E-01 \\
\hline a & 35.45 & & & $1.56 E-01$ & $1.60 \mathrm{E}-01$ & $1.60 E-01$ & 1.05E-01 & $2.20 E-01$ & $1.77 E+00$ \\
\hline NO2 & 46.01 & & & $2.35 E+00$ & $2.25 E+00$ & $2.35 E+00$ & $1.98 E+00$ & $1.70 E+02$ & $2.36 E+01$ \\
\hline $\mathrm{NOS}$ & 62.00 & & & $2.17 E+01$ & $2.11 E+01$ & $2.11 E+01$ & $1.29 E+02$ & $2.17 E+01$ & $1.05 E+02$ \\
\hline PO4 & 94.07 & & & 2.28E-01 & 2.37E-01 & 2.37E-01 & $5.22 E+00$ & $1.33 E-01$ & $7.56 E+00$ \\
\hline so4 & 96.06 & & & 1.25E-01 & 1.25E-01 & 1.25E-01 & $0.70 E+01$ & $7.78 E-01$ & $6.53 E+00$ \\
\hline$\infty$ & 60.01 & & & & & & & & $2.58 E+01$ \\
\hline OH & 17.01 & & & & & & $1.73 E+01$ & & $1.29 E+01$ \\
\hline \multicolumn{2}{|c|}{ Tof Anlons: } & $0.00 E+00$ & $0.00 E+00$ & $2.53 E+01$ & $2.46 E+01$ & $2.47 E+01$ & $2.52 E+02$ & $1.94 E+02$ & $1.84 E+02$ \\
\hline & & & & & & & & & \\
\hline \multirow{2}{*}{\multicolumn{2}{|c|}{ Tot Org C: }} & & & & & & 7.96E-03 & & $1.86 \mathrm{E}-03$ \\
\hline & & & & & & & & & \\
\hline \multicolumn{2}{|c|}{ Tol Comp: } & $1.07 E+02$ & 7.24E-01 & 5.07E+01 & $4.97 E+01$ & $4.88 E+01$ & $5.00 E+02$ & $2.16 E+02$ & $2.91 E+02$ \\
\hline & & & & & & & & & \\
\hline True & & uCI/L & $\mathrm{UCI} / \mathrm{L}$ & uCI/L & UCI/L & uCl/L & uCI/L & UCI/L & UCI/L \\
\hline Am-241 & 241.06 & $6.07 E+04$ & & 3.20E-02 & 1.50E-01 & $4.10 E-02$ & 8.70E-01 & $3.30 \mathrm{E}-02$ & \\
\hline $\mathrm{Cm}-243$ & 243.00 & & & & & & & & \\
\hline $\mathrm{Cm}-244$ & 244.00 & & & & & & & & \\
\hline $\mathrm{Cm}-24 \mathrm{x}$ & 243.56 & $2.88 E+02$ & & & & & & & \\
\hline Np-237 & 237.05 & $1.56 E+00$ & & & & & & & \\
\hline Pu-238 & 238.05 & $1.62 E+03$ & & & & & & & \\
\hline Pu-239 & 239.05 & 1.17E+04 & & $1.00 \mathrm{E}-01$ & $1.00 E-01$ & $1.10 E-01$ & $4.53 E+00$ & $4.40 E-02$ & $1.60 E-01$ \\
\hline Pu-240 & 240.05 & $4.08 E+03$ & & & & & & & \\
\hline Pu-241 & 241.06 & $1.40 E+05$ & & & & & & & \\
\hline Pu-242 & 242.00 & & & & & & & & \\
\hline Pu-244 & 244.00 & & & & & & & & \\
\hline n-TRUs & & $\mathrm{UCI} / \mathrm{L}$ & UCI/L & $\mathrm{UCI} / \mathrm{L}$ & $\mathrm{UCI} / \mathrm{L}$ & UCI/L & UCI/L & $\mathrm{UCI} / \mathrm{L}$ & $\mathrm{UCI/L}$ \\
\hline $\mathrm{H}-3$ & 3.02 & $9.55 \mathrm{E}-02$ & $3.00 E-02$ & & & & & & \\
\hline C.14 & 14.00 & & & & & & & & $2.30 \mathrm{E}-02$ \\
\hline $1-129$ & 129.00 & $3.36 E-02$ & $2.16 \mathrm{E}-02$ & & & & & & \\
\hline $\mathrm{Nb}-94$ & \begin{tabular}{|l|}
94.00 \\
\end{tabular} & $3.72 E-03$ & $7.32 E-04$ & & & & & & \\
\hline N1.63 & 63.00 & $2.28 E-01$ & $4.80 \mathrm{E}-01$ & & & & & & \\
\hline So-79 & 79.00 & $7.28 \mathrm{E}-01$ & $1.80 \mathrm{E}-02$ & & & & & & \\
\hline Sr-90 & 90.00 & & & $5.20 \mathrm{E}-01$ & 5.40E-01 & 5.20E-01 & $1.58 E+03$ & $5.90 \mathrm{E}-01$ & $1.75 E+00$ \\
\hline TC-99 & 99.00 & $6.46 \mathrm{E}+01$ & $2.41 E+00$ & $2.99 E+00$ & $2.99 E+00$ & $2.93 E+00$ & $3.69 E+02$ & $2.50 E+00$ & \\
\hline Co-144 & 144.00 & & & & & & & & \\
\hline Co-60 & 60.00 & & & & & & & & \\
\hline C8-134 & 134.00 & & & & & & & & \\
\hline C8-137 & 137.00 & & & $5.30 E+03$ & $5.10 E+03$ & $5.10 E+03$ & $6.96 E+05$ & $4.67 E+03$ & $3.90 E+03$ \\
\hline Eu-152 & 152.00 & & & & & & & & \\
\hline Eu-154 & 154.00 & & & & & & & & \\
\hline Eu-155 & 155.00 & & & & & & & & \\
\hline$R u-106$ & 106.00 & & & & & & & & \\
\hline$S b-125$ & 125.00 & & & & & & & & \\
\hline $\mathrm{Zr}-95$ & 91.22 & & & & & & & & \\
\hline & & & & & & & & & \\
\hline Tot TAU & & $2.19 \mathrm{E}+05$ & $0.00 E+00$ & $1.32 \mathrm{E}-01$ & $2.50 \mathrm{E}-01$ & 1.51E-01 & $5.40 E+00$ & $7.70 \mathrm{E}-02$ & $1.60 \mathrm{E}-01$ \\
\hline Tot n-TR & iUs & $6.56 \mathrm{E}+01$ & $2.96 \mathrm{E}+00$ & $5.30 E+03$ & $5.10 E+03$ & $5.10 E+03$ & $6.98 E+05$ & $4.67 E+03$ & $3.90 E+03$ \\
\hline Tot Rad & llonucllde & $2.19 E+05$ & $3.11 E+02$ & $5.30 E+03$ & $5.10 E+03$ & $5.10 E+03$ & $6.98 E+05$ & $4.67 E+03$ & $3.90 E+03$ \\
\hline
\end{tabular}


Llquild.Values

SY-102 LIOUID COMPOSITIONS

\begin{tabular}{|c|c|c|c|c|c|c|c|c|}
\hline \multicolumn{2}{|c|}{ 8ample II102SY1-2 } & 102SYSuper & R-3316 & A-3317 & A-3318 & A-3037 & R-3038 & R-3326 \\
\hline \multicolumn{2}{|c|}{ 8ample / $10 / 25 / 88$} & $6 / 1 / 88$ & $11 / 1 / 84$ & $11 / 1 / 84$ & $11 / 1 / 84$ & $11 / 1 / 84$ & $11 / 1 / 84$ & $?$ \\
\hline \multirow{3}{*}{ Analyole } & $11 / 19 / 90$ & $3 / 23 / 89$ & $3 / 29 / 85$ & $3 / 20 / 85$ & $3 / 29 / 85$ & $10 / 5 / 84$ & $10 / 5 / 84$ & $12 / 31 / 84$ \\
\hline & $P Q$ & $\mathrm{PCl}$ & Rockwell & Rockwell & Rockwoll & Rockwell & Rockwell & Rockwoll \\
\hline & $?$ & Wolss & Bratzel & Bralzel & Bratzol & Bratzel & Bratzol & Bratzel \\
\hline \multicolumn{2}{|c|}{ Sample SOct'88core } & $?$ & 6, boltom & 6".bottom & 6, bottom & 10p & mildle & 7 \\
\hline \multicolumn{2}{|c|}{ Sample IComp 1/2 } & High value & & & & & & \\
\hline \multirow{2}{*}{\multicolumn{2}{|c|}{$\begin{array}{l}\text { 8p.Qr.101 } 1.02 \\
\text { Aeferene Woles to }\end{array}$}} & $d=1(?)$ & $d=1.41$ & $d=1.44$ & $d=1.42$ & $g=1.03$ & $80=1.06$ & $89=1.06$ \\
\hline & & Woles (PCL) td & Bralzel to & Bratzel to & Bratzol to & Bratzol to & Bratzel 10 & Bratzol to \\
\hline & KIrch" & \begin{tabular}{|l|} 
Carothers \\
\end{tabular} & Gale & Gab & Qab & Tulberg & Tulberg & Tulberg \\
\hline & $11 / 19 / 80$ & $3 / 23 / 89$ & $3 / 29 / 85$ & $3 / 29 / 85$ & $3 / 29 / 85$ & $10 / 5 / 84$ & $10 / 5 / 84$ & $12 / 31 / 84$ \\
\hline Phase: & Llquild & Llquid & Llquild & Llquild & Llquild & \begin{tabular}{|l} 
Llquild \\
\end{tabular} & Liquild & Clquild \\
\hline Specle & $O / L$ & $9 / L$ & $0 / L$ & $9 / L$ & $9 / L$ & $9 / L$ & $9 / L$ & $g / L$ \\
\hline \multicolumn{9}{|l|}{ Aq } \\
\hline Al & $1.35 E+00$ & $2.2 y E+00$ & $6.58 E+00$ & $9.69 \mathrm{E}+00$ & $1.01 E+01$ & $1.40 E+00$ & $1.70 E+00$ & $1.75 E+00$ \\
\hline As & $2.25 E-03$ & & & & & & & \\
\hline$B$ & & $1.04 E-02$ & & & & & & \\
\hline \multicolumn{9}{|l|}{$\mathrm{Ba}$} \\
\hline \multicolumn{9}{|l|}{ BI } \\
\hline$a$ & $4.41 E-03$ & $7.21 \mathrm{E} \cdot 03$ & & & & $9.02 E-04$ & & \\
\hline cd & & & 5.91E-02 & $3.52 E \cdot 02$ & $2.56 \mathrm{E}-02$ & $6.60 E-03$ & $8.21 E-03$ & $1.04 E-02$ \\
\hline$C_{0}$ & & $2.38 E \cdot 02$ & & & & & & \\
\hline$C_{r}\left(V_{1}\right)$ & & $4.89 E-02$ & $1.15 E+00$ & $1.17 E+00$ & $1.20 E+00$ & $3.50 E-02$ & $4.40 E-02$ & \\
\hline $\mathrm{Cr}(\mathrm{TOU})$ & $9.88 E-03$ & $4.89 E-02$ & $1.15 E+00$ & $1.17 E+00$ & $1.20 E+00$ & $3.50 \mathrm{E}-02$ & $4.40 E-02$ & $5.09 E-02$ \\
\hline a & & $4.45 \mathrm{E}-03$ & $3.64 E \cdot 03$ & $3.27 E-03$ & $2.30 \mathrm{E}-03$ & & & \\
\hline \multicolumn{9}{|l|}{ Dy } \\
\hline Fo & $1.68 E-03$ & $4.47 E-03$ & $3.64 E-03$ & $5.98 \mathrm{E}-03$ & $6.25 E-03$ & $1.70 E-03$ & $2.80 \mathrm{E}-03$ & 5.92E-03 \\
\hline$K$ & $2.47 E+00$ & $1.02 E+00$ & $1.55 \mathrm{E}+00$ & $2.03 E+00$ & $1.97 E+00$ & $7.51 E-02$ & $8.99 \mathrm{E}-02$ & \\
\hline \multicolumn{9}{|l|}{ La } \\
\hline \multicolumn{9}{|l|}{$\mathrm{LI}$} \\
\hline $\operatorname{Ln}$ & $0.00 E+00$ & 2.67E-02 & $0.00 E+00$ & $0.00 E+00$ & $0.00 E+00$ & $0.00 E+00$ & $0.00 E+00$ & \\
\hline $\mathrm{Mg}$ & & & $3.65 E-03$ & $2.99 E-03$ & $2.31 E-03$ & $9.99 E-05$ & $1.10 \mathrm{E}-04$ & \\
\hline $\mathrm{Mn}$ & & & 3.64E-03 & $3.54 \mathrm{E}-03$ & $3.14 E-03$ & $1.05 E-04$ & $1.00 \mathrm{E}-04$ & $1.01 E-03$ \\
\hline \multicolumn{9}{|l|}{ Mo } \\
\hline $\mathrm{Na}$ & $2.00 E+01$ & $3.66 E+01$ & & & & & & \\
\hline \multicolumn{9}{|l|}{ Nd } \\
\hline $\mathrm{Ni}$ & & & & & & $3.00 \mathrm{E}-04$ & $3.00 E-04$ & $3.92 E+00$ \\
\hline$P$ & $9.29 E-02$ & $2.35 E-01$ & & & & $1.20 E-01$ & $1.50 E-01$ & \\
\hline \multicolumn{9}{|l|}{$P_{0}$} \\
\hline Ph & & & & & & & & \\
\hline$R$ & & & & & & & & \\
\hline So & & & & & & & & \\
\hline So & 2.37E-06 & & & & & & & \\
\hline s & 3.37E-02 & $7.02 E-02$ & & & & & & \\
\hline$S r$ & & & & & & & & \\
\hline To & & & & & & & & \\
\hline Th & & & & & & & & \\
\hline $\mathrm{TI}$ & & & & & & & & \\
\hline TI & & & & & & & & \\
\hline$U$ & $7.14 \mathrm{E}-03$ & & & & & & & \\
\hline$V$ & & & & & & & & \\
\hline $\mathrm{Zn}$ & $1.31 \mathrm{E}-03$ & & & & & & & \\
\hline $\mathrm{Zr}$ & & & & & & & & \\
\hline Tot Meta & $2.40 E+01$ & $4 . v 3 E+01$ & $1.05 E+01$ & $1.41 E+01$ & $1.45 E+01$ & $1.67 E+00$ & $2.04 E+00$ & $5.74 E+00$ \\
\hline & & & & & & & & \\
\hline
\end{tabular}


Llquid. Values

SY-102 LIOUID COMPOSITIONS

\begin{tabular}{|c|c|c|c|c|c|c|c|c|}
\hline \multicolumn{2}{|c|}{ 8ample $11102 S Y 1.2$} & 1028YSuper & A.3310 & R-3317 & R-3318 & R.3037 & A.3038 & R.3326 \\
\hline Anlone & $g / L$ & $\begin{array}{ll}/ L \\
\end{array}$ & $g / L$ & $9 / \mathrm{L}$ & $g / L$ & $9 / 6$ & $9 / L$ & $9 / 2$ \\
\hline$F$ & $5.13 E-01$ & $2.85 E-01$ & $2.51 E+00$ & $2.07 E+00$ & $1.58 E+00$ & $7.33 \mathrm{E} .02$ & $1.59 E+00$ & $5.17 E .02$ \\
\hline a & $1.60 E+00$ & $2.80 \mathrm{E} \cdot 01$ & $4.75 E+00$ & $5.50 E+00$ & $5.96 \mathrm{E}+00$ & & $5.96 E+00$ & \\
\hline $\mathrm{NO2}$ & $2.02 E+00$ & & $7.30 \mathrm{E}+01$ & $7.64 E+01$ & $7.59 E+01$ & $1.80 E+00$ & $7.59 E+01$ & $2.20 E+00$ \\
\hline $\mathrm{NO} 3$ & $2.34 E+01$ & $3.50 E+01$ & $1.71 E+02$ & $2.15 E+02$ & $2.15 E+02$ & $2.86 E+01$ & $2.15 E+02$ & $3.53 E+01$ \\
\hline POA & $7.60 \mathrm{E}-01$ & $1.42 E+00$ & $6.76 E+00$ & $4.94 E+00$ & $4.42 E+00$ & $3.67 E \cdot 01$ & $4.42 E+00$ & $4.28 E .01$ \\
\hline SO4 & $7.68 E-01$ & $1.44 E+00$ & $4.61 E+01$ & $2.07 E+01$ & $1.58 E+01$ & 3.85E-01 & $1.58 E+01$ & $3.25 E-01$ \\
\hline$\infty$ & $3.78 E+00$ & $2.76 E+00$ & $3.38 E+01$ & $3.73 E+01$ & $4.30 E+01$ & & $4.30 E+01$ & $2.23 E+00$ \\
\hline $\mathrm{OH}$ & $6.82 E+00$ & $8.92 E+00$ & $1.61 E+01$ & $2.48 E+01$ & $2.33 E+01$ & $6.90 \mathrm{E}+00$ & $2.33 E+01$ & $8.03 E+00$ \\
\hline Tot Anlo & $3.97 E+01$ & $1.29 E+02$ & $3.54 E+02$ & $3.86 E+02$ & $3.85 E+02$ & $3.81 E+01$ & $3.85 E+02$ & $4.86 \mathrm{E}+01$ \\
\hline & & & & & & & & \\
\hline Tot Ora 1 & $2.08 E \cdot 04$ & $5.55 E+00$ & & & & & $2.39 E-04$ & $2.28 E-04$ \\
\hline & & & & & & & & \\
\hline Tol Com & $6.37 E+01$ & $2.63 E+02$ & $3.65 E+02$ & $4.00 E+02$ & $3.98 E+02$ & $3.98 E+01$ & $3.87 E+02$ & $5.43 E+01$ \\
\hline & & & & & & & & \\
\hline TAU & UCIIL & uCI/L & uCI/L & UCI/L & $\mathrm{uCI} / \mathrm{L}$ & $\mathrm{uCI} / \mathrm{L}$ & $4 \mathrm{CI} / \mathrm{L}$ & UCI/L \\
\hline Am-241 & & $1.28 E+00$ & $1.02 E+01$ & & $1.90 \mathrm{E}+01$ & $1.08 E+00$ & $2.76 E+01$ & \\
\hline $\mathrm{Cm}-243$ & & & & & & & & \\
\hline $\mathrm{Cm} \cdot 244$ & & & & & & & & \\
\hline$C_{m-24 x}$ & & & & & & & & \\
\hline Np.237 & & & & & & & & \\
\hline Pu-238 & & & & & & & & \\
\hline Pu-239 & $1.60 \mathrm{E} \cdot 01$ & $1.00 E+00$ & $1.92 E+00$ & $7.06 E+00$ & 9.27E+00 & & & \\
\hline Pu-240 & & & & & & & & \\
\hline Pu-241 & & & & & & $3.00 E+01$ & $6.75 E+01$ & $2.11 E+01$ \\
\hline Pu-242 & & & & & & & & \\
\hline Pu-244 & & & & & & & & \\
\hline n-TRUs & UCI/L & UCI/L & UCI/L & $\mathrm{UCI} / \mathrm{L}$ & UCI/L & $\mathrm{UCI/L}$ & $\mathrm{UCI/L}$ & $\mathrm{UCI} / \mathrm{L}$ \\
\hline $\mathrm{H}-3$ & & & & & & & & \\
\hline C. 14 & $2.30 E-02$ & & & & & . & & \\
\hline 1.129 & & & & & & & & \\
\hline $\mathrm{Nb}-94$ & & & & & & & & \\
\hline $\mathrm{N} 1-63$ & & & & & & & & \\
\hline So.79 & & & & & & & & \\
\hline Sr-90 & $1.75 E+00$ & & $8.84 E+02$ & $1.67 E+03$ & $1.79 E+03$ & & & $1.29 E+00$ \\
\hline Tc-99 & & $1.00 E+01$ & & & & & & \\
\hline Co.144 & & & & & & & & \\
\hline Co.60 & & & & & & & & \\
\hline C8-134 & & & & & & & & \\
\hline Cs-137 & $3.90 E+03$ & $1.02 E+04$ & $2.54 E+05$ & $3.21 E+05$ & $3.06 \mathrm{E}+05$ & $5.35 E+03$ & $6.55 E+03$ & $6.61 E+03$ \\
\hline Eu-152 & & & & & & & & \\
\hline Eu-154 & & & & & & & & \\
\hline Eu-155 & & & & & & & & \\
\hline$R u-106$ & & & & & & & & \\
\hline Sb-125 & & & & & & & & \\
\hline$Z_{r-95}$ & & & & & & & & \\
\hline & & & & & & & & \\
\hline Tot TRUs & $1.60 \mathrm{E}-01$ & $2.28 E+00$ & $1.21 E+01$ & $7.06 \mathrm{E}+00$ & $2.83 E+01$ & $3.11 E+01$ & $8.51 E+01$ & $2.11 E+01$ \\
\hline Tot n-TRI & $3.90 E+03$ & $1.02 E+04$ & $2.55 E+05$ & $3.23 E+05$ & $3.08 E+05$ & $5.35 \mathrm{E}+03$ & $6.55 E+03$ & $6.61 E+03$ \\
\hline Tot Radl. & $3.90 E+03$ & $1.02 E+04$ & $2.55 \mathrm{E}+05$ & $3.23 E+05$ & $3.08 E+05$ & $5.38 E+03$ & $6.65 E+03$ & $6.63 E+03$ \\
\hline
\end{tabular}


Liquild.Values

SY.102 LLOUID COMPOSITIONS

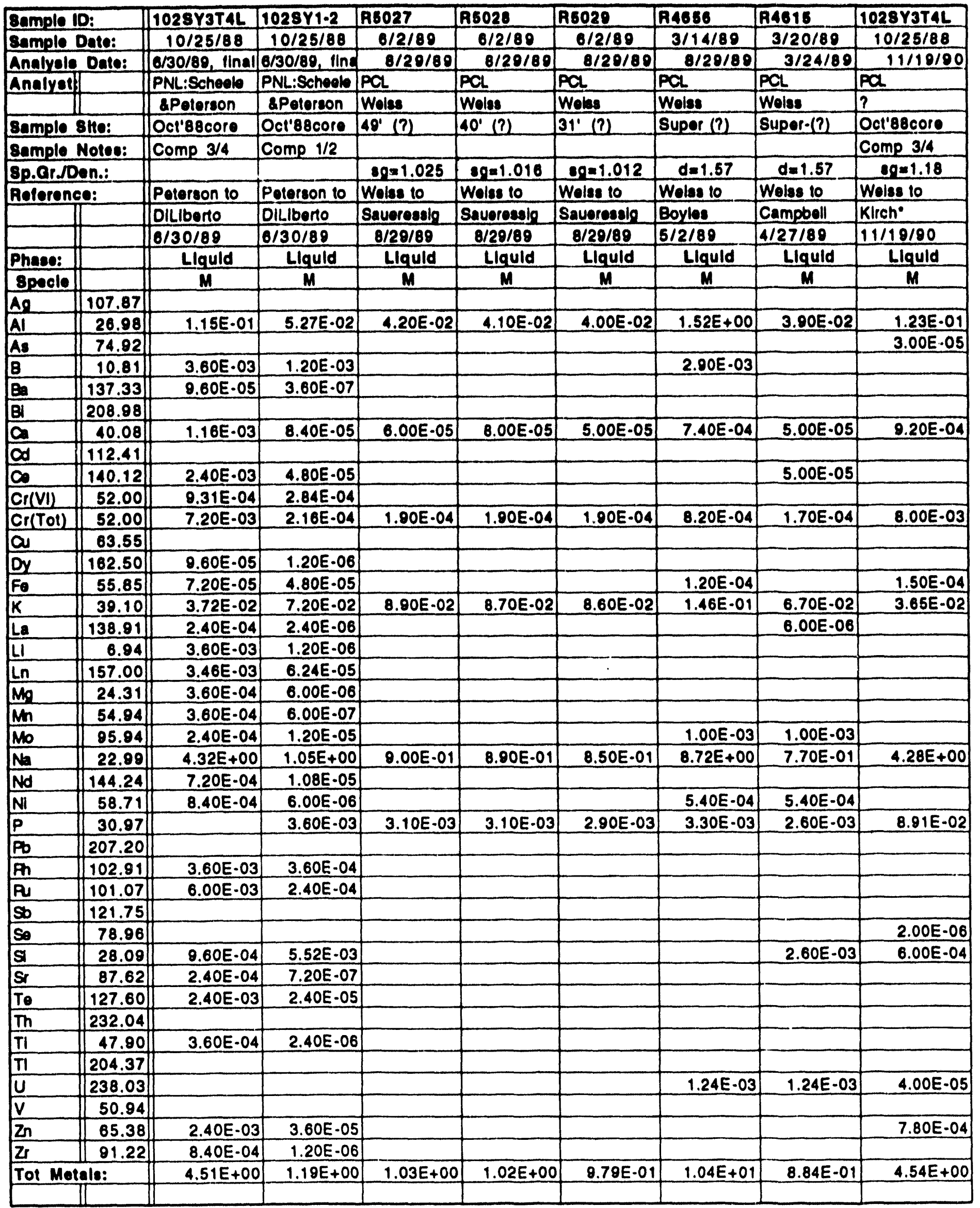


Lquild.Values

SY-102 LIOUID COMPOSITIONS

\begin{tabular}{|c|c|c|c|c|c|c|c|c|c|}
\hline \multicolumn{2}{|c|}{ Eample 1D: } & \multirow{2}{*}{$\frac{1028 \text { YaTAL }}{M}$} & \multirow{2}{*}{$\frac{1028 Y 1.2}{M}$} & \multirow{2}{*}{$\frac{85027}{M}$} & \multirow{2}{*}{$\frac{\text { A6020 }}{M}$} & \multirow{2}{*}{$\frac{\mathrm{A5020}}{\mathrm{M}}$} & \multirow{2}{*}{$\frac{94686}{M}$} & \multirow{2}{*}{\begin{tabular}{|c|} 
R4616 \\
$M$ \\
\end{tabular}} & \multirow{2}{*}{\begin{tabular}{|c|} 
1028Y3T4L \\
$M$ \\
\end{tabular}} \\
\hline Anlone & & & & & & & & & \\
\hline$F$ & 19.00 & & & \begin{tabular}{|c|}
$4.00 E .02$ \\
\end{tabular} & $3.00 E \cdot 02$ & $3.00 E .02$ & $0.80 \mathrm{E} \cdot 02$ & $3.40 E .02$ & 2.70 E.02 \\
\hline$a$ & 35.45 & & & $4.40 \mathrm{E} .03$ & $4.50 E \cdot 03$ & 4.50E-03 & $5.50 E-03$ & $6.20 E \cdot 03$ & 5.00E.02 \\
\hline NO2 & 46.01 & & & $5.10 E \cdot 02$ & $4.90 E-02$ & $5.10 E \cdot 02$ & $4.30 E-02$ & $3.70 E+00$ & $5.14 E .01$ \\
\hline $\mathrm{NOS}$ & 62.00 & & & $3.50 E-01$ & $3.40 \mathrm{E}-01$ & $3.40 E-01$ & $2.08 E+00$ & $3.50 E-01$ & $1.70 E+00$ \\
\hline POA & 04.07 & & & $2.40 E .03$ & $2.50 E .03$ & $2.50 \mathrm{E} \cdot 03$ & $5.50 E-02$ & $1.40 E-03$ & $7.06 \mathrm{E}-02$ \\
\hline 804 & 06.08 & & & $1.30 E-03$ & $1.30 E \cdot 03$ & $1.30 E \cdot 03$ & $1.01 \mathrm{E}+00$ & $8.10 E \cdot 03$ & $6.80 \mathrm{E}-02$ \\
\hline$\infty$ & 60.01 & & & & & & & & $4.30 E-01$ \\
\hline $\mathrm{aH}$ & 17.01 & & & & & & $1.02 E+00$ & & $7.60 E \cdot 01$ \\
\hline \multicolumn{2}{|c|}{ Tor Anlons: } & $0.00 E+00$ & $0.00 E+00$ & $2.48 E+00$ & $2.44 E+00$ & $2.36 E+00$ & $2.35 E+01$ & $5.63 E+00$ & $1.26 E+01$ \\
\hline & & & & & & & & & \\
\hline \multicolumn{2}{|c|}{ Tot Org C: } & & & & & & $1.25 E+01$ & & $2.20 E+00$ \\
\hline & & & & & & & & & \\
\hline \multicolumn{2}{|c|}{ Tot Comp: } & $4.51 E+00$ & $1.10 E+00$ & $4.86 E+00$ & $4.79 E+00$ & $4.62 E+00$ & $5.05 E+01$ & $1.16 E+01$ & $2.72 E+01$ \\
\hline & & & & & & & & & \\
\hline TRE & & UCI/L & UCI/L & uCI/L & uCl/L & $\mathrm{UCI} / \mathrm{L}$ & $\mathrm{UCI} / \mathrm{L}$ & $\mathrm{uCI} / \mathrm{L}$ & $4 \mathrm{CI} / \mathrm{L}$ \\
\hline$A m-241$ & 241.06 & $6.07 E+04$ & & $3.20 E \cdot 02$ & $1.50 \mathrm{E} \cdot 01$ & $4.10 E .02$ & $8.70 E-01$ & $3.30 \mathrm{E} \cdot 02$ & \\
\hline Cm-243 & 243.00 & & & & & & & & \\
\hline $\mathrm{Cm}-244$ & 244.00 & & & & & & & & \\
\hline$C_{m-24 x}$ & 243.56 & $2.88 E+02$ & $2.88 E+02$ & & & & & & \\
\hline Np.237 & 237.05 & $1.56 E+00$ & $1.56 E+00$ & & & & & & \\
\hline Pu-238 & 238.05 & $1.62 E+03$ & $1.62 E+03$ & & & & & & \\
\hline PU-239 & 230.05 & $1.17 E+04$ & $1.17 E+04$ & $1.00 E-01$ & $1.00 E \cdot 01$ & $1.10 \mathrm{E} \cdot 01$ & $4.53 E+00$ & $4.40 E .02$ & $1.60 \mathrm{E} \cdot 01$ \\
\hline Pu-240 & 240.05 & $4.08 E+03$ & $4.08 E+03$ & & & & & & \\
\hline$P u-241$ & 241.06 & $1.40 E+05$ & $1.40 E+05$ & & & & & & \\
\hline Pu-242 & 242.00 & & & & & & & & \\
\hline Pu-244 & 244.00 & & & & & & & & \\
\hline n-TRUs & & $\mathrm{UCK} / \mathrm{L}$ & uCI/L & UCI/L & UCI/L & UCI/L & UCI/L & UCI/L & $4 \mathrm{CI} / \mathrm{L}$ \\
\hline $\mathrm{H}-3$ & 3.02 & $9.55 E-02$ & 9.55E-02 & & & & & & \\
\hline C.14 & 14.00 & & & & & . & & & $2.30 E-02$ \\
\hline 1.129 & 129.00 & $36 \mathrm{E} \cdot 02$ & $3.36 E-02$ & & & & & & \\
\hline Nb-94 & 04.00 & $3.72 E-03$ & $3.72 E \cdot 03$ & & & & & & \\
\hline NI-63 & 63.00 & $2.28 E-01$ & 2.28E-01 & & & & & & \\
\hline So-79 & 79.00 & 28E-01 & $7.28 E-01$ & & & & & & \\
\hline Sr-90 & 80.00 & & & 5.20E-01 & $5.40 E \cdot 01$ & 5.20E-01 & $1.58 E+03$ & $5.00 E-01$ & $1.75 E+00$ \\
\hline \begin{tabular}{|l|} 
Tc-99 \\
\end{tabular} & 99.00 & $6.46 E+01$ & $6.46 E+01$ & $2.89 E+00$ & $2.99 E+00$ & $2.93 E+00$ & $3.69 E+02$ & $2.50 E+00$ & \\
\hline $\mathrm{Co}_{0} 144$ & 144.00 & & & & & & & & \\
\hline Co-60 & 60.00 & & & & & & & & \\
\hline$C_{8-134}$ & 134.00 & & & & & & & & \\
\hline Cs-137 & 137.00 & & & $5.30 E+03$ & $5.10 E+03$ & $5.10 E+03$ & $6.96 \mathrm{E}+05$ & $4.67 E+03$ & $3.90 E+03$ \\
\hline Eu-152 & 152.00 & & & & & & & & \\
\hline Eu-154 & 154.00 & & & & & & & & \\
\hline Eu-155 & 155.00 & & & & & & & & \\
\hline$R_{u-106}$ & 106.00 & & & & & & & & \\
\hline Sb-125 & 125.00 & & & & & & & & \\
\hline 21.05 & 91.22 & & & & & & & & \\
\hline & & & & & & & & & \\
\hline Tot TRU & & $2.19 E+05$ & $1.58 E+05$ & $1.32 E-01$ & $2.50 E-01$ & $1.51 \mathrm{E}-01$ & $5.40 E+00$ & $7.70 \mathrm{E}-02$ & $1.60 \mathrm{E}-01$ \\
\hline Tol n-TR & & $6.56 E+01$ & $6.56 \mathrm{E}+01$ & $5.30 E+03$ & $5.10 E+03$ & $5.10 E+03$ & $6.08 E+05$ & $4.67 E+03$ & $3.80 E+03$ \\
\hline Tol Rad & lonucllde & $2.19 E+05$ & $1.58 E+05$ & $5.30 \mathrm{E}+03$ & $5.10 E+03$ & $5.10 E+03$ & $6.08 E+05$ & $4.67 E+03$ & $3.90 E+03$ \\
\hline
\end{tabular}


Llquid.Values

SY-102 LIOUID COMPOSITIONS

\begin{tabular}{|c|c|c|c|c|c|c|c|c|}
\hline \multirow{2}{*}{\multicolumn{2}{|c|}{$\frac{\text { 8ample ll1028Y1-2 }}{\text { sample / } 10 / 25 / 88}$}} & 1028Y8uper & A.3316 & R.3317 & A.3318 & R-3037 & A-3038 & R-3328 \\
\hline & & $6 / 1 / 88$ & $11 / 1 / 84$ & $11 / 1 / 84$ & $11 / 1 / 84$ & $11 / 1 / 84$ & $11 / 1 / 84$ & $?$ \\
\hline \multirow{3}{*}{$\begin{array}{l}\text { Analyale } \\
\text { Analyae: }\end{array}$} & $11 / 19 / 80$ & $3 / 23 / 80$ & $3 / 29 / 85$ & $3 / 29 / 85$ & $3 / 20 / 85$ & $10 / 5 / 84$ & $10 / 5 / 84$ & $12 / 31 / 84$ \\
\hline & $P Q$ & $\mathrm{PCL}$ & Rockwell & Rockwell & Rockwell & Pockwoll & Rockwell & Rochwall \\
\hline & $?$ & Woles & Bratzel & Bratzel & Bratzel & Bratzel & Bratzel & Bratzel \\
\hline \multicolumn{2}{|c|}{ sample foct'B8core } & $?$ & 6:bollom & 6 , bollom & 0. bollom & 100 & middle & $?$ \\
\hline \multicolumn{2}{|c|}{ Eample IComp 1/2 } & Hloh value & & & & & & \\
\hline \multirow{2}{*}{\multicolumn{2}{|c|}{$\begin{array}{l}\text { 8p.Ordor } \quad 1.02 \\
\text { Roferene Woles to }\end{array}$}} & $d=1(?)$ & $d=1.41$ & $d=1.44$ & $d=1.42$ & $89=1.03$ & $90=1.06$ & $89=1.06$ \\
\hline & & Woles (PCL) id & Bralzel to & Bratzel to & Braczel to & Bratzel 10 & Bralzel to & Bratzel to \\
\hline & ||Klrah* & Carothers & Cale & Gale & Cab & Tulberg & Tulborg & Tulberg \\
\hline & $11 / 10 / 90$ & $3 / 23 / 80$ & $3 / 20 / 85$ & $3 / 20 / 85$ & $3 / 29 / 85$ & $10 / 5 / 84$ & $10 / 5 / 84$ & $12 / 31 / 84$ \\
\hline Phase: & Llauld & Llquid & Llquild & Llquid & Llquid & Llquild & Llquild & Llquild \\
\hline 8pecle & $M$ & $M$ & $M$ & $M$ & $M$ & $\mathbf{M}$ & $\mathbf{M}$ & $M$ \\
\hline \multicolumn{9}{|l|}{$A_{0}$} \\
\hline Al & $5.00 \mathrm{E}-02$ & $8.50 \mathrm{E}-02$ & 2.44E-01 & $3.59 E-01$ & $3.75 E-01$ & $5.19 E-02$ & $6.30 E-02$ & $6.50 \mathrm{E} \cdot 02$ \\
\hline As & $3.00 E-05$ & & & & & & & \\
\hline $\mathbf{B}$ & & $0.60 \mathrm{E}-04$ & & & & & & \\
\hline \multicolumn{9}{|l|}{$B$} \\
\hline \multicolumn{9}{|l|}{ B } \\
\hline a & $1.10 \mathrm{E}-04$ & $1.80 E-04$ & & & & 2.25E-05 & & \\
\hline$\infty$ & & & $5.26 E-04$ & $3.13 E \cdot 04$ & 2.28E-04 & 5.87E-05 & 7.30E-05 & 9.24E-05 \\
\hline$\infty$ & & $1.70 E-04$ & & & & & & \\
\hline Cr(Vi) & & $9.40 E-04$ & $2.22 E-02$ & $2.25 \mathrm{E}-02$ & $2.30 E-02$ & $6.73 E-04$ & $8.46 E-04$ & \\
\hline Cr(Tol) & $1.90 \mathrm{E}-04$ & $9.40 \mathrm{E}-04$ & 2.22E-02 & $2.25 E-02$ & $2.30 \mathrm{E}-02$ & $6.73 E \cdot 04$ & $8.46 \mathrm{E}-04$ & 9.70E-04 \\
\hline a & & $7.00 E-05$ & 5.73E-05 & $5.15 E-05$ & $3.62 E-05$ & & & \\
\hline \multicolumn{9}{|l|}{ Dy } \\
\hline Fo & $3.00 \mathrm{E}-05$ & $8.00 \mathrm{E}-05$ & 6.52E-05 & $1.07 E-04$ & $1.12 E-04$ & 3.04E-05 & 5.01E-05 & $1.06 E-04$ \\
\hline $\mathbf{K}$ & 6.32E-02 & $2.61 E-02$ & 3.97E-02 & 5.20E-02 & 5.03E-02 & $1.92 E-03$ & $2.30 \mathrm{E} \cdot 03$ & \\
\hline \multicolumn{9}{|l|}{ Le } \\
\hline \multicolumn{9}{|l|}{ LI } \\
\hline $\operatorname{Ln}$ & $0.00 E+00$ & $1.70 E-04$ & $0.00 E+00$ & $0.00 E+00$ & $0.00 E+00$ & $0.00 E+00$ & $0.00 E+00$ & \\
\hline $\mathbf{M g}$ & & & $1.50 E-04$ & $1.23 E-04$ & $0.49 E-05$ & $4.11 E-06$ & $4.52 E-06$ & \\
\hline $\operatorname{Mn}$ & & & $6.62 E-05$ & $6.45 E-05$ & $5.72 E-05$ & 1.92E.06 & $1.82 E-08$ & $1.84 E \cdot 05$ \\
\hline \multicolumn{9}{|l|}{ Mo } \\
\hline$N$ & 8.71E-01 & $1.59 E+00$ & & & & & & \\
\hline \multicolumn{9}{|l|}{ No } \\
\hline $\mathbf{N}$ & & & & & & $5.11 E-06$ & 5.11E-06 & $6.68 E-02$ \\
\hline $\mathbf{p}$ & $3.00 \mathrm{E}-03$ & $7.60 \mathrm{E}-03$ & & & & $3.87 \mathrm{E}-03$ & $4.84 E-03$ & \\
\hline \multicolumn{9}{|l|}{$\mathbf{P O}$} \\
\hline \multicolumn{9}{|l|}{ F } \\
\hline $\mathbf{P u}_{\mathbf{u}}$ & & & & & & & & \\
\hline 50 & & & & & & & & \\
\hline So & $3.00 E-08$ & & & & & & & \\
\hline $\mathbf{s}$ & $1.20 E-03$ & $2.50 E-03$ & & & & & & \\
\hline Sr & & & & & & & & \\
\hline To & & & & & & & & \\
\hline Th & & & & & & & & \\
\hline$\pi$ & & & & & & & & \\
\hline$T$ & & & & & & & & \\
\hline$U$ & $3.00 E-05$ & & & & & & & \\
\hline V & & & & & & & & \\
\hline Zn & $2.00 E-05$ & & & & & & & \\
\hline $\mathbf{Z}_{\mathbf{r}}$ & & & & & & & & \\
\hline Tot Mete & 9.89E-01 & $1.71 E+00$ & 3.07E-01 & 4.34E-01 & 4.49E-01 & 5.85E-02 & 7.11E-02 & 1.33E-01 \\
\hline & & & & & & & & \\
\hline
\end{tabular}


Llquid.Values

SY.102 LIOUID COMPOSITIONS

\begin{tabular}{|c|c|c|c|c|c|c|c|c|}
\hline \multicolumn{2}{|c|}{ Sample II102SY1.2 } & \multirow{2}{*}{$\frac{102 \text { SYSuper }}{M}$} & \multirow{2}{*}{$\frac{A .3316}{M}$} & \multirow{2}{*}{$\frac{A .3317}{M}$} & \multirow{2}{*}{$\frac{R .3318}{M}$} & \multirow{2}{*}{$\frac{R-3037}{M}$} & \multirow{2}{*}{$\frac{R-3038}{N}$} & \multirow{2}{*}{$\frac{R-3326}{M}$} \\
\hline Anlons & $M$ & & & & & & & \\
\hline$F$ & $2.70 \mathrm{E}-02$ & $1.50 E-02$ & $1.32 \mathrm{E} \cdot 01$ & $1.09 E-01$ & 8.36E-02 & $3.86 \mathrm{E}-03$ & 8.36E-02 & 2.72E.03 \\
\hline a & $4.50 E-02$ & $7.90 \mathrm{E} \cdot 03$ & $1.34 \mathrm{E} \cdot 01$ & $1.55 E-01$ & $1.68 E-01$ & & $1.68 E-01$ & \\
\hline $\mathrm{NO2}$ & 4.38E-02 & & $1.60 \mathrm{E}+00$ & $1.66 E+00$ & $1.65 E+00$ & $3.01 E-02$ & $1.65 E+00$ & 4.70E.02 \\
\hline $\mathrm{NOS}$ & $3.78 E-01$ & 5.64E-01 & $2.75 E+00$ & $3.46 E+00$ & $3.46 E+00$ & 4.61E-01 & $3.46 E+00$ & 5.70E-01 \\
\hline POA & $8.00 \mathrm{E}-03$ & $1.50 \mathrm{E} \cdot 02$ & $7.12 E .02$ & $5.20 E \cdot 02$ & $4.65 E \cdot 02$ & $3.86 E-03$ & $4.65 E \cdot 02$ & 4.51E.03 \\
\hline $\mathrm{SO4}$ & $8.00 \mathrm{E}-03$ & $1.50 \mathrm{E}-02$ & $4.80 \mathrm{E} \cdot 01$ & $2.15 E-01$ & $1.65 E-01$ & $4.01 E-03$ & $1.65 \mathrm{E}-01$ & $3.38 E \cdot 03$ \\
\hline$\infty$ & $6.30 \mathrm{E}-02$ & $4.60 \mathrm{E}-02$ & 5.63E.01 & $6.21 E \cdot 01$ & $7.16 E-01$ & & $7.16 E-01$ & $3.71 E-02$ \\
\hline $\mathrm{OH}$ & 4.01E-01 & $5.83 E-01$ & 9.47E.01 & $1.46 E+00$ & $1.37 E+00$ & $4.06 \mathrm{E} \cdot 01$ & $1.37 E+00$ & 4.72E.01 \\
\hline Tot Anlo & $2.90 \mathrm{E}+00$ & $4.59 E+00$ & $7.02 E+00$ & $8.22 E+00$ & $8.16 \mathrm{E}+00$ & 9.82E-01 & $7.74 E+00$ & $1.34 E+00$ \\
\hline Tot Org 1 & $2.12 E \cdot 01$ & $4.62 \mathrm{E}-01$ & & & & & 2.53E-01 & $2.42 \mathrm{E}-01$ \\
\hline Tol Com & $5.95 E+00$ & $9.60 E+00$ & $1.40 E+01$ & $1.64 E+01$ & $1.63 E+01$ & $1.96 \mathrm{E}+00$ & 1.57E+01 & $2.92 E+00$ \\
\hline & & & & & & & & \\
\hline TRls & uCI/L & $\mathrm{uCl} / \mathrm{L}$ & $\mathrm{uCl} / \mathrm{L}$ & UCIIL & uCI/L & UCIRL & uCI/L & $\triangle \mathrm{Cl} / \mathrm{L}$ \\
\hline Am-241 & & $1.28 \mathrm{E}+00$ & $1.02 E+01$ & & $1.90 \mathrm{E}+01$ & $1.08 E+00$ & $2.76 \mathrm{E}+01$ & \\
\hline $\mathrm{Cm}-243$ & & & & & & & & \\
\hline $\mathrm{Cm} \cdot 244$ & & & & & & & & \\
\hline Cm-24x & & & & & & & & \\
\hline Np.237 & & & & & & & & \\
\hline Pu-238 & & & & & & & & \\
\hline Pu.239 & $1.60 \mathrm{E}-01$ & $1.00 E+00$ & $1.92 E+00$ & $7.06 E+00$ & $9.27 E+00$ & & & \\
\hline Pu-240 & & & & & & & & \\
\hline Pu-241 & & & & & & $3.00 E+01$ & $6.75 E+01$ & $2.11 E+01$ \\
\hline Pu-242 & & & & & & & & \\
\hline Pu-244 & & & & & & & & \\
\hline n-True & $4 \mathrm{CI} / \mathrm{L}$ & $\mathrm{uCI/L}$ & UCI/L & $\mathrm{UCI} / \mathrm{L}$ & $\mathrm{UCl} / \mathrm{L}$ & uCI/L & $\mathrm{UCl} / \mathrm{L}$ & $\mathrm{UCI} / \mathrm{L}$ \\
\hline $\mathrm{H}-3$ & & & & & & & & \\
\hline C.14 & $2.30 E-02$ & & & & & & & \\
\hline 1.129 & & & & & & & & \\
\hline $\mathrm{Nb} .94$ & & & & & & & & \\
\hline $\mathrm{N} 1.63$ & & & & & & & & \\
\hline So.79 & & & & & & & & \\
\hline Sr.90 & $1.75 E+00$ & & $8.84 E+02$ & $1.67 E+03$ & $1.79 \mathrm{E}+03$ & & & $1.29 E+00$ \\
\hline Tc.99 & & $1.00 E+01$ & & & & & & \\
\hline Co-144 & & & & & & & & \\
\hline Co.60 & & & & & & & & \\
\hline C8.134 & & & & & & & & \\
\hline C8.137 & $3.00 E+03$ & $1.02 E+04$ & $2.54 E+05$ & $3.21 E+05$ & $3.06 E+05$ & $5.35 E+03$ & $6.55 E+03$ & $6.61 E+03$ \\
\hline Eu-152 & & & & & & & & \\
\hline Eu-154 & & & & & & & & \\
\hline Eu-155 & & & & & & & & \\
\hline$R_{u}-106$ & & & & & & & & \\
\hline $\mathrm{Sb}-125$ & & & & & & & & \\
\hline $\mathrm{Zr}-95$ & & & & & & & & \\
\hline & & & & & & & & \\
\hline Tot TRUs & $1.60 E-01$ & $2.28 E+00$ & $1.21 E+01$ & $7.06 E+00$ & $2.83 E+01$ & $3.11 E+01$ & $9.51 E+01$ & $2.11 E+01$ \\
\hline Tot n-TRI & $3.90 E+03$ & $1.02 E+04$ & $2.55 \mathrm{E}+05$ & $3.23 E+05$ & $3.08 E+05$ & $5.35 E+03$ & $6.55 E+03$ & $6.61 E+03$ \\
\hline Tot Radh & $3.90 E+03$ & $1.02 E+04$ & $2.55 E+05$ & $3.23 E+05$ & $3.08 E+05$ & $5.3(15+03$ & $6.65 E+03$ & $6.63 E+03$ \\
\hline
\end{tabular}




\section{SY-102 SOLID COMPOSITIONS}

Filename: Solid.Values 


\begin{tabular}{|c|c|c|c|c|c|c|c|c|c|c|c|}
\hline \multirow{2}{*}{\multicolumn{2}{|c|}{\begin{tabular}{|l} 
Sample ID: \\
Sample Dato:
\end{tabular}}} & $102-S Y \cdot 4 B$ & $102 S Y 3 T 4 S$ & 102SY3T4S & $102 S Y 3 T 4 S$ & 102SYSollds & R-3316 & R-3317 & R-3318 & R-3316 & R-3036 \\
\hline & & $10 / 25 / 88$ & $10 / 25 / 88$ & $10 / 25 / 88$ & $10 / 25 / 88$ & $7 / 1 / 88$ & $11 / 1 / 84$ & $11 / 1 / 84$ & $11 / 1 / 84$ & $11 / 1 / 84$ & \begin{tabular}{|c|}
$?$ \\
\end{tabular} \\
\hline \multicolumn{2}{|c|}{ Analysis Date: } & $6 / 30 / 89$ & $6 / 30 / 89$ & $7 / 6 / 90$ & & $3 / 23 / 89$ & $3 / 29 / 85$ & $3 / 29 / 85$ & $3 / 29 / 85$ & $1 / 10 / 85$ & $10 / 5 / 84$ \\
\hline \multirow[t]{2}{*}{ Analyset } & & PNL: Scheole & PNL: Scheole & PCL: Herting & & PCL: Weiss & Rockwell AL: & Rockwell AL: & Rockwell AL: & Rockwell AL: & Rockwell AL: \\
\hline & & \& Peterson & 2 Peterson & & & & Bratzel & Bratzel & Bratzel & Bratzel & Bratzel \\
\hline \multicolumn{2}{|c|}{ Sample Site: } & Oct'88core & Oct'88core & Oct '88 core & Oct '88 coro & $?$ & $6^{\circ}$, bottom & 6", bottom & 6", bottom & $6^{\circ}$. bottom & bottom (?) \\
\hline \multicolumn{2}{|c|}{ Sample Notes: } & Segment 4 & Comp 3/4 & & $d=1.5$ (est) & \begin{tabular}{|l|} 
High values \\
\end{tabular} & Cent. solids & Cent. solids & Cent. solids & $d=1.54$ & $d=1.65(?)$ \\
\hline \multicolumn{2}{|c|}{ Reforence: } & Peterson to & Peterson to & Herting to & Kirkbride to & Weiss (PCL) & Bratzel to & Bratzel to & Bratzel to & Bratzel to & Bratzel to \\
\hline & & Diliberto & Diliberto & Sasakd & Orme & to Carothers & Gale & Gale & Gale & Gale & Tulberg \\
\hline & & $6 / 30 / 89$ & $6 / 30 / 89$ & $7 / 6 / 90$ & $12 / 10 / 92$ & $3 / 23 / 89$ & $3 / 29 / 85$ & $3 / 29 / 85$ & $3 / 29 / 85$ & $1 / 10 / 85$ & $10 / 5 / 84$ \\
\hline Phase: & & \begin{tabular}{|l|l} 
Solld \\
\end{tabular} & \begin{tabular}{|l|} 
Solld \\
\end{tabular} & Solld & \begin{tabular}{|l|} 
Solld \\
\end{tabular} & \begin{tabular}{|l|l} 
\\
Solld
\end{tabular} & Solld & Solld & Solld & Solld & Solid \\
\hline Specie & Mass & $w 1 \%$ & $w t \%$ & $w t \%$ & $w t \%$ & $w t \%$ & $w 1 \%$ & $w t \%$ & $w i \%$ & $w t \%$ & $w t \%$ \\
\hline $\mathrm{Ag}$ & 107.87 & & & & $0.0144 \%$ & & & & & & \\
\hline Al & \begin{tabular}{|l|}
26.98 \\
\end{tabular} & $4.8027 \%$ & $3.4806 \%$ & $9.0000 \%$ & $3.2378 \%$ & $0.8800 \%$ & $9.2100 \%$ & $7.3000 \%$ & $7.7500 \%$ & $5.2013 \%$ & $16.0000 \%$ \\
\hline As & 74.92 & $0.6818 \%$ & & & $0.0499 \%$ & & & & & & \\
\hline$B$ & 10.81 & $0.0173 \%$ & $0.0195 \%$ & & $0.0144 \%$ & $0.0030 \%$ & & & & & \\
\hline $\mathrm{Ba}$ & 137.33 & $0.0027 \%$ & $0.0093 \%$ & & & & & & & & \\
\hline B & 208.98 & & & & & $0.0540 \%$ & & & & & \\
\hline $\mathrm{Ca}$ & 40.08 & $0.0421 \%$ & $0.5691 \%$ & $0.7100 \%$ & $0.4542 \%$ & $0.7590 \%$ & & & & & $0.4500 \%$ \\
\hline Cd & 112.41 & & & & $0.0600 \%$ & $0.0610 \%$ & $0.0324 \%$ & $0.0150 \%$ & $0.0164 \%$ & $0.0183 \%$ & $0.2200 \%$ \\
\hline $\mathrm{Ce}$ & 140.12 & $0.0420 \%$ & $0.0560 \%$ & & $0.0654 \%$ & $0.0240 \%$ & & & & & \\
\hline $\mathrm{Cr}(\mathrm{V})$ & 52.00 & $0.1279 \%$ & $0.1549 \%$ & $0.4300 \%$ & $0.1040 \%$ & $0.0820 \%$ & $3.6300 \%$ & $2.9900 \%$ & $4.1900 \%$ & $2.0584 \%$ & $9.1700 \%$ \\
\hline $\mathrm{Cr}(\mathrm{Tol})$ & 52.00 & $1.3259 \%$ & $1.6431 \%$ & $2.0100 \%$ & $1.7332 \%$ & $0.0820 \%$ & $3.6300 \%$ & $2.9900 \%$ & $4.1900 \%$ & $2.0584 \%$ & $9.1700 \%$ \\
\hline a & 63.55 & & & & $0.0847 \%$ & $0.0250 \%$ & $0.0063 \%$ & $0.0036 \%$ & $0.0053 \%$ & $0.0035 \%$ & \\
\hline Dy & 162.50 & $0.0033 \%$ & $0.0052 \%$ & & & & & & & & \\
\hline$F_{\theta}$ & \begin{tabular}{|l|}
55.85 \\
\end{tabular} & $0.4468 \%$ & $3.1889 \%$ & $4.3500 \%$ & $1.8616 \%$ & $3.7710 \%$ & $2.0600 \%$ & $0.9570 \%$ & $1.2700 \%$ & $1.1688 \%$ & $5.1000 \%$ \\
\hline$K$ & \begin{tabular}{|l|}
39.10 \\
\end{tabular} & $0.2385 \%$ & $0.2307 \%$ & $0.0700 \%$ & $0.2085 \%$ & $0.0800 \%$ & $0.0830 \%$ & $0.0227 \%$ & $0.0466 \%$ & $0.0470 \%$ & \\
\hline La & 138.91 & $0.0081 \%$ & $0.0139 \%$ & & & & & & & & \\
\hline 4 & 6.94 & $0.0014 \%$ & $0.0014 \%$ & & $0.0014 \%$ & & & & & & \\
\hline $\operatorname{Ln}$ & 157.00 & $0.0907 \%$ & $0.1149 \%$ & & $0.1047 \%$ & $0.1047 \%$ & $0.0000 \%$ & $0.0000 \%$ & $0.0000 \%$ & $0.0000 \%$ & $0.0000 \%$ \\
\hline $\mathrm{Mg}$ & 24.31 & $0.0097 \%$ & $0.1726 \%$ & $0.1600 \%$ & $0.1134 \%$ & $0.1520 \%$ & $0.1700 \%$ & $0.0684 \%$ & $0.0894 \%$ & $0.0987 \%$ & $0.2500 \%$ \\
\hline $\mathrm{Mn}$ & 54.94 & $0.1373 \%$ & $1.2581 \%$ & $0.9800 \%$ & $0.6593 \%$ & $0.6400 \%$ & $0.7000 \%$ & $0.3500 \%$ & $0.4400 \%$ & $0.3935 \%$ & $1.9800 \%$ \\
\hline Mo & 95.94 & $0.0096 \%$ & $0.0077 \%$ & & $0.0064 \%$ & & & & & & \\
\hline $\mathrm{Na}$ & \begin{tabular}{|l|}
22.99 \\
\end{tabular} & $19.4264 \%$ & $10.0695 \%$ & $9.4800 \%$ & $9.1959 \%$ & $1.5800 \%$ & & & & & \\
\hline Nd & 144.24 & $0.0288 \%$ & $0.0288 \%$ & & $0.0288 \%$ & & & & & & \\
\hline $\mathrm{Ni}$ & \begin{tabular}{|l|}
58.71 \\
\end{tabular} & $0.0294 \%$ & $0.0528 \%$ & $0.8900 \%$ & $0.0391 \%$ & $0.0560 \%$ & & & & & $0.0700 \%$ \\
\hline$p$ & 30.97 & $1.1770 \%$ & $0.4027 \%$ & $0.5800 \%$ & & $0.2550 \%$ & & & & & $0.4800 \%$ \\
\hline$\overline{P D}$ & 207.20 & & & & $0.2210 \%$ & $0.1720 \%$ & & & & & \\
\hline $\boldsymbol{m}$ & 102.91 & $0.0206 \%$ & $0.0412 \%$ & & $0.0343 \%$ & & & & & & \\
\hline $\mathbf{R u}$ & \begin{tabular}{|l|}
101.07 \\
\end{tabular} & $0.0040 \%$ & $0.0404 \%$ & & $0.0337 \%$ & & & & & & \\
\hline Sb & 121.75 & & & & $0.0244 \%$ & & & & & & \\
\hline So & $\begin{array}{l}78.96 \\
\end{array}$ & $0.7106 \%$ & & & $0.1579 \%$ & & & & & & \\
\hline
\end{tabular}


SY-102 SOUD COMPOSITIONS

\begin{tabular}{|c|c|c|c|c|c|c|c|c|c|c|c|}
\hline \multicolumn{2}{|c|}{ Sample ID: } & \multirow{2}{*}{\begin{tabular}{|r|}
$102-S Y-4 B$ \\
$0.0843 \%$ \\
\end{tabular}} & \multirow{2}{*}{\begin{tabular}{|r|}
$1025 Y 3 T 4 S$ \\
$0.2696 \%$ \\
\end{tabular}} & \multirow{2}{*}{ 102SY3T4S } & \multirow{2}{*}{\begin{tabular}{|r|} 
102SY3T4S \\
$0.1498 \%$ \\
\end{tabular}} & \multirow{2}{*}{\begin{tabular}{|r|}
102 SYSollds \\
$0.0880 \%$ \\
\end{tabular}} & \multirow{2}{*}{ R-3316 } & \multirow[t]{2}{*}{ R-3317 } & \multirow[t]{2}{*}{ A-3318 } & \multirow[t]{2}{*}{ R-3316 } & \multirow[t]{2}{*}{ R-3036 } \\
\hline $\mathbf{s}$ & 28.09 & & & & & & & & & & \\
\hline $\mathrm{Sr}$ & 87.62 & $0.0018 \%$ & $0.0175 \%$ & & $0.0058 \%$ & $0.0110 \%$ & & & & & \\
\hline Te & 127.60 & $0.0255 \%$ & $0.0255 \%$ & & $0.0255 \%$ & & & & & & \\
\hline Th & 232.04 & & & & $0.4641 \%$ & & & & & & \\
\hline$\pi$ & 47.90 & $0.0038 \%$ & $0.0144 \%$ & & $0.0096 \%$ & & & & & & \\
\hline$\pi$ & 204.37 & & & & $0.1362 \%$ & & & & & & \\
\hline $\mathrm{U}$ & 238.03 & $0.1300 \%$ & & & $0.4761 \%$ & & & & & & \\
\hline $\mathbf{v}$ & 50.94 & & & & $0.0034 \%$ & & & & & & \\
\hline Zn & 65.38 & $0.0065 \%$ & $0.0588 \%$ & & $0.0305 \%$ & $0.0500 \%$ & & & & & \\
\hline $\mathbf{Z r}$ & 91.22 & $0.0065 \%$ & $0.0456 \%$ & & $0.0243 \%$ & & & & & & \\
\hline \multicolumn{2}{|c|}{ Tot Motals: } & $29.4244 \%$ & $21.7230 \%$ & $28.2300 \%$ & $19.6251 \%$ & $8.7430 \%$ & $15.8917 \%$ & $11.7067 \%$ & $13.8077 \%$ & $8.9896 \%$ & $33.7200 \%$ \\
\hline & & & & & & & & & & & \\
\hline Anions & & $w 1 \%$ & $w t \%$ & $m t \%$ & $w t \%$ & $w t \%$ & $w 1 \%$ & $w 1 \%$ & $w 1 \%$ & $w t \%$ & $w t \%$ \\
\hline \begin{tabular}{|l|}
$F$ \\
\end{tabular} & 19.00 & $0.1653 \%$ & & $0.1100 \%$ & $0.3800 \%$ & $0.0080 \%$ & & & & & \\
\hline a & 35.45 & $0.7091 \%$ & & $0.1700 \%$ & $0.3545 \%$ & $0.7600 \%$ & $0.5200 \%$ & $0.6000 \%$ & $0.6360 \%$ & $0.2955 \%$ & \\
\hline $\mathrm{NO2}$ & 46.01 & $4.5775 \%$ & & & $2.4536 \%$ & & & & & & \\
\hline $\mathrm{NO3}$ & 62.00 & $20.1516 \%$ & & $4.9300 \%$ & $12.4010 \%$ & & & & & & \\
\hline PO4 & 94.97 & $4.5586 \%$ & & $0.8800 \%$ & $3.7989 \%$ & $2.0000 \%$ & & & & $0.0418 \%$ & \\
\hline $\mathrm{SO}_{4}$ & 96.06 & $0.7685 \%$ & & $1.9600 \%$ & $0.6404 \%$ & $2.0000 \%$ & $4.3600 \%$ & $1.3900 \%$ & $5.3000 \%$ & $2.3831 \%$ & \\
\hline$\infty$ & 60.01 & $0.0000 \%$ & & & $2.4004 \%$ & & & & & & \\
\hline $\mathrm{aH}$ & 17.01 & $1.7007 \%$ & & $0.1500 \%$ & $1.7007 \%$ & & & & & & \\
\hline \multicolumn{2}{|c|}{ Tot Anlons: } & $32.6313 \%$ & $0.0000 \%$ & $8.2000 \%$ & $24.1294 \%$ & $4.7680 \%$ & $4.8800 \%$ & $1.9900 \%$ & $5.9360 \%$ & $2.7203 \%$ & $0.0000 \%$ \\
\hline & & & & & & & & & & & \\
\hline \multicolumn{2}{|c|}{ Tol Org C: } & $0.8700 \%$ & & & & $0.7550 \%$ & & & & & $0.0303 \%$ \\
\hline & & & & & & & & & & & \\
\hline \multicolumn{2}{|c|}{ Tot Comp: } & $62.9257 \%$ & $21.7230 \%$ & $36.4300 \%$ & $43.7545 \%$ & $14.2660 \%$ & $20.7717 \%$ & $13.6967 \%$ & $19.7437 \%$ & $11.7100 \%$ & $33.7503 \%$ \\
\hline & & & & & & & & & & & \\
\hline TRUs & & $(0 / g)$ & $(g / g)$ & $(g / g)$ & $(g / g)$ & $(g / g)$ & $(g / g)$ & $(g / g)$ & $(g / g)$ & $(g / g)$ & $(g / g)$ \\
\hline Am-241 & 241.06 & 2.81E-07 & 2.83E-06 & $2.48 E-05$ & $6.00 \mathrm{E}-06$ & $1.31 \mathrm{E}-05$ & $6.81 E-06$ & 2.05E-06 & $3.00 \mathrm{E}-06$ & $3.86 E-06$ & \\
\hline $\mathrm{Cm}-243$ & 243.00 & & & & & & & & & & \\
\hline $\mathrm{Cm}-244$ & 244.00 & & & & 6.67E-10 & & & & & & \\
\hline$C m-24 x$ & 243.56 & $6.84 E-10$ & $3.02 E-10$ & & & & & & & & \\
\hline Np-237 & 237.05 & 8.28E-07 & 1.14E-06 & & 1.33E-06 & & $3.37 E-02$ & 2.50E-02 & 3.62E-02 & $1.90 \mathrm{E}-02$ & \\
\hline Pu-238 & 238.05 & 2.14E-09 & 4.55E-08 & & & & & & & & \\
\hline Pu-239 & 239.05 & 2.07E-06 & 4.49E-05 & & 6.67E-05 & $4.32 E-04$ & $1.20 E-04$ & 3.38E-05 & $4.16 \mathrm{E}-05$ & 6.81E-05 & \\
\hline $\mathrm{Pu}-240$ & 240.05 & $1.70 E-07$ & $5.18 E-06$ & & 6.67E-06 & & & & & & \\
\hline Pu-241 & 241.06 & $1.17 \mathrm{E}-08$ & 3.44E-07 & & & & & & & & $2.31 E-08$ \\
\hline Pu-242 & 242.00 & & & & & & & & & & \\
\hline $\mathrm{Pu}-244$ & 244.00 & & & & & & & & & & \\
\hline
\end{tabular}




\begin{tabular}{|c|c|c|c|c|c|c|c|c|c|c|c|}
\hline \multicolumn{2}{|c|}{ Sample ID: } & \multirow{2}{*}{$\frac{102-S Y-4 B}{(g / q)}$} & \multirow{2}{*}{$\frac{1025 Y 3 T 4 S}{(\mathrm{~g} / \mathrm{g})}$} & \multirow{2}{*}{\begin{tabular}{|c|} 
102SY3T4S \\
$(g / q)$
\end{tabular}} & \multirow{2}{*}{\begin{tabular}{|c|} 
102SY3T4S \\
$(\mathrm{g} / \mathrm{g})$ \\
\end{tabular}} & \multirow{2}{*}{\begin{tabular}{|c|} 
102SYSollds \\
$(0 / 9)$ \\
\end{tabular}} & \multirow{2}{*}{$\frac{R-3316}{(0 / 9)}$} & \multirow{2}{*}{\begin{tabular}{|l|}
$\frac{R-3317}{(g / g)}$ \\
\end{tabular}} & \multirow{2}{*}{$\frac{R-3318}{(9 / 9)}$} & \multirow{2}{*}{\begin{tabular}{|l}
$\frac{R-3316}{(g / g)}$ \\
\end{tabular}} & \multirow{2}{*}{\begin{tabular}{|r|}
$R-3036$ \\
$(g / g)$ \\
\end{tabular}} \\
\hline n-TRUs & & & & & & & & & & & \\
\hline $\mathrm{H}-3$ & 3.02 & $1.33 E-13$ & $6.34 E-14$ & & & & & & & & \\
\hline C-14 & 14.00 & $3.99 E-10$ & & & $4.44 E-10$ & & & & & & \\
\hline $1-129$ & 129.00 & $1.34 E-06$ & $1.34 E-06$ & & $1.49 E-06$ & & & & & & \\
\hline $\mathrm{Nb}-94$ & 94.00 & $2.13 E-08$ & $1.20 E-08$ & & & & & & & & \\
\hline $\mathrm{Ni}-63$ & 63.00 & 5.05E-08 & $9.58 E-08$ & & $6.97 E-08$ & & & & & & \\
\hline Se-79 & 79.00 & $4.52 E-09$ & 2.56E-09 & & & & & & & & \\
\hline Sr-90 & 90.00 & 4.90E-07 & & $1.52 E-06$ & $4.83 E-07$ & & $1.83 E-06$ & 1.36E-06 & $1.90 \mathrm{E}-06$ & $1.04 E-06$ & 5.58E-06 \\
\hline Tc-99 & 99.00 & $1.18 E-05$ & $1.28 E-05$ & & 1.17E-05 & 2.33E-06 & & & & & \\
\hline Ce-144 & 144.00 & $3.42 E-10$ & & & $4.14 E-10$ & & & & & & \\
\hline Co-60 & 60.00 & $9.62 E-11$ & & & $1.17 E-10$ & & $6.19 E-10$ & $4.41 E-10$ & & $3.50 E-10$ & \\
\hline Cs-134 & 134.00 & $4.90 E-11$ & & & $5.10 E-11$ & & & & & & \\
\hline Cs-137 & 137.00 & $1.71 E-06$ & & $2.06 E-07$ & $1.52 E-06$ & $1.64 E-07$ & $1.76 \mathrm{E}-06$ & $1.52 E-06$ & 2.03E-06 & 9.95E-07 & $1.15 E-06$ \\
\hline Eu-152 & 152.00 & $8.50 E-10$ & & & $7.56 \mathrm{E}-10$ & & $4.81 E-08$ & $3.61 E-08$ & $5.28 E-08$ & 2.72E-08 & \\
\hline Eu-154 & 154.00 & 5.49E-09 & & & $9.76 E-09$ & & $2.02 E-08$ & $1.55 \mathrm{E}-08$ & $2.08 \mathrm{E}-08$ & $1.14 E-08$ & \\
\hline Eu-155 & 155.00 & & & & & & & & & & \\
\hline$R u-106$ & 106.00 & $4.78 E-10$ & & & $3.99 E-10$ & & & & & & \\
\hline Sb-125 & 125.00 & $1.53 E-09$ & & & $1.27 \mathrm{E}-09$ & & & & & $5.34 E-10$ & \\
\hline \multirow[t]{2}{*}{$\mathrm{Zr}-95$} & 91.22 & & & & & & $1.94 E-11$ & $1.46 \mathrm{E}-11$ & & $1.10 \mathrm{E}-11$ & \\
\hline & & & & & & & & & & & \\
\hline \multicolumn{2}{|c|}{ Tot TRUs } & $3.36 \mathrm{E}-06$ & $5.45 \mathrm{E}-05$ & $2.48 E-05$ & $8.07 E-05$ & $4.45 E-04$ & $3.38 E-02$ & $2.50 \mathrm{E}-02$ & $3.62 E-02$ & 1.91E-02 & $2.31 E-08$ \\
\hline \multicolumn{2}{|c|}{ Tot n-TRUs } & $1.54 E-05$ & $1.43 \mathrm{E}-05$ & $1.73 E-06$ & $1.52 E-05$ & $2.50 E-06$ & $3.66 \mathrm{E}-06$ & $2.93 \mathrm{E}-06$ & $4.01 E-06$ & 2.07E-06 & $6.74 E-06$ \\
\hline \multicolumn{2}{|c|}{ Tot Radionuclld } & $1.88 E-05$ & $6.88 E-05$ & $2.65 E-05$ & 9.59E-05 & 4.47E-04 & $3.38 E-02$ & $2.50 E-02$ & $3.62 E-02$ & 1.91E-02 & $6.76 E-06$ \\
\hline & & & & & & & & & & & \\
\hline
\end{tabular}




\begin{tabular}{|c|c|c|c|c|c|c|c|c|c|c|c|}
\hline \multicolumn{2}{|c|}{ Samplo 1D: } & $102-5 Y-4 B$ & 102SY3T4S & 102SY3T4S & 102SY3T4S & 102SYSollds & R-3316 & R-3317 & R-3318 & R-3316 & R-3036 \\
\hline \multicolumn{2}{|c|}{ Sample Dato: } & $10 / 25 / 88$ & $10 / 25 / 88$ & \begin{tabular}{|l|l|}
$10 / 25 / 88$ \\
\end{tabular} & $10 / 25 / 88$ & $7 / 1 / 88$ & $11 / 1 / 84$ & $11 / 1 / 84$ & $11 / 1 / 84$ & \begin{tabular}{|l}
$11 / 1 / 84$ \\
\end{tabular} & \begin{tabular}{|l}
$?$ \\
\end{tabular} \\
\hline \multirow{3}{*}{$\begin{array}{l}\text { Analysis } \\
\text { Analyst }\end{array}$} & Date: & $6 / 30 / 89$ & $6 / 30 / 89$ & $7 / 6 / 90$ & & $3 / 23 / 89$ & $3 / 29 / 85$ & $3 / 29 / 85$ & $3 / 29 / 85$ & $1 / 10 / 85$ & $10 / 5 / 84$ \\
\hline & & \begin{tabular}{|l|} 
PNL: Schoele \\
\end{tabular} & PNL: Schoele & PCL: Herting & & PCL:Woiss & Rockwoll AL: & Rockwell AL: & Rockwell AL: & Rockwell AL: & Rockwell AL: \\
\hline & & \& Peterson & \& Peterson & & & & Bratzel & Bratzel & Bratzel & Bratzel & Bratzel \\
\hline \multicolumn{2}{|c|}{ Sample Slie: } & Oct'8bcore & Oct'88coro & Oct ' 88 core & Oct ' 88 core & $?$ & 6", bottom & $6^{\circ}$. bottom & 6", bottom & $6^{\circ}$, bottom & bottom (?) \\
\hline \multirow{2}{*}{\multicolumn{2}{|c|}{\begin{tabular}{|l|} 
Sample Notes: \\
Reforence: \\
\end{tabular}}} & \begin{tabular}{|l|} 
Segment $* 4$ \\
\end{tabular} & Comp 3/4 & $d=1.02$ & $\alpha=1.5$ (est) & High values & Cent. sollds & \begin{tabular}{|l|} 
Cont. solids \\
\end{tabular} & \begin{tabular}{|c|} 
Cent. solids \\
\end{tabular} & $d=1.54$ & $d=1.65(?)$ \\
\hline & & Peterson to & Peterson to & Herting to & Kirkbride to & Weiss (PCL) & Bratzel to & Bratzel to & Bratzel to & Bratzel to & Bratzel to \\
\hline \multirow{4}{*}{\begin{tabular}{|l||} 
\\
Phaso: \\
Spocio \\
\end{tabular}} & & Diliberto & Diliberto & Sasaki & Orme & to Carothers & Gale & Gale & Gale & Gale & Tulberg \\
\hline & & $6 / 30 / 89$ & $6 / 30 / 89$ & $7 / 6 / 90$ & $12 / 10 / 92$ & $3 / 23 / 89$ & $3 / 29 / 85$ & $3 / 29 / 85$ & $3 / 29 / 85$ & $1 / 10 / 85$ & $10 / 5 / 84$ \\
\hline & & \begin{tabular}{|l|} 
Solld \\
\end{tabular} & \begin{tabular}{|l|} 
Solld \\
\end{tabular} & Solld & \begin{tabular}{|l|} 
Solid \\
\end{tabular} & Solld & Solld & Solld & Solld & Solld & Solld \\
\hline & Mass & $\mathrm{mg} / \mathrm{g}$ & $\mathrm{mg} / \mathrm{g}$ & $\mathrm{mg} / \mathrm{g}$ & $\mathrm{mg} / \mathrm{g}$ & $\mathrm{mg} / \mathrm{g}$ & $\mathrm{mg} / \mathrm{g}$ & $\mathrm{mg} / \mathrm{g}$ & $\mathrm{mg} / \mathrm{g}$ & $\mathrm{mg} / \mathrm{g}$ & $\mathrm{mg} / \mathrm{g}$ \\
\hline$A g$ & 107.87 & & & & $1.44 \mathrm{E}-01$ & & & & & & \\
\hline $\mathrm{Al}$ & 26.98 & $4.80 E+01$ & $3.48 E+01$ & $9.00 E+01$ & $3.24 E+01$ & $8.80 E+00$ & $9.21 E+01$ & $7.30 E+01$ & $7.75 E+01$ & $5.20 \mathrm{E}+01$ & $1.60 \mathrm{E}+02$ \\
\hline As & 74.92 & $6.82 E+00$ & & & $4.99 E-01$ & & & & & & \\
\hline$B$ & 10.81 & $1.73 \mathrm{E}-01$ & 1.95E-01 & & $1.44 E-01$ & $3.00 \mathrm{E}-02$ & & & & & \\
\hline$B a$ & 137.33 & $2.75 \mathrm{E}-02$ & $9.34 \mathrm{E}-02$ & & & & & & & & \\
\hline B & 208.98 & & & & & $5.40 E-01$ & & & & & \\
\hline $\mathrm{Ca}$ & 40.08 & 4.21E-01 & $5.69 E+00$ & $7.10 E+00$ & $4.54 E+00$ & $7.59 \mathrm{E}+00$ & & & & & $4.50 E+00$ \\
\hline Cd & 112.41 & & & & $6.00 \mathrm{E}-01$ & $6.10 \mathrm{E}-01$ & $3.24 E-01$ & $1.50 \mathrm{E}-01$ & 1.64E-01 & $1.83 \mathrm{E}-01$ & $2.20 E+00$ \\
\hline$C_{\theta}$ & 140.12 & $4.20 \mathrm{E}-01$ & $5.60 \mathrm{E}-01$ & & $6.54 \mathrm{E}-01$ & $2.40 E-01$ & & & & & \\
\hline $\operatorname{Cr}(\mathrm{VI})$ & 52.00 & $1.28 E+00$ & $1.55 E+00$ & $4.30 E+00$ & $1.04 E+00$ & $8.20 E-01$ & $3.63 E+01$ & $2.99 E+01$ & $4.19 E+01$ & $2.06 E+01$ & $9.17 E+01$ \\
\hline $\operatorname{Cr}($ Tot $)$ & 52.00 & $1.33 E+01$ & $1.64 E+01$ & $2.01 E+01$ & $1.73 E+01$ & $8.20 E-01$ & $3.63 E+01$ & $2.99 E+01$ & $4.19 E+01$ & $2.06 E+01$ & $9.17 E+01$ \\
\hline a & 63.55 & & & & $8.47 \mathrm{E}-01$ & $2.50 E-01$ & $6.27 \mathrm{E}-02$ & $3.59 \mathrm{E}-02$ & $5.34 \mathrm{E}-02$ & $3.55 \mathrm{E}-02$ & \\
\hline Dy & 162.50 & $3.25 \mathrm{E}-02$ & $5.20 \mathrm{E}-02$ & & & & & & & & \\
\hline$F_{\theta}$ & \begin{tabular}{|l|}
55.85 \\
\end{tabular} & $4.47 E+00$ & $3.19 E+01$ & $4.35 E+01$ & $1.86 E+01$ & $3.77 E+01$ & $2.06 E+01$ & $9.57 E+00$ & $1.27 E+01$ & $1.17 E+01$ & $5.10 E+01$ \\
\hline $\mathbf{K}$ & \begin{tabular}{|l|}
39.10 \\
\end{tabular} & $2.38 E+00$ & $2.31 E+00$ & $7.00 E-01$ & $2.09 E+00$ & $8.00 E-01$ & $8.30 E-01$ & 2.27E-01 & $4.66 \mathrm{E}-01$ & $4.70 E-01$ & \\
\hline La & \begin{tabular}{|l|}
138.91 \\
\end{tabular} & $8.06 E-02$ & $1.39 \mathrm{E}-01$ & & & & & & & & \\
\hline$\underline{\underline{ }}$ & \begin{tabular}{|l|}
6.94 \\
\end{tabular} & $1.39 \mathrm{E}-02$ & $1.39 \mathrm{E}-02$ & & $1.39 \mathrm{E}-02$ & & & & & & \\
\hline Ln & 157.00 & 9.07E-01 & $1.15 E+00$ & & $1.05 E+00$ & $2.40 \mathrm{E}-01$ & $0.00 E+00$ & $0.00 E+00$ & $0.00 E+00$ & $0.00 E+00$ & $0.00 E+00$ \\
\hline $\mathrm{Mg}$ & 24.31 & $9.72 \mathrm{E}-02$ & $1.73 E+00$ & $1.60 E+00$ & $1.13 E+00$ & $1.52 E+00$ & $1.70 E+00$ & $6.84 \mathrm{E}-01$ & $8.94 \mathrm{E}-01$ & $\begin{array}{c}9.87 \mathrm{E}-01 \\
\end{array}$ & $2.50 E+00$ \\
\hline $\mathrm{Mn}$ & 54.94 & $1.37 E+00$ & $1.26 E+01$ & $9.80 E+00$ & $6.59 E+00$ & $6.40 E+00$ & $7.00 E+00$ & $3.50 E+00$ & $4.40 E+00$ & $3.94 E+00$ & $1.98 E+01$ \\
\hline Mo & 95.94 & $9.59 \mathrm{E}-02$ & $7.68 \mathrm{E}-02$ & & $6.40 \mathrm{E}-02$ & & & & & & \\
\hline $\mathrm{Na}$ & \begin{tabular}{|l|}
22.99 \\
\end{tabular} & $1.94 E+02$ & $1.01 E+02$ & $9.48 E+01$ & $9.20 E+01$ & $1.58 E+01$ & & & & & \\
\hline Nd & 144.24 & $2.88 \mathrm{E}-01$ & $2.88 \mathrm{E}-01$ & & $2.88 \mathrm{E}-01$ & & & & & & \\
\hline $\mathbf{N}$ & 58.71 & $2.94 \mathrm{E}-01$ & $5.28 \mathrm{E}-01$ & $8.90 E+00$ & $3.91 E-01$ & $5.60 \mathrm{E}-01$ & & & & & 7.00E-01 \\
\hline$P$ & \begin{tabular}{|l|}
30.97 \\
\end{tabular} & $1.18 E+01$ & $4.03 E+00$ & $5.80 E+00$ & & $2.55 E+00$ & & & & & $4.80 \mathrm{E}+00$ \\
\hline $\mathbf{P B}$ & 207.20 & & & & $2.21 E+00$ & $1.72 E+00$ & & & & & \\
\hline $\mathbf{F}$ & 102.91 & $2.06 \mathrm{E}-01$ & $4.12 E-01$ & & $3.43 E-01$ & & & & & & \\
\hline $\mathbf{P u}$ & 101.07 & $4.04 \mathrm{E}-02$ & $4.04 \mathrm{E}-01$ & & 3.37E-01 & & & & & & \\
\hline sob & 121.75 & & & & $2.44 \mathrm{E}-01$ & & & & & & \\
\hline Se & 78.96 & $7.11 E+00$ & & & $1.58 E+00$ & & & & & & \\
\hline
\end{tabular}




\begin{tabular}{|c|c|c|c|c|c|c|c|c|c|c|c|}
\hline \multicolumn{2}{|c|}{ Samplo ID: } & \multirow{2}{*}{\begin{tabular}{|c|}
$102-S Y-A B$ \\
$8.43 E-01$
\end{tabular}} & \multirow{2}{*}{\begin{tabular}{|l|}
$102 S Y 3 T 4 S$ \\
$2.70 E+00$
\end{tabular}} & \multirow{2}{*}{ 102SY3T4S } & \multirow{2}{*}{\begin{tabular}{|r|}
$102 S Y 3 T 4 S$ \\
$1.50 E+00$ \\
\end{tabular}} & \multirow{2}{*}{\begin{tabular}{|c|}
102 SYSollds \\
$8.80 \mathrm{E}-01$
\end{tabular}} & \multirow{2}{*}{ R-3316 } & \multirow[t]{2}{*}{ R-3317 } & \multirow[t]{2}{*}{ R-3318 } & \multirow[t]{2}{*}{ R-3316 } & \multirow[t]{2}{*}{ A-3036 } \\
\hline $\mathbf{s}$ & 28.09 & & & & & & & & & & \\
\hline $\mathrm{Sr}$ & 87.62 & $1.75 \mathrm{E}-02$ & \begin{tabular}{|r|}
$1.75 E-01$ \\
\end{tabular} & & 5.84E-02 & \begin{tabular}{|c|}
$1.10 \mathrm{E}-01$ \\
\end{tabular} & & & & & \\
\hline$T_{\theta}$ & 127.60 & $2.55 \mathrm{E}-01$ & $2.55 \mathrm{E}-01$ & & 2.55E-01 & & & & & & \\
\hline$T h$ & 232.04 & & & & $4.64 E+00$ & & & & & & \\
\hline$\pi$ & \begin{tabular}{|l|}
47.90 \\
\end{tabular} & 3.83E-02 & $1.44 \mathrm{E}-01$ & & $9.58 \mathrm{E}-02$ & & & & & & \\
\hline$\pi$ & 204.37 & & & & $1.36 E+00$ & & & & & & \\
\hline$U$ & 238.03 & $1.30 E+00$ & & & $4.76 E+00$ & & & & & & \\
\hline $\mathbf{v}$ & 50.94 & & & & $3.40 \mathrm{E}-02$ & & & & & & \\
\hline $\mathrm{Zn}$ & 65.38 & $6.54 \mathrm{E}-02$ & $5.88 \mathrm{E}-01$ & & $3.05 \mathrm{E}-01$ & $5.00 \mathrm{E}-01$ & & & & & \\
\hline $\mathrm{Zr}$ & 91.22 & $6.48 \mathrm{E}-02$ & $4.56 \mathrm{E}-01$ & & $2.43 \mathrm{E}-01$ & & & & & & \\
\hline \multicolumn{2}{|c|}{ Tot Motals: } & $2.96 \mathrm{E}+02$ & $2.20 E+02$ & $2.82 E+02$ & $1.98 E+02$ & $8.85 E+01$ & $1.59 E+02$ & 1.17E+02 & $1.38 E+02$ & $8.99 E+01$ & $3.37 E+02$ \\
\hline Anlons & & $\mathrm{mg} / \mathrm{g}$ & $\mathrm{mg} / \mathrm{g}$ & $\mathrm{mg} / \mathrm{g}$ & $\mathrm{mq} / \mathrm{g}$ & $\mathrm{mg} / \mathrm{g}$ & $\mathrm{mg} / \mathrm{g}$ & $\mathrm{mg} / \mathrm{g}$ & $\mathrm{mg} / \mathrm{g}$ & $\mathrm{mg} / \mathrm{g}$ & $\mathrm{mg} / \mathrm{g}$ \\
\hline$F$ & 19.00 & $1.65 E+00$ & & $1.10 E+00$ & $3.80 E+00$ & $8.00 E-02$ & & & minges & & \\
\hline$a$ & 35.45 & $7.09 E+00$ & & $1.70 E+00$ & $3.55 E+00$ & $7.60 \mathrm{E}+00$ & $5.20 E+00$ & $6.00 E+00$ & $6.36 \mathrm{E}+00$ & $2.95 E+00$ & \\
\hline NO2 & 46.01 & $4.58 E+01$ & & & $2.45 \mathrm{E}+01$ & & & & & & \\
\hline NO3 & 62.00 & $2.02 E+02$ & & $4.93 E+01$ & $1.24 E+02$ & & & & & & \\
\hline PO4 & 94.97 & $4.56 E+01$ & & $8.80 E+00$ & $3.80 E+01$ & $2.00 E+01$ & & & & $4.18 \mathrm{E}-01$ & \\
\hline $\mathrm{SO4}$ & 96.06 & $7.68 E+00$ & & $1.96 E+01$ & $6.40 \mathrm{E}+00$ & $2.00 E+01$ & $4.36 E+01$ & 1.39E+01 & $5.30 \mathrm{E}+01$ & $2.38 E+01$ & \\
\hline $\mathrm{COO}$ & 60.01 & $0.00 E+00$ & & & $2.40 E+01$ & & & & & & \\
\hline $\mathrm{OH}$ & 17.01 & $1.70 E+01$ & & $1.50 E+00$ & $1.70 E+01$ & & & & & & \\
\hline \multicolumn{2}{|c|}{ Tot Anlons: } & $3.26 E+02$ & $0.00 E+00$ & $8.20 E+01$ & $2.41 E+02$ & $4.77 \mathrm{E}+01$ & $4.88 E+01$ & 1.99E+01 & $5.94 E+01$ & $2.72 E+01$ & $0.00 E+00$ \\
\hline & & & & & & & & & & & \\
\hline \multirow{2}{*}{\multicolumn{2}{|c|}{ Tot Org C: }} & & & & & $7.55 \mathrm{E}+00$ & & & & & $5.00 E-01$ \\
\hline & & & & & & & & & & & \\
\hline \multicolumn{2}{|c|}{ Tot Comp: } & $6.23 \mathrm{E}+02$ & $2.20 E+02$ & $3.64 E+02$ & $4.40 E+02$ & $1.44 E+02$ & $2.08 E+02$ & $1.37 E+02$ & $1.97 E+02$ & $1.17 E+02$ & $3.38 E+02$ \\
\hline & & & & & & & & & & & \\
\hline IRUs & & $\mathrm{uCl} / \mathrm{g}$ & $4 \mathrm{Cl} / \mathrm{g}$ & $\mathrm{uCl} / \mathrm{g}$ & uCl/g & $u C l / g$ & $u C \|_{Q}$ & $\mathbf{u C l} / \mathrm{g}$ & uCl/g & $\mathrm{uCl} / \mathrm{g}$ & uCl/g \\
\hline Am-241 & 241.06 & $9.73 E-01$ & $9.82 E+00$ & $8.60 E+01$ & $2.08 E+01$ & $4.53 E+01$ & $2.36 \mathrm{E}+01$ & $7.12 E+00$ & $1.04 E+01$ & $1.37 E+01$ & \\
\hline $\mathrm{Cm}-243$ & 243.00 & & & & & & & & & & \\
\hline $\mathrm{Cm}-244$ & 244.00 & & & & $5.46 \mathrm{E}-02$ & & & & & & \\
\hline$C(n-2 \wedge x$ & 243.56 & $4.30 \mathrm{E}-02$ & $1.90 \mathrm{E}-02$ & & & & & & & & \\
\hline Np-237 & 237.05 & $5.90 \mathrm{E}-04$ & $8.10 \mathrm{E}-04$ & & $9.50 \mathrm{E}-04$ & & $2.40 E+01$ & $1.78 E+01$ & $2.58 E+01$ & $1.39 E+01$ & \\
\hline Pu-238 & 238.05 & $3.70 \mathrm{E}-02$ & $7.88 \mathrm{E}-01$ & & & & & & & & \\
\hline Pu-239 & 239.05 & $1.30 \mathrm{E}-01$ & $2.82 E+00$ & & $4.18 E+00$ & $2.71 E+01$ & $7.55 E+00$ & $2.12 E+00$ & $2.61 E+00$ & $4.39 E+00$ & \\
\hline$P u-240$ & 240.05 & $3.90 \mathrm{E}-02$ & $1.19 E+00$ & & $1.53 E+00$ & & & & & & \\
\hline$\overline{F u}-241$ & 241.06 & $1.22 E+00$ & $3.58 E+01$ & & & & & & & & $2.41 E+00$ \\
\hline Pu-242 & 242.00 & & & & & & & & & & \\
\hline Pu-244 & 244.00 & & & & & & & & & & \\
\hline
\end{tabular}




\begin{tabular}{|c|c|c|c|c|c|c|c|c|c|c|c|}
\hline \multicolumn{2}{|c|}{ Sample 1D: } & \multirow{2}{*}{\begin{tabular}{|c|}
$102-S Y-4 B$ \\
$\mathrm{C} I / 9$ \\
\end{tabular}} & \multirow{2}{*}{\begin{tabular}{|c|}
$1025 Y 3 T 4 S$ \\
$\mathrm{uCl} / \mathrm{g}$ \\
\end{tabular}} & \multirow{2}{*}{\begin{tabular}{|c|}
$1025 Y 3 T 4 S$ \\
$\mathrm{CCl} / \mathrm{g}$ \\
\end{tabular}} & \multirow{2}{*}{\begin{tabular}{|c|} 
102SY3T4S \\
uCI/q \\
\end{tabular}} & \multirow{2}{*}{$\begin{array}{c}\text { 102SYSollds } \\
\mathrm{uCl} / \mathrm{g}\end{array}$} & \multirow{2}{*}{\begin{tabular}{|c|} 
A-3316 \\
UCI/g
\end{tabular}} & \multirow{2}{*}{$\begin{array}{r}\mathrm{R-3317} \\
\mathrm{uCl} / \mathrm{g}\end{array}$} & \multirow{2}{*}{\begin{tabular}{|r|} 
u-3318 \\
Cl/g \\
\end{tabular}} & \multirow{2}{*}{\begin{tabular}{|r|} 
A-3316 \\
$u C l / g$ \\
\end{tabular}} & \multirow{2}{*}{$\frac{\mathrm{R}-3036}{\mathrm{uCl} / \mathrm{g}}$} \\
\hline n-TRUa & & & & & & & & & & & \\
\hline $\mathrm{H}-3$ & 3.02 & \begin{tabular}{|l|}
$1.30 \mathrm{E}-03$ \\
\end{tabular} & \begin{tabular}{|c|}
$6.20 E-04$ \\
\end{tabular} & & & & & & & & \\
\hline C-14 & 14.00 & $1.80 \mathrm{E}-03$ & & & $2.00 E-03$ & & & & & & \\
\hline $1-129$ & 129.00 & 2.40E-04 & 2.40E-04 & & 2.67E-04 & & & & & & \\
\hline $\mathrm{Nb}-94$ & 94.00 & 4.10E-03 & 2.30E-03 & & & & & & & & \\
\hline $\mathrm{NI}-63$ & 63.00 & $2.90 E+00$ & $5.50 \mathrm{E}+00$ & & $4.00 E+00$ & & & & & & \\
\hline Se-79 & 79.00 & $3.18 E-04$ & 1.80 E-04 & & & & & & & & \\
\hline Sr-90 & 90.00 & $6.76 E+01$ & & $2.10 \mathrm{E}+02$ & $6.67 \mathrm{E}+01$ & & $2.53 E+02$ & $1.88 E+02$ & $2.62 E+02$ & $1.47 E+02$ & $7.71 E+02$ \\
\hline Tc.99 & 99.00 & 2.02E-01 & 2.20E-01 & & $2.00 E-01$ & $4.00 E-02$ & & & & & \\
\hline Ce-144 & 144.00 & $1.10 \mathrm{E}+00$ & & & $1.33 E+00$ & & & & & & \\
\hline Co-60 & 60.00 & $1.10 \mathrm{E}-01$ & & & $1.33 E-01$ & & 7.08E-01 & 5.04E-01 & & 4.11E-01 & \\
\hline \begin{tabular}{|c|} 
Cs-134 \\
\end{tabular} & 134.00 & $6.40 \mathrm{E}-02$ & & & 6.67E-02 & & & & & & \\
\hline Cs-137 & 137.00 & $1.50 E+02$ & & $1.80 E+01$ & $1.33 E+02$ & $1.44 E+01$ & $1.54 E+02$ & $1.33 E+02$ & $1.78 E+02$ & $8.93 E+01$ & $1.01 E+02$ \\
\hline Eu-152 & 152.00 & $1.50 \mathrm{E}-01$ & & & 1.33E-01 & & $8.48 E+00$ & $6.37 E+00$ & $9.32 E+00$ & $4.93 E+00$ & \\
\hline Eu-154 & 154.00 & $1.50 \mathrm{E}+00$ & & & $2.67 E+00$ & & $5.51 E+00$ & $4.25 E+00$ & $5.69 E+00$ & $3.20 E+00$ & \\
\hline Eu-155 & 155.00 & & & & & & & & & & \\
\hline \begin{tabular}{|l|}
$\mathrm{Ru}-106$ \\
\end{tabular} & 106.00 & $1.60 \mathrm{E}+00$ & & & $1.33 E+00$ & & & & & & \\
\hline Sb-125 & 125.00 & $1.60 E+00$ & & & $1.33 E+00$ & & & & & 5.75E-01 & \\
\hline $\mathrm{Zr}-95$ & 91.22 & & & & & & $4.38 \mathrm{E}-01$ & 3.31E-01 & & 2.55E-01 & \\
\hline Tot TAU & & $2.44 E+00$ & $5.04 E+01$ & $8.60 E+01$ & $2.66 E+01$ & $7.24 E+01$ & $5.52 E+01$ & $2.70 E+01$ & $3.88 E+01$ & $3.21 E+01$ & $2.41 E+00$ \\
\hline Tot Nont & TRU & $2.27 E+02$ & $5.72 E+00$ & $2.28 E+02$ & $2.11 E+02$ & $1.44 E+01$ & $4.22 E+02$ & $3.32 E+02$ & $4.55 E+02$ & $2.46 \mathrm{E}+02$ & $8.72 E+02$ \\
\hline Tot Rad! & llonuclid & $2.29 E+02$ & $5.62 E+01$ & $3.14 E+02$ & $2.38 E+02$ & $8.68 E+01$ & $4.77 E+02$ & $3.59 \mathrm{E}+02$ & $4.94 E+02$ & $2.78 E+02$ & $8.74 E+02$ \\
\hline & & & & & & & & & & & \\
\hline
\end{tabular}




\begin{tabular}{|c|c|c|c|c|c|c|c|c|c|c|c|}
\hline \multirow{2}{*}{\multicolumn{2}{|c|}{$\begin{array}{l}\text { Sample ID: } \\
\text { Sample Date: }\end{array}$}} & $102-5 Y-48$ & $102 S Y 3 T 4 S$ & 102SY3T4S & $1025 Y 3 T 4 S$ & 1025YSollds & A-3316 & R-3317 & A-3318 & R-3316 & A-3036 \\
\hline & & $10 / 25 / 88$ & $10 / 25 / 88$ & $10 / 25 / 88$ & $10 / 25 / 88$ & $7 / 1 / 88$ & $11 / 1 / 84$ & $11 / 1 / 84$ & $11 / 1 / 84$ & $11 / 1 / 84$ & $?$ \\
\hline \multicolumn{2}{|c|}{ Analysle Date: } & $6 / 30 / 89$ & \begin{tabular}{|l|}
$6 / 30 / 89$ \\
\end{tabular} & $7 / 6 / 90$ & & $3 / 23 / 89$ & $3 / 29 / 85$ & $3 / 29 / 85$ & $3 / 29 / 85$ & $1 / 10 / 85$ & $10 / 5 / 84$ \\
\hline \multirow[t]{2}{*}{ Analyst } & & PNL: Scheole & PNL: Scheele & PCL: Herting & & PCL: Woiss & Rockwell AL: & Rockwell AL: & Rockwell AL: & Rockwell AL: & Rockwell AL: \\
\hline & & \& Peterson & \& Peterson & & & & Bratzel & Bratzel & Bratzel & Bratzel & Bratzel \\
\hline \multicolumn{2}{|c|}{ Sample Slte: } & Oct'88core & Oct'88core & Oct '88 core & Oct ' 88 core & $?$ & 6., bottom & $6^{\circ}$, bottom & $6^{\circ}$, bottom & 6., bottom & bottom (?) \\
\hline \multicolumn{2}{|c|}{ Sample Notes: } & Segment 4 & Comp 3/4 & $d=1.02$ & $d=1.5$ (est) & High values & Cent. solids & Cent. solids & Cent. solids & $d=1.54$ & $d=1.65(?)$ \\
\hline \multicolumn{2}{|c|}{ Roference: } & Peterson to & Peterson to & Herting to & Kirkbride to & Weiss (PCL) & Bratzel to & Bratzel to & Bratzel to & Bratzel to & Bratzel to \\
\hline & & Diliberto & Diliberto & Sasaki & Orme & to Carothers & Gale & Gale & Gale & Gale & Tulberg \\
\hline & & $6 / 30 / 89$ & $6 / 30 / 89$ & $7 / 6 / 90$ & $12 / 10 / 92$ & $3 / 23 / 89$ & $3 / 29 / 85$ & $3 / 29 / 85$ & $3 / 29 / 85$ & $1 / 10 / 85$ & $10 / 5 / 84$ \\
\hline Phase: & & Solld & \begin{tabular}{|l|} 
Solld \\
\end{tabular} & \begin{tabular}{|l|} 
Solid \\
\end{tabular} & Solld & Solld & Solld & Solld & Solld & Solld & Solld \\
\hline Note: & & \multicolumn{4}{|c|}{ Assumed a density of $1.5 \mathrm{~g} / \mathrm{mL}$ to convert from $\mathrm{mg} / \mathrm{g}$} & & & & & & \\
\hline Specie & Mass & O/L & \begin{tabular}{|c|}
$\mathrm{g} / \mathrm{L}$ \\
\end{tabular} & \begin{tabular}{l|l}
$/ L$ \\
\end{tabular} & $\begin{array}{ll}/ 2 \\
\end{array}$ & $g / L$ & $g / L$ & $g / L$ & $g / L$ & $g / L$ & $g / L$ \\
\hline $\mathrm{Ag}$ & 107.87 & & & & $2.16 E-01$ & & & & & & \\
\hline Al & 26.98 & $7.20 \mathrm{E}+01$ & $5.22 E+01$ & $1.35 E+02$ & $4.86 E+01$ & $1.32 E+01$ & $1.38 E+02$ & $1.10 E+02$ & $1.16 E+02$ & $7.80 E+01$ & $2.40 E+02$ \\
\hline As & 74.92 & $1.02 E+01$ & & & 7.49E-01 & & & & & & \\
\hline$B$ & 10.81 & $2.59 E-01$ & 2.92E-01 & & 2.16E-01 & $4.50 \mathrm{E}-02$ & & & & & \\
\hline $\mathrm{Ba}$ & 137.33 & $4.12 E-02$ & $1.40 \mathrm{E}-01$ & & & & & & & & \\
\hline 8 & 208.98 & & & & & $8.10 \mathrm{E}-01$ & & & & & \\
\hline $\mathrm{Ca}$ & 40.08 & 6.31E-01 & $8.54 E+00$ & $1.07 E+01$ & $6.81 E+00$ & $1.14 E+01$ & & & & & $6.75 E+00$ \\
\hline Cd & 112.41 & & & & $8.99 E-01$ & $9.15 \mathrm{E}-01$ & $4.86 \mathrm{E}-01$ & 2.25E-01 & $2.46 E-01$ & $2.75 \mathrm{E}-01$ & $3.30 \mathrm{E}+00$ \\
\hline Co & 140.12 & 6.31E-01 & 8.41E-01 & & 9.81E-01 & $3.60 E-01$ & & & & & \\
\hline Cr(VI) & 52.00 & $1.92 E+00$ & $2.32 E+00$ & $6.45 E+00$ & $1.56 \mathrm{E}+00$ & $1.23 E+00$ & $5.45 E+01$ & $4.49 E+01$ & $6.29 E+01$ & $3.09 E+01$ & $1.38 E+02$ \\
\hline $\mathrm{Cr}$ (Tot) & 52.00 & $1.99 E+01$ & $2.46 E+01$ & $3.02 E+01$ & $2.60 E+01$ & $1.23 E+00$ & $5.45 E+01$ & $4.49 E+01$ & $6.29 E+01$ & $3.09 E+01$ & $1.38 E+02$ \\
\hline$a_{1}$ & 63.55 & & & & $1.27 \mathrm{E}+00$ & $3.75 E-01$ & 9.41E-02 & 5.39E-02 & $8.01 E-02$ & $5.32 \mathrm{E}-02$ & \\
\hline Dy & 162.50 & $4.88 \mathrm{E}-02$ & $7.80 \mathrm{E}-02$ & & & & & & & & \\
\hline$F_{\theta}$ & 55.85 & $6.70 E+00$ & $4.78 E+01$ & $6.53 E+01$ & $2.79 E+01$ & $5.66 E+01$ & $3.09 E+01$ & $1.44 E+01$ & $1.91 E+01$ & $1.75 \mathrm{E}+01$ & $7.65 E+01$ \\
\hline$K$ & 39.10 & $3.58 E+00$ & $3.46 E+00$ & $1.05 E+00$ & $3.13 E+00$ & $1.20 \mathrm{E}+00$ & $1.25 E+00$ & $3.41 \mathrm{E}-01$ & $6.99 E-01$ & $7.05 E-01$ & \\
\hline $\mathrm{La}$ & 138.91 & $1.21 \mathrm{E}-01$ & $2.08 E-01$ & & & & & & & & \\
\hline 4 & 6.94 & $2.08 E-02$ & 2.08E-02 & & $2.08 E-02$ & & & & & & \\
\hline $\ln$ & 157.00 & $1.36 \mathrm{E}+00$ & $1.72 E+00$ & & $1.57 E+00$ & $3.60 \mathrm{E}-01$ & $0.00 E+00$ & $0.00 E+00$ & $0.00 E+00$ & $0.00 E+00$ & $0.00 E+00$ \\
\hline $\mathrm{Mg}$ & 24.31 & $1.46 E-01$ & $2.59 E+00$ & $2.40 E+00$ & $1.70 E+00$ & $2.28 E+00$ & $2.55 E+00$ & $1.03 E+00$ & $1.34 E+00$ & $1.48 E+00$ & $3.75 E+00$ \\
\hline $\mathrm{Mn}$ & 54.94 & $2.06 E+00$ & $1.89 E+01$ & $1.47 E+01$ & $9.89 E+00$ & $9.60 \mathrm{E}+00$ & $1.05 E+01$ & $5.25 E+00$ & $6.60 \mathrm{E}+00$ & $5.90 \mathrm{E}+00$ & $2.97 E+01$ \\
\hline Mo & 95.94 & $1.44 E-01$ & $1.15 E-01$ & & 9.59E-02 & & & & & & \\
\hline $\mathrm{Na}$ & \begin{tabular}{|r|}
22.99 \\
\end{tabular} & $2.91 \mathrm{E}+02$ & $1.51 E+02$ & $1.42 E+02$ & $1.38 E+02$ & $2.37 E+01$ & & & & & \\
\hline Nd & 144.24 & $4.33 E-01$ & $4.33 E-01$ & & 4.33E-01 & & & & & & \\
\hline $\mathrm{Ni}$ & 58.71 & $4.40 E-01$ & $7.93 E-01$ & $1.34 E+01$ & 5.87E-01 & $8.40 E-01$ & & & & & $1.05 E+00$ \\
\hline$P$ & 30.97 & $1.77 \mathrm{E}+01$ & $6.04 E+00$ & $8.70 E+00$ & & $3.83 E+00$ & & & & & $7.20 E+00$ \\
\hline$P_{D}$ & 207.20 & & & & $3.32 E+00$ & $2.58 E+00$ & & & & & \\
\hline $\mathbf{F}$ & \begin{tabular}{|l|}
102.91 \\
\end{tabular} & 3.09E-01 & $6.17 \mathrm{E}-01$ & & 5.15E-01 & & & & & & \\
\hline $\mathbf{P u}$ & \begin{tabular}{|l|}
101.07 \\
\end{tabular} & $6.06 \mathrm{E}-02$ & $6.06 E-01$ & & 5.05E-01 & & & & & & \\
\hline Sb & 121.75 & & & & $3.65 E-01$ & & & & & & \\
\hline
\end{tabular}




\begin{tabular}{|c|c|c|c|c|c|c|c|c|c|c|c|}
\hline \multicolumn{2}{|c|}{ Sample 10: } & \multirow{2}{*}{\begin{tabular}{|c|}
$102-S Y-4 B$ \\
$1.07 E+01$
\end{tabular}} & \multirow{2}{*}{ 102SY3T4S } & \multirow[t]{2}{*}{ 102SY3T4S } & \multirow{2}{*}{\begin{tabular}{|r|}
$1025 Y 3 T 4 S$ \\
$2.37 E+00$ \\
\end{tabular}} & \multirow{2}{*}{ 102SYSollds } & \multirow[t]{2}{*}{ A-3316 } & \multirow[t]{2}{*}{ A-3317 } & \multirow[t]{2}{*}{ A-3318 } & \multirow[t]{2}{*}{ A-3316 } & \multirow[t]{2}{*}{ A-3036 } \\
\hline Se & 78.96 & & & & & & & & & & \\
\hline $\mathbf{s}$ & 28.09 & $1.26 E+00$ & $4.04 E+00$ & & $2.25 \mathrm{E}+00$ & $1.32 E+00$ & & & & & \\
\hline $\mathrm{Sr}$ & 87.62 & 2.63E-02 & $2.63 E-01$ & & $8.76 E-02$ & $1.65 \mathrm{E}-01$ & & & & & \\
\hline Te & 127.60 & 3.83E-01 & 3.83E-01 & & 3.83E-01 & & & & & & \\
\hline Th & 232.04 & & & & $6.96 \mathrm{E}+00$ & & & & & & \\
\hline$\pi$ & 47.90 & 5.75E-02 & $2.16 E-01$ & & $1.44 E-01$ & & & & & & \\
\hline$\pi$ & 204.37 & & & & $2.04 E+00$ & & & & & & \\
\hline $\mathrm{U}$ & 238.03 & $1.95 E+00$ & & & $7.14 E+00$ & & & & & & \\
\hline$v$ & 50.94 & & & & 5.09E-02 & & & & & & \\
\hline $\mathbf{Z n}$ & 65.38 & 9.81E-02 & 8.83E-01 & & $4.58 E-01$ & $7.50 E-01$ & & & & & \\
\hline $\mathrm{Zr}$ & 91.22 & 9.71E-02 & 6.84E-01 & & $3.65 \mathrm{E}-01$ & & & & & & \\
\hline \multicolumn{2}{|c|}{ Tot Motals: } & $4.45 E+02$ & $3.30 E+02$ & $4.23 E+02$ & $2.98 E+02$ & $1.33 E+02$ & $2.38 E+02$ & $1.76 E+02$ & $2.07 E+02$ & $1.35 E+02$ & $5.06 E+02$ \\
\hline & & & & & & & & & & & \\
\hline Anlons & & $g / L$ & $g / L$ & $g / L$ & $g / 2$ & $0 / 2$ & $g / L$ & $g / L$ & $g / L$ & $g / L$ & $g / L$ \\
\hline $\mathbf{F}$ & 19.00 & $2.48 E+00$ & & $1.65 E+00$ & $5.70 E+00$ & $1.20 E-01$ & & & & & \\
\hline a & 35.45 & $1.06 E+01$ & & $2.55 E+00$ & $5.32 E+00$ & $1.14 E+01$ & $7.80 E+00$ & $9.00 E+00$ & $9.54 E+00$ & $4.43 E+00$ & \\
\hline $\mathrm{NO2}$ & 46.01 & $6.87 E+01$ & & & $3.68 E+01$ & & & & & & \\
\hline $\mathrm{NO3}$ & 62.00 & $3.02 E+02$ & & $7.40 E+01$ & $1.86 E+02$ & & & & & & \\
\hline PO4 & 94.97 & $6.84 E+01$ & & $1.32 E+01$ & $5.70 E+01$ & $3.00 E+01$ & & & & $6.26 \mathrm{E}-01$ & \\
\hline 504 & 96.06 & $1.15 E+01$ & & $2.94 E+01$ & $9.61 E+00$ & $3.00 E+01$ & $6.54 E+01$ & $2.09 E+01$ & $7.95 E+01$ & $3.57 E+01$ & \\
\hline 003 & 60.01 & $0.00 E+00$ & & & $3.60 E+01$ & & & & & & \\
\hline $\mathrm{OH}$ & 17.01 & $2.55 E+01$ & & $2.25 E+00$ & $2.55 E+01$ & & & & & & \\
\hline \multicolumn{2}{|c|}{ Tot Anlons: } & $4.89 E+02$ & $0.00 E+00$ & $1.23 E+02$ & $3.62 E+02$ & $7.15 E+01$ & $7.32 E+01$ & $2.99 E+01$ & $8.90 E+01$ & $4.08 E+01$ & $0.00 E+00$ \\
\hline & & & & & & & & & & & \\
\hline \multirow{2}{*}{\multicolumn{2}{|c|}{ Tot Org C: }} & & & & & $1.13 E+01$ & & & & & $7.50 \mathrm{E}-01$ \\
\hline & & & & & & & & & & & \\
\hline \multicolumn{2}{|c|}{ Tot Comp: } & $9.34 E+02$ & $3.30 E+02$ & $5.46 \mathrm{E}+02$ & $6.59 E+02$ & $2.16 \mathrm{E}+02$ & $3.12 E+02$ & $2.05 E+02$ & $2.96 \mathrm{E}+02$ & $1.76 E+02$ & $5.07 E+02$ \\
\hline & & & & & & & & & & & \\
\hline TRUe & & $\mathrm{uCI} / \mathrm{L}$ & $u \mathrm{CI} / \mathrm{L}$ & $\mathrm{uCI} / \mathrm{L}$ & $\mathrm{uCI} / \mathrm{L}$ & $u C I / L$ & $u C I / L$ & $u C I / L$ & $\mathrm{UCI} / \mathrm{L}$ & $\mathrm{uCM} / \mathrm{L}$ & UCIL \\
\hline Am-241 & 241.06 & $1.46 \mathrm{E}+03$ & $1.47 E+04$ & $1.23 E+05$ & $3.12 E+04$ & $6.79 E+04$ & $3.54 E+04$ & $1.07 E+04$ & $1.56 E+04$ & $2.06 E+04$ & \\
\hline Cm-243 & 243.00 & & & & & & & & & & \\
\hline $\mathrm{Cm}-244$ & 244.00 & & & & $8.19 E+01$ & & & & & & \\
\hline$C m-24 x$ & 243.56 & $6.45 E+01$ & $2.85 E+01$ & & & & & & & & \\
\hline Np-237 & 237.05 & 8.85E-01 & $1.22 E+00$ & & $1.43 E+00$ & & $3.60 E+04$ & $2.67 E+04$ & $3.87 E+04$ & $2.09 E+04$ & \\
\hline Pu-238 & 238.05 & $5.55 E+01$ & $1.18 E+03$ & & & & & & & & \\
\hline Pu-239 & 239.05 & $1.95 E+02$ & $4.23 \mathrm{E}+03$ & & $6.28 E+03$ & $4.07 E+04$ & $1.13 E+04$ & $3.18 E+03$ & $3.92 E+03$ & $6.58 E+03$ & \\
\hline $\mathrm{Pu}-240$ & 240.05 & $5.85 E+01$ & $1.79 E+03$ & & $2.30 E+03$ & & & & & & \\
\hline Pu-241 & 241.06 & $1.83 E+03$ & $5.37 E+04$ & & & & & & & & $3.62 E+03$ \\
\hline Pu-242 & 242.00 & & & & & & & & & & \\
\hline $\mathrm{Pu}-244$ & 244.00 & & & & & & & & & & \\
\hline
\end{tabular}


SY-102 SOUD COMPOSTIONS

\begin{tabular}{|c|c|c|c|c|c|c|c|c|c|c|c|}
\hline \multicolumn{2}{|c|}{ Sample 1D: } & \multirow{2}{*}{\begin{tabular}{|c|}
$102-5 Y-4 B$ \\
$U C I / L$ \\
\end{tabular}} & \multirow{2}{*}{\begin{tabular}{|c|}
$1025 Y 3 T 4 S$ \\
$U C I / L$ \\
\end{tabular}} & \multirow{2}{*}{\begin{tabular}{|c|}
$102 S Y 3 T 4 S$ \\
UCIIL
\end{tabular}} & \multirow{2}{*}{\begin{tabular}{|c|} 
102SY3T4S \\
$\mathrm{UCI} / \mathrm{L}$ \\
\end{tabular}} & \multirow{2}{*}{\begin{tabular}{|c|} 
102SYSolids \\
$\mathrm{uCl} / \mathrm{L}$ \\
\end{tabular}} & \multirow{2}{*}{\begin{tabular}{|c|}
$\mathrm{R}-3316$ \\
$\mathrm{uCl} / \mathrm{L}$ \\
\end{tabular}} & \multirow{2}{*}{\begin{tabular}{|r|}
$\mathrm{A}-3317$ \\
$\mathrm{CCI} / \mathrm{L}$ \\
\end{tabular}} & \multirow{2}{*}{\begin{tabular}{|r|} 
R-3318 \\
uCI/L \\
\end{tabular}} & \multirow{2}{*}{$\begin{array}{r}\mathrm{R}-3316 \\
\mathrm{UCI} / \mathrm{L}\end{array}$} & \multirow{2}{*}{$\frac{R-3036}{u C I / L}$} \\
\hline n-TRUs & & & & & & & & & & & \\
\hline $\mathrm{H}-3$ & 3.02 & $1.95 E+00$ & 9.30E-01 & & & & & & & & \\
\hline$c-14$ & 14.00 & $2.70 E+00$ & & & $3.00 E+00$ & & & & & & \\
\hline $1-129$ & 129.00 & $3.60 E-01$ & $3.60 E-01$ & & $4.00 E-01$ & & & & & & \\
\hline $\mathrm{Nb}-94$ & 94.00 & $6.15 E+00$ & $3.45 E+00$ & & & & & & & & \\
\hline $\mathrm{Ni}-63$ & 63.00 & $4.35 E+03$ & $8.25 E+03$ & & $6.00 E+03$ & & & & & & \\
\hline Se-79 & 79.00 & 4.77E-01 & $2.70 E-01$ & & & & & & & & \\
\hline Sr-90 & 90.00 & $1.01 E+05$ & & $3.15 E+05$ & $1.00 E+05$ & & $3.80 E+05$ & $2.82 E+05$ & $3.93 E+05$ & $2.21 E+05$ & $1.16 E+06$ \\
\hline Tc-99 & 99.00 & $3.03 E+02$ & $3.30 E+02$ & & $3.00 E+02$ & $6.00 E+01$ & & & & & \\
\hline$C_{0-144}$ & 144.00 & $1.65 E+03$ & & & $2.00 E+03$ & & & & & & \\
\hline Co-60 & 60.00 & $1.65 E+02$ & & & $2.00 E+02$ & & $1.06 E+03$ & $7.56 \mathrm{E}+02$ & & $6.17 E+02$ & \\
\hline Cs-134 & 134.00 & $9.60 \mathrm{E}+01$ & & & $1.00 \mathrm{E}+02$ & & & & & & \\
\hline Cs-137 & 137.00 & $2.25 E+05$ & & $2.70 E+04$ & 2.COE+05 & $2.15 E+04$ & $2.31 E+05$ & $2.00 E+05$ & $2.67 E+05$ & $1.34 E+05$ & $1.52 E+05$ \\
\hline Eu-152 & 152.00 & $2.25 E+02$ & & & $2.00 E+02$ & & $1.27 E+04$ & $9.56 E+03$ & $1.40 E+04$ & $7.40 E+03$ & \\
\hline Eu-154 & 154.00 & $2.25 E+03$ & & & $4.00 \mathrm{E}+03$ & & $8.27 E+03$ & $6.38 E+03$ & $8.54 E+03$ & $4.80 E+03$ & \\
\hline Eu-155 & 155.00 & & & & & & & & & & \\
\hline Ru-106 & 106.00 & $2.40 \mathrm{E}+03$ & & & $2.00 \mathrm{E}+03$ & & & & & & \\
\hline $\mathrm{Sb}-125$ & 125.00 & $2.40 E+03$ & & & $2.00 E+03$ & & & & & $8.63 E+02$ & \\
\hline Zr-95 & 91.22 & & & & & & $6.57 E+02$ & $4.97 E+02$ & & $3.82 E+02$ & \\
\hline & & & & & & & & & & & \\
\hline \multicolumn{2}{|c|}{ Tol TRUs } & $3.66 E+03$ & $7.57 E+04$ & $1.29 E+05$ & $3.99 E+04$ & $1.09 E+05$ & $8.27 E+04$ & $4.06 \mathrm{E}+04$ & $5.82 E+04$ & $4.81 E+04$ & $3.62 E+03$ \\
\hline \multicolumn{2}{|c|}{ Tot n-TRUs } & $3.40 \mathrm{E}+05$ & $8.59 E+03$ & $3.42 E+05$ & $3.17 E+05$ & $2.16 E+04$ & $6.33 E+05$ & $4.99 E+05$ & $6.83 E+05$ & $3.69 E+05$ & $1.31 E+06$ \\
\hline \multicolumn{2}{|c|}{ Tot Radlonuclld } & $3.44 E+05$ & $8.42 E+04$ & $4.71 E+05$ & $3.57 \mathrm{E}+05$ & $1.30 E+05$ & $7.16 \mathrm{E}+05$ & $5.39 E+05$ & $7.41 E+05$ & $4.17 E+05$ & $1.31 E+06$ \\
\hline
\end{tabular}


1988 AND 1990 CORE ANALYSIS COMPARISON

Filename: 3T4S.Data.Solid 


\begin{tabular}{|c|c|c|c|c|c|c|c|c|c|c|c|}
\hline \multicolumn{2}{|c|}{ Sample ID: } & $4 B$ & $3 T 4 S$ & 3T4S & 3T4S-1 & $3 T 4 S-3$ & $3 T 4 S-8$ & 34 COMP-6 & 34 COMP-7 & 3TAS Ave & 34 Conp Ave \\
\hline \multicolumn{2}{|c|}{ Sample Date: } & $10 / 25 / 88$ & $10 / 25 / 88$ & $10 / 25 / 88$ & $10 / 25 / 88$ & $10 / 25 / 88$ & $10 / 25 / 88$ & $2 / 27 / 90$ & $2 / 27 ; 90$ & & \\
\hline \multirow{2}{*}{\multicolumn{2}{|c|}{$\begin{array}{l}\text { Analyets Date: } \\
\text { Analyet }\end{array}$}} & $6 / 30 / 89$ & $6 / 30 / 89$ & $7 / 6 / 90$ & $?$ & ? & $?$ & $?$ & $?$ & & \\
\hline & & PNL: Scheole & PNL: Schoole & PCL: Herting & PNL: Lumotta & PNL: Lumotta & PNL: Lumetta & PNL: Lumetta & PNL: Lumetta & & \\
\hline & & \& Peterson & \& Peterson & & \& Swanson & \& Swanson & \& Swanson & \& Swanson & \begin{tabular}{|l|} 
Swanson \\
\end{tabular} & & \\
\hline \multicolumn{2}{|c|}{ Sample Slte: } & Oct'88 core & Oct'88 core & Oct'88 core & Oct'88 core & Oct'88 core & Oct'88 coro & Fob'90 core & Feb'90 core & & \\
\hline \multicolumn{2}{|c|}{ Sample Notes: } & Segment 4 & Comp 384 & Comp 3/4 & Comp 3/4 & Comp 3/4 & Comp 3/4 & Comp 3/4 & Comp 3/4 & & \\
\hline \multicolumn{2}{|c|}{ Reference: } & Peterson to & Peterson to & Herting to & Draft Report & Draft Report & Draft Report & Draft Report & Draft Report & & \\
\hline & & Diliberto & Diliberto & Sasaki & & & & & & & \\
\hline & & $6 / 30 / 89$ & $6 / 30 / 89$ & \begin{tabular}{|l}
$7 / 6 / 90$ \\
\end{tabular} & $3 / 1 / 93$ & $3 / 1 / 93$ & $3 / 1 / 93$ & $3 / 1 / 93$ & $3 / 1 / 93$ & & \\
\hline Phase: & & Solld & Solld & Solld & Solid & Solld & Solld & Solld & Solld & Solld & Solld \\
\hline Specle & Mase & $w t \%$ & wt\% & $w 1 \%$ & $w t \%$ & $w t \%$ & $w t \%$ & $m i x$ & $w t \%$ & $w 1 \%$ & wtx \\
\hline Al & 26.98 & $5 \%$ & $3 \%$ & $9.0000 \%$ & $3.3600 \%$ & $2.8600 \%$ & $4.3100 \%$ & $1.9000 \%$ & $2.2400 \%$ & $4.6021 \%$ & $2.0700 \%$ \\
\hline $\mathrm{Ca}$ & 40.08 & $0 \%$ & $1 \%$ & $0.7100 \%$ & $0.7100 \%$ & $0.7800 \%$ & $0.0400 \%$ & $0.1600 \%$ & $0.2700 \%$ & $0.5618 \%$ & $0.2150 \%$ \\
\hline $\operatorname{Cr}(T \circ t)$ & 52.00 & $1 \%$ & $2 \%$ & $2.0100 \%$ & $2.3500 \%$ & $2.4200 \%$ & $2.7700 \%$ & $1.0200 \%$ & $1.1600 \%$ & $2.2386 \%$ & $1.0900 \%$ \\
\hline Fo & 55.85 & $0 \%$ & $3 \%$ & $4.3500 \%$ & $4.2700 \%$ & $4.3100 \%$ & $5.1700 \%$ & $1.0000 \%$ & $1.0400 \%$ & $4.2578 \%$ & $1.0200 \%$ \\
\hline $\mathbf{K}$ & 39.10 & $0 \%$ & $0 \%$ & $0.0700 \%$ & $0.1800 \%$ & & $0.1400 \%$ & $0.1700 \%$ & & $0.1552 \%$ & $0.1700 \%$ \\
\hline $\mathrm{Mn}$ & 54.94 & $0 \%$ & $1 \%$ & $0.9800 \%$ & $1.7100 \%$ & & $2.1100 \%$ & $0.2700 \%$ & & $1.5145 \%$ & $0.2700 \%$ \\
\hline $\mathbf{P}$ & 30.97 & $1 \%$ & $0 \%$ & $0.5800 \%$ & $0.4900 \%$ & $0.5000 \%$ & $0.1200 \%$ & $0.9500 \%$ & $0.7800 \%$ & $0.4185 \%$ & $0.8650 \%$ \\
\hline$P b$ & 207.20 & & & & $0.3200 \%$ & $0.3300 \%$ & $0.3800 \%$ & $0.0700 \%$ & $0.0700 \%$ & $0.3433 \%$ & $0.0700 \%$ \\
\hline Th & 232.04 & & & & $0.8600 \%$ & $0.8400 \%$ & $0.9100 \%$ & $0.0400 \%$ & $0.1000 \%$ & $0.8700 \%$ & $0.0700 \%$ \\
\hline $\mathrm{U}$ & 238.03 & $0 \%$ & & & $0.2000 \%$ & $0.2600 \%$ & $0.2500 \%$ & & & $0.2367 \%$ & \\
\hline \multicolumn{2}{|c|}{ Total Metals: } & $8.3003 \%$ & $10.7731 \%$ & $17.7000 \%$ & $14.4500 \%$ & $12.3000 \%$ & $16.2000 \%$ & $5.5800 \%$ & $5.6600 \%$ & & \\
\hline
\end{tabular}




\begin{tabular}{|c|c|c|c|c|c|c|c|c|c|}
\hline \multirow[b]{2}{*}{ Catlon } & \multirow[b]{2}{*}{$(+1)}$. & \multirow[b]{2}{*}{ Mases } & \multicolumn{4}{|c|}{ MUNIMUM NECATIVE DN CABE } & \multirow[b]{2}{*}{ Maee } & \multirow[b]{2}{*}{$W t \%$} & \multirow[b]{2}{*}{ Net $(\cdot)$} \\
\hline & & & Wix & Not $(t)$ & Anlon & $(+1 \cdot)$ & & & \\
\hline$A_{9}$ & 1 & 107.87 & & & $\mathbf{F}$ & .1 & 10.00 & $0.17 \%$ & -0.8701 \\
\hline Al & 3 & 26.08 & $4.80 \%$ & 63.3098 & a & .1 & 36.45 & $0.71 \%$ & -2.0001 \\
\hline As & 6 & 74.92 & & & $\mathrm{Br}$ & .1 & 70.01 & & \\
\hline $\mathbf{B}$ & 3 & 10.81 & & & 1 & .1 & 126.00 & & \\
\hline $\mathrm{Ba}$ & 2 & 137.33 & $0.00 \%$ & 0.0030 & $\mathrm{NO2}$ & .1 & 46.01 & $4.58 \%$ & .0 .0400 \\
\hline B & 3 & 208.08 & & & NO3 & -1 & 62.00 & $20.15 \%$ & .32 .5000 \\
\hline a & 2 & 40.08 & $0.04 \%$ & 0.2101 & PO4 & .3 & 04.07 & $4.66 \%$ & -14.3900 \\
\hline$\infty$ & 2 & 112.41 & & & 504 & .2 & 20.06 & $0.77 \%$ & .1 .0000 \\
\hline$a$ & 3 & 52.00 & $1.33 \%$ & 7.6500 & $\infty$ & .2 & 60.01 & & \\
\hline$Q$ & 2 & 63.55 & & & OH & .1 & 17.01 & $1.70 \%$ & -9.0098 \\
\hline$F_{0}$ & 3 & 55.85 & $0.45 \%$ & 2.4001 & $0^{*}$ & .2 & 16.00 & $0.17 \%$ & -2.0099 \\
\hline$K$ & 1 & 39.10 & $0.24 \%$ & 0.6100 & $\mathrm{OH}^{\circ}$ & .1 & 17.01 & $0.22 \%$ & -1.2990 \\
\hline 4 & 1 & 6.94 & $0.00 \%$ & 0.0202 & $0^{\circ}$ & 0 & 16.00 & $1.39 \%$ & 0.0000 \\
\hline $\operatorname{Ln}$ & 3 & 157.00 & $0.09 \%$ & 0.1733 & $N$ & -3 & 14.01 & & \\
\hline $\mathrm{Mg}$ & 2 & 24.31 & $0.01 \%$ & 0.0798 & $P$ & .3 & 30.07 & & \\
\hline $\mathrm{Mn}$ & 4 & 54.94 & $0.14 \%$ & 0.8907 & $s$ & .2 & 32.06 & & \\
\hline Mo & 3 & 95.94 & $0.01 \%$ & 0.0300 & so & .2 & 78.06 & $0.71 \%$ & -1.7909 \\
\hline $\mathrm{Na}$ & 1 & 22.99 & $19.43 \%$ & 84.5002 & $c$ & .4 & 12.01 & & \\
\hline $\mathrm{Ni}$ & 2 & 58.71 & $0.03 \%$ & 0.1002 & $\mathbf{s}$ & .4 & 28.00 & $0.08 \%$ & .1 .2006 \\
\hline$P_{0}$ & 2 & 207.20 & & & $H$ & 1 & 1.01 & & \\
\hline F & 3 & 102.01 & $0.02 \%$ & 0.0601 & $A_{B}$ & .3 & 74.02 & $0.68 \%$ & -2.7228 \\
\hline $\mathrm{Au}_{1}$ & 3 & 101.07 & $0.00 \%$ & 0.0110 & $\mathrm{~B}$ & .0 .5 & 10.81 & $0.02 \%$ & .0 .0800 \\
\hline So & 3 & 121.75 & & & & & & & \\
\hline Se & -2 & 78.96 & & & & & & & \\
\hline$S$ & .4 & 28.09 & & & & & & & \\
\hline$S r$ & 2 & 87.62 & $0.00 \%$ & 0.0041 & & & & & \\
\hline To & 2 & 127.60 & $0.03 \%$ & 0.0400 & & & ' & & \\
\hline Th & 4 & 232.04 & & & & & & & \\
\hline $\mathrm{TI}$ & 4 & 47.90 & $0.00 \%$ & 0.0317 & & & & & \\
\hline TI & 3 & 204.37 & & & & & & & \\
\hline$U$ & 4 & 238.03 & $0.13 \%$ & 0.2185 & & & & & \\
\hline $\mathrm{V}$ & 3 & 50.94 & & & & & & & \\
\hline $\mathrm{Zn}$ & 2 & 65.38 & $0.01 \%$ & 0.0189 & & & & & \\
\hline $\mathrm{Zr}$ & 4 & 91.22 & $0.01 \%$ & 0.0285 & & & & & \\
\hline \multicolumn{3}{|c|}{ Cation Totals $(w t \% / t)$} & $26.76 \%$ & 150.5610 & Anion & Totals & $(m+x / 1)$ & $35.81 \%$ & -80.5230 \\
\hline \multicolumn{3}{|c|}{ Wi\% Cation + Anion } & $62.67 \%$ & & & & & & \\
\hline & & & & & & & & & \\
\hline \multicolumn{3}{|c|}{ Wi\% Cation + Oxide } & $40.56 \%$ & (calc) & $\mathrm{OH}^{\cdots \cdot \cdots}$ & -1 & 17.01 & $9.08 \%$ & -53.3698 \\
\hline & & & $38.40 \%$ & $(\exp )$ & \multicolumn{3}{|c|}{ Total Anion Charge *.* } & & -133.8928 \\
\hline & & & & & & & & & \\
\hline Notes & & & & & & & & & \\
\hline \multicolumn{10}{|c|}{ 1) Assumes that only N, P, S, B, As, So and Si exist as oxyanions. } \\
\hline \multicolumn{10}{|c|}{\begin{tabular}{|l|l|l|} 
2) Data from Schoole and Poterson's analysis of 102-SY-4B solid & & \\
\end{tabular}} \\
\hline \multicolumn{10}{|c|}{ 3) - Includes values of mass and charge for $\mathrm{O}$ and $\mathrm{OH}$ tied up in $\mathrm{FeOOH}$ and $\mathrm{MnO}(\mathrm{OH}) 2$. } \\
\hline \multicolumn{10}{|c|}{\begin{tabular}{ll|l|l|} 
4) " includes mass of $O$ tied up in borate, arsenate, selenate and allicate. & \\
\end{tabular}} \\
\hline \multicolumn{10}{|c|}{ 5) -... If hydroxide instead of nitrate is the counterion for aluminum in the eludge, then } \\
\hline & 10 total & nion charge & becomes: & $8.133 .8, \mathrm{muc}$ & ch close & in to the & lotal cation & charge ca & culated! \\
\hline & & & & & & & & & \\
\hline & & & & & & & & & \\
\hline & & & & & & & & & \\
\hline & & & & & & & & & \\
\hline
\end{tabular}




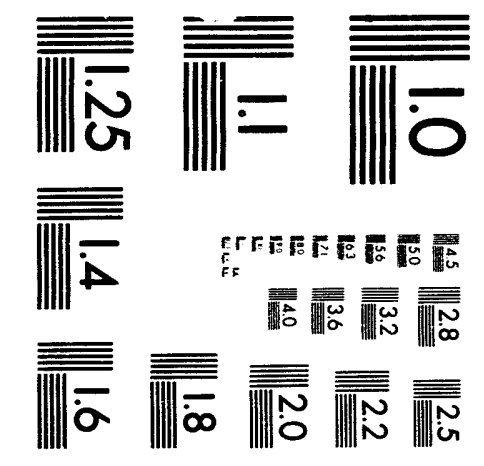



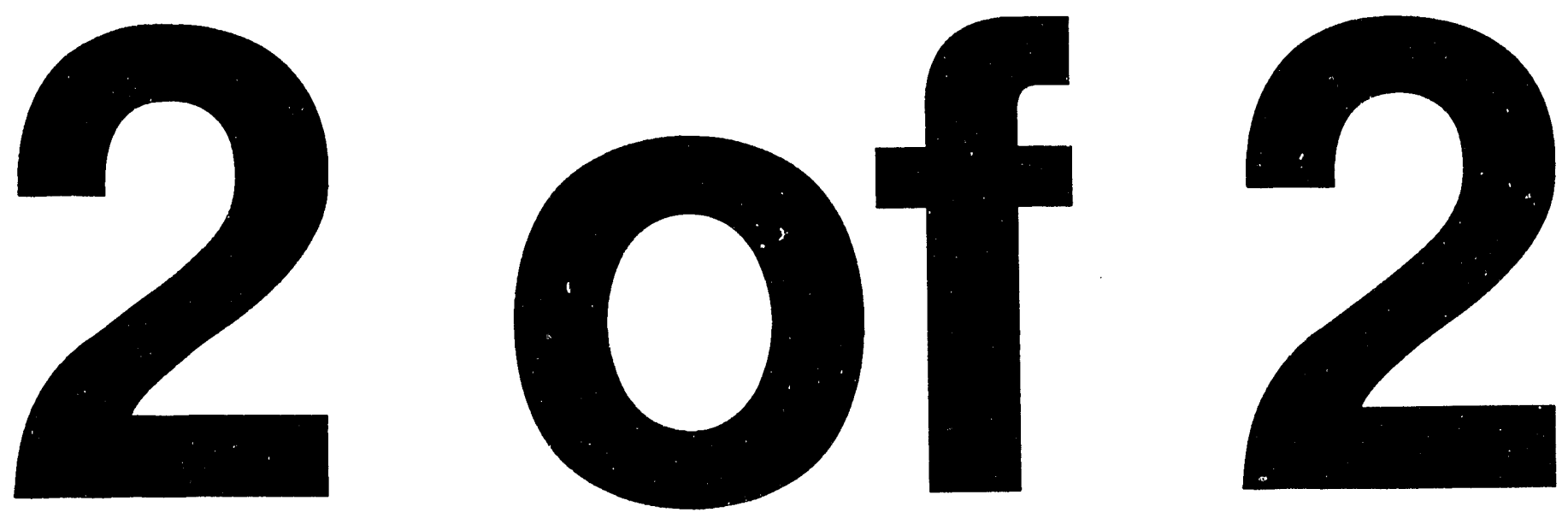


\begin{tabular}{|c|c|c|c|c|c|c|c|c|c|}
\hline \multirow[b]{2}{*}{ Catlon } & \multirow[b]{2}{*}{$(+1-)$} & \multirow[b]{2}{*}{ Mases } & \multicolumn{4}{|c|}{ MAXIMUM NEGATIVE ION CASE } & \multirow[b]{2}{*}{ Mases } & \multirow[b]{2}{*}{ Wt\% } & \multirow[b]{2}{*}{ Net $(-)$} \\
\hline & & & $W t \%$ & Net $(t)$ & Anlon & $(+1-)$ & & & \\
\hline $\mathrm{Ag}$ & 1 & 107.87 & & & \begin{tabular}{|l|l|}
$F$ \\
\end{tabular} & -1 & 19.00 & $0.17 \%$ & -0.8701 \\
\hline Al & 3 & 26.98 & & & $a$ & -1 & 35.45 & $0.71 \%$ & -2.0001 \\
\hline As & 5 & 74.92 & & & $\mathrm{Br}$ & -1 & 79.91 & & \\
\hline B & 3 & 10.81 & & & 1 & -1 & 126.90 & & \\
\hline $\mathrm{Ba}$ & 2 & 137.33 & $0.00 \%$ & 0.0039 & NO2 & -1 & 46.01 & $4.58 \%$ & -9.9499 \\
\hline $\mathrm{Bi}$ & 3 & 208.98 & & & $\mathrm{NOS}$ & -1 & 62.00 & $20.15 \%$ & -32.5000 \\
\hline ca & 2 & 40.08 & $0.04 \%$ & 0.2101 & PO4 & -3 & 94.97 & $4.56 \%$ & -14.3999 \\
\hline Cd & 2 & 112.41 & & & so4 & -2 & 96.06 & $0.77 \%$ & -1.6000 \\
\hline$a$ & 3 & 52.00 & & & $\infty$ & -2 & 60.01 & & \\
\hline as & 2 & 63.55 & & & $\mathrm{OH}$ & -1 & 17.01 & $1.70 \%$ & -9.9998 \\
\hline $\mathrm{Fe}_{\mathrm{e}}$ & 3 & 55.85 & $0.45 \%$ & 2.4001 & Al & -1 & 26.98 & $4.80 \%$ & -17.7899 \\
\hline $\mathbf{K}$ & 1 & 39.10 & $0.24 \%$ & 0.6100 & As & -3 & 74.92 & $0.68 \%$ & -2.7228 \\
\hline $\mathrm{Li}$ & 1 & 6.94 & $0.00 \%$ & 0.0202 & 8 & -0.5 & 10.81 & $0.02 \%$ & -0.0800 \\
\hline $\operatorname{Ln}$ & 3 & 157.00 & $0.10 \%$ & 0.1911 & $a$ & -2 & 52.00 & $1.33 \%$ & -5.1000 \\
\hline $\mathrm{Mg}$ & 2 & 24.31 & $0.01 \%$ & 0.0798 & Mo & -2 & 95.94 & $0.01 \%$ & -0.0200 \\
\hline $\mathrm{Mn}$ & 4 & 54.94 & $0.14 \%$ & 0.9897 & $V$ & -3 & 50.94 & & \\
\hline Mo & 3 & 05.94 & & & So & -2 & 78.96 & $0.71 \%$ & -1.7999 \\
\hline $\mathrm{Na}$ & 1 & 22.99 & $19.43 \%$ & 84.5002 & Si & -4 & 28.09 & $0.08 \%$ & -1.2006 \\
\hline $\mathrm{Ni}$ & 2 & 58.71 & $0.03 \%$ & 0.1002 & $0^{\circ}$ & -2 & 16.00 & $0.17 \%$ & -2.0999 \\
\hline $\mathrm{Pb}$ & 2 & 207.20 & & & $\mathrm{OH}^{*}$ & -1 & 17.01 & $0.22 \%$ & -1.2999 \\
\hline Fh & 3 & 102.91 & $0.02 \%$ & 0.0601 & 0 & 0 & 16.00 & $3.03 \%$ & 0.0000 \\
\hline Ru & 3 & 101.07 & $0.00 \%$ & 0.0119 & $\mathrm{OH}^{\circ *}$ & 0 & 17.01 & $12.10 \%$ & 0.0000 \\
\hline Sb & 3 & 121.75 & & & $N$ & -3 & 14.01 & & \\
\hline Se & -2 & 78.96 & & & $P$ & .3 & 30.97 & & \\
\hline Si & .4 & 28.09 & & & $s$ & -2 & 32.06 & & \\
\hline Sr & 2 & 87.62 & $0.00 \%$ & 0.0041 & C & -4 & 12.01 & & \\
\hline Te & 2 & 127.60 & $0.03 \%$ & 0.0400 & $\mathrm{H}$ & 1 & 1.01 & & \\
\hline Th & 4 & 232.04 & & & & & & & \\
\hline $\mathrm{Ti}$ & 4 & 47.90 & $0.00 \%$ & 0.0317 & & & & & \\
\hline $\mathrm{TI}$ & 3 & 204.37 & & & & & & & \\
\hline$\underline{u}$ & 4 & 238.03 & $0.13 \%$ & 0.2185 & & & & & \\
\hline V & 3 & 50.94 & & & & & & & \\
\hline $\mathrm{Zn}$ & 2 & 65.38 & $0.01 \%$ & 0.0199 & & & & & \\
\hline $\mathrm{Zr}$ & 4 & 91.22 & $0.01 \%$ & 0.0285 & & & & & \\
\hline \multicolumn{3}{|c|}{ Cation Totals $(w+\% / t)$} & $20.63 \%$ & 89.5298 & Anion & Totals & $(w+\% / \cdot)$ & $55.78 \%$ & -103.4329 \\
\hline \multicolumn{3}{|c|}{ Wi\% Cation + Anion } & $76.42 \%$ & & & & & & \\
\hline & & & & & & & & & \\
\hline \multicolumn{3}{|c|}{ Wt\% Cation + Oxide } & $40.56 \%$ & (calc) & & & & & \\
\hline & & & $38.40 \%$ & (exp) & & & & & \\
\hline & & & & & & & & & \\
\hline Notes & & & & & & & & & \\
\hline \multicolumn{10}{|c|}{ 1) Assumes that in addition to $N, P, S, B, A s$, Se and Si existing as oxyanions, } \\
\hline \multicolumn{10}{|c|}{$\mathrm{Cr}_{\mathrm{r}}$ and $\mathrm{MO}$ also exist as oxyanions and $\mathrm{Al}$ as the hydroxyanion. } \\
\hline \multicolumn{9}{|c|}{\begin{tabular}{|l|l|l|} 
2) Data from Scheele and Peterson's analysis of 102-SY-4B solid & & \\
\end{tabular}} & \\
\hline \multicolumn{10}{|c|}{ 3) " includes values of mass and charge for $\mathrm{O}$ and $\mathrm{OH}$ tied up in $\mathrm{FeOOH}$ and $\mathrm{MnO}(\mathrm{OH}) 2$. } \\
\hline \multicolumn{10}{|c|}{ 4) "* includes mass of $\mathrm{O}$ tied up in borate, arsenate, selenate, silicate, chromate and } \\
\hline \multicolumn{10}{|c|}{\begin{tabular}{|c|l|l|l|} 
molybdate, as well as $\mathrm{OH}$ tied up in the $\mathrm{A}(\mathrm{OH}) 4$ anion. & & & \\
\end{tabular}} \\
\hline & & & & & & & & & \\
\hline & & & & & & & & & \\
\hline & & & & & & & & & \\
\hline & & & & & & & & & \\
\hline
\end{tabular}




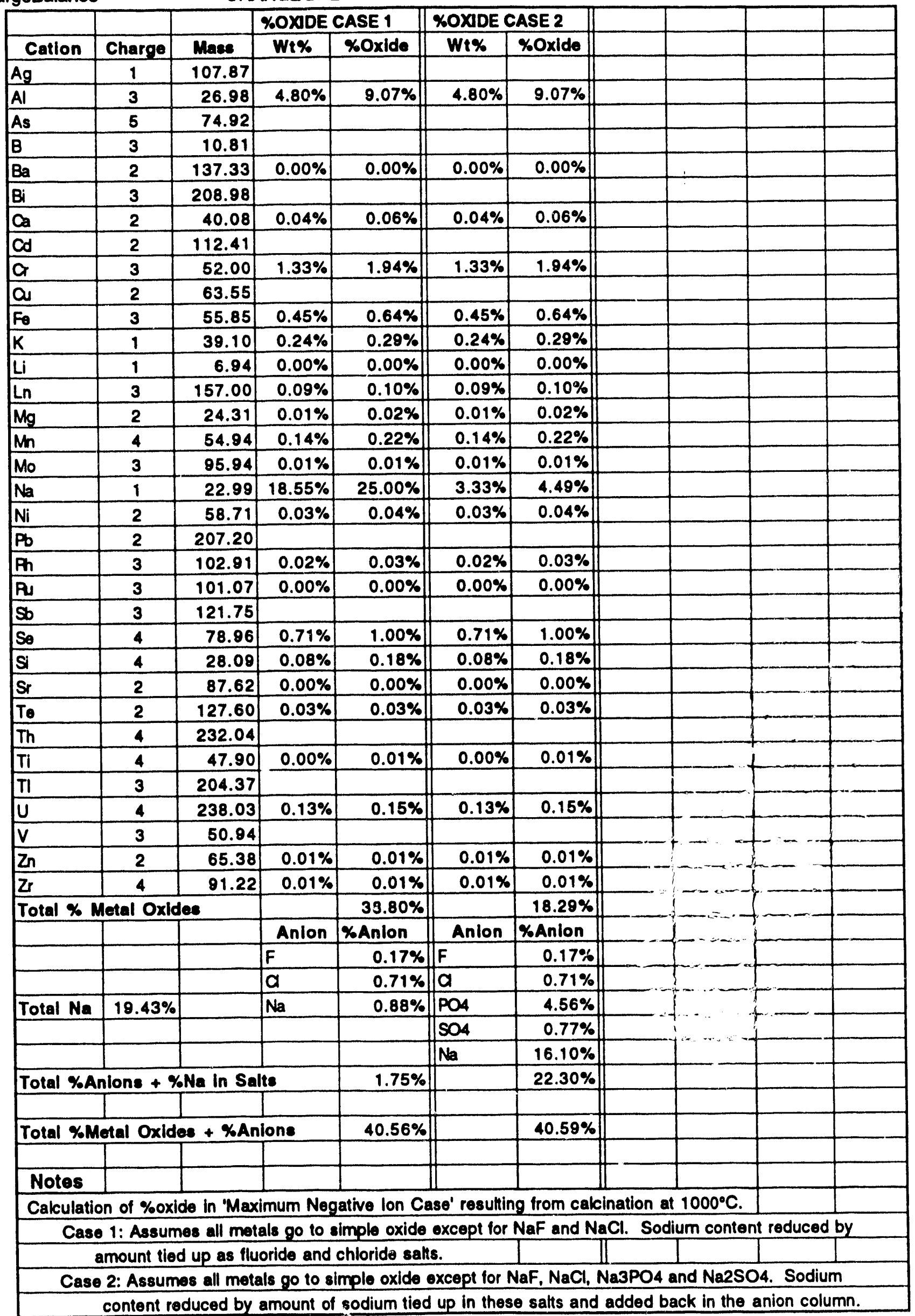


ChargeBalance.complete

REASONABLE CHARGE BALANCE

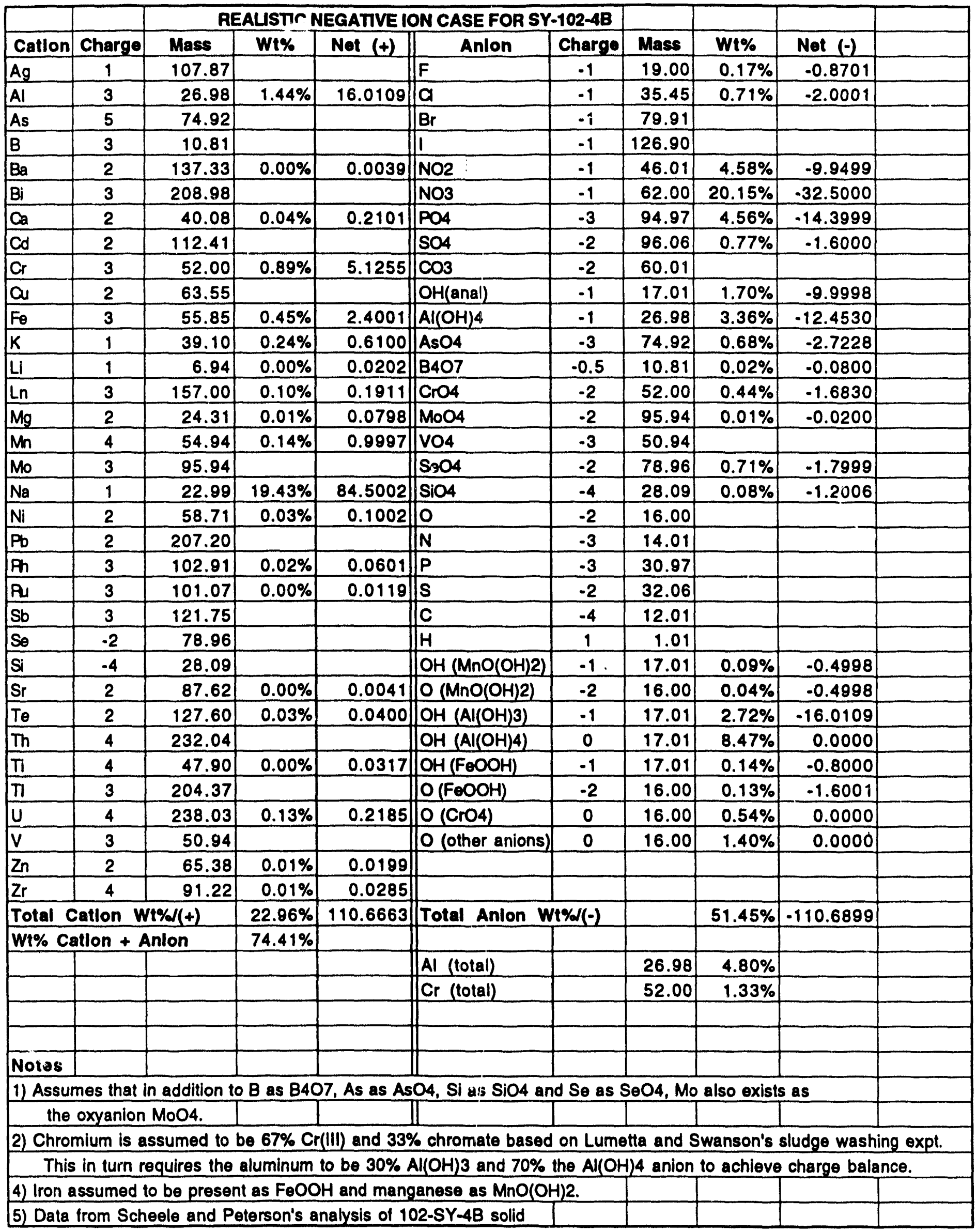


ChargeBalance.complete

REASONABLE CHARGE BALANCE

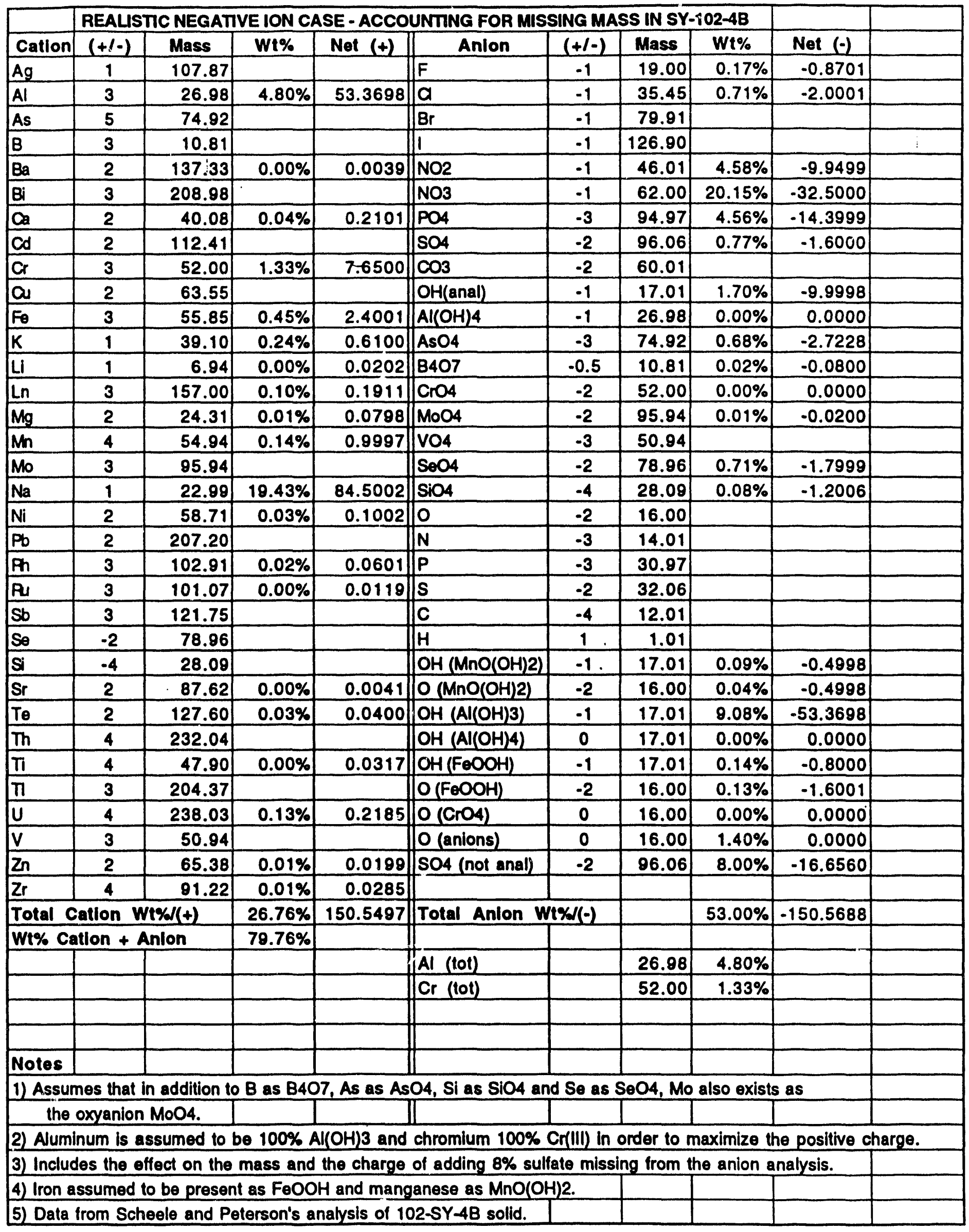



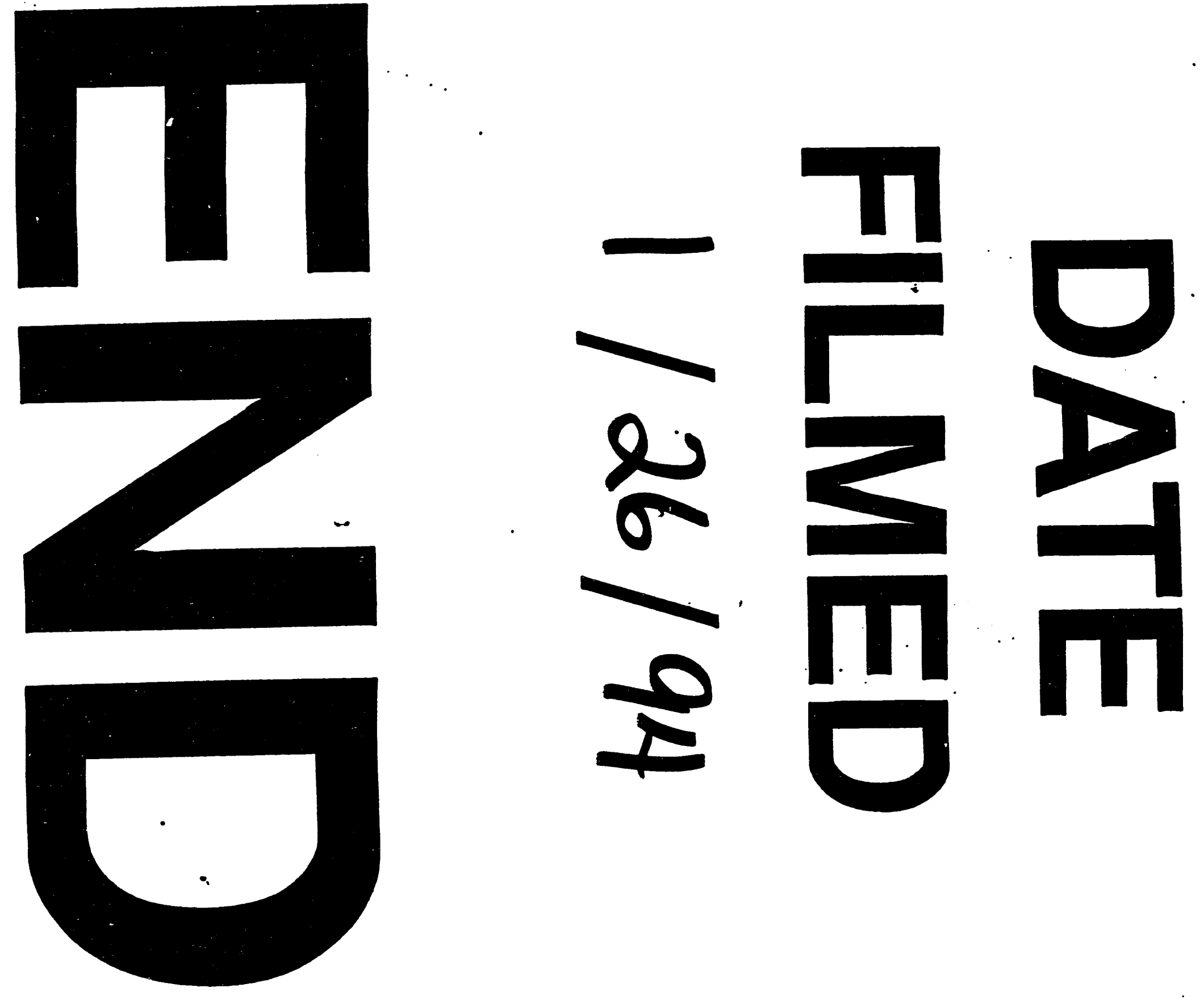


\section{(1)

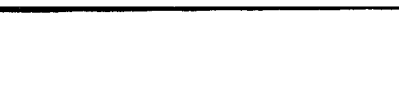$$
-
$$

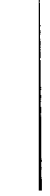

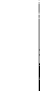

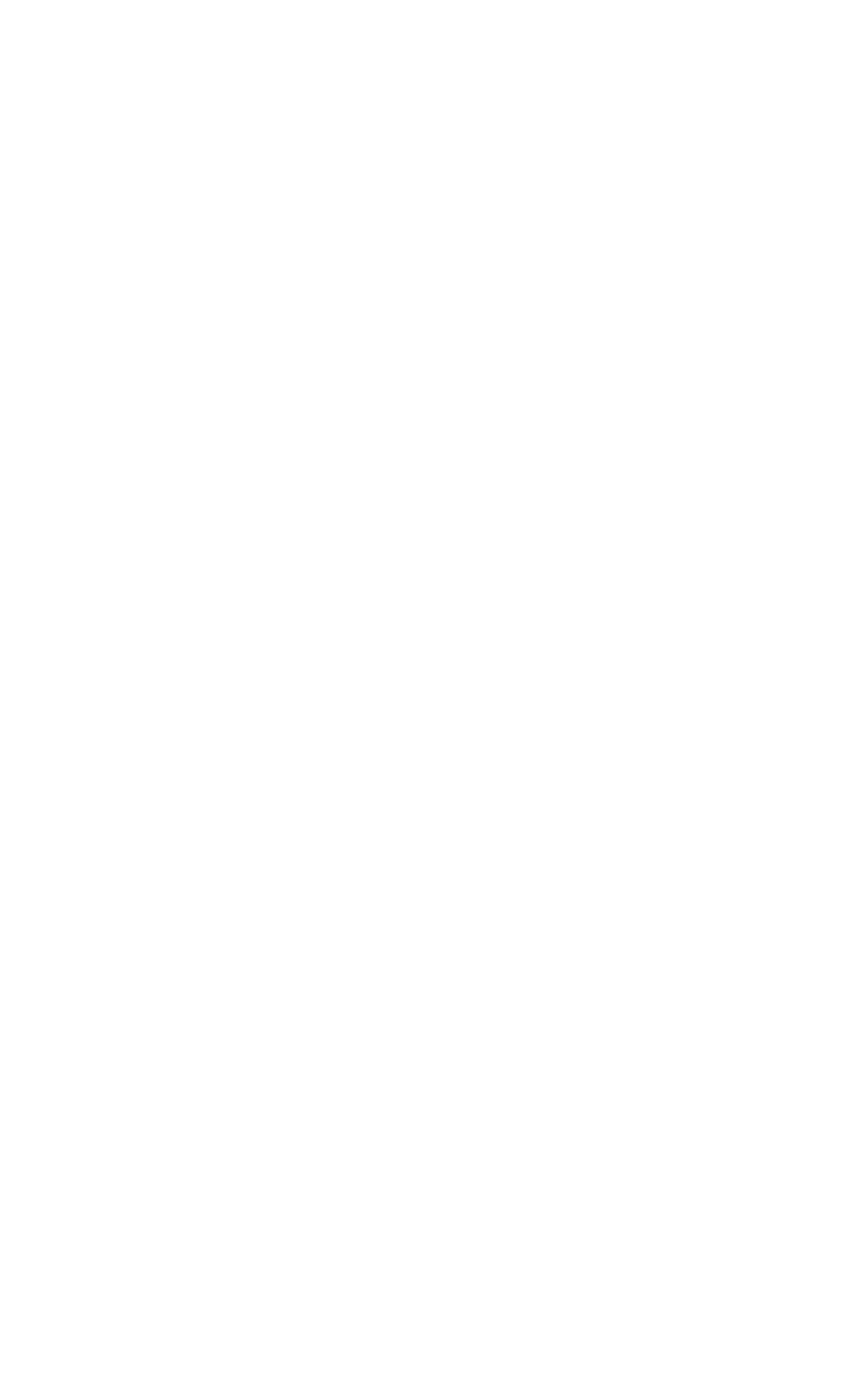

